\title{
5.12 Source of Oceanic Magnetic Anomalies and the Geomagnetic Polarity Timescale
}

J. S. Gee, University of California, San Diego, La Jolla, CA, USA

D. V. Kent, Rutgers University, Piscataway, NJ, USA

(C) 2007 Elsevier B.V. All rights reserved.

\begin{tabular}{lll}
\hline 5.12 .1 & Introduction & 455 \\
5.12 .2 & Magnetic Anomalies as Records of Geomagnetic Field Behavior & 458 \\
5.12 .2 .1 & Polarity Reversals and the Geomagnetic Polarity Timescale & 458 \\
5.12 .2 .2 & Geomagnetic Intensity Fluctuations & 462 \\
5.12 .2 .3 & Anomaly Skewness and Nondipole Field & 469 \\
$5.12 .3 \quad$ & Magnetic Source Regions & 470 \\
5.12 .3 .1 & Magnetization of Lavas & 472 \\
5.12 .3 .1 .1 & Initial grain size and composition & 472 \\
5.12 .3 .1 .2 & Low-temperature alteration & 474 \\
5.12 .3 .2 & Magnetization of Dikes & 481 \\
5.12 .3 .3 & Magnetization of Gabbros & 484 \\
5.12 .3 .4 & Mantle-Derived Peridotites & 488 \\
5.12 .4 & Crustal Accretion and Structure of the Magnetic Source & 489 \\
5.12 .4 .1 & Nonvertical Magnetic Boundaries & 490 \\
5.12 .4 .2 & Rotations of the Magnetic Source Layer & 493 \\
5.12 .5 & Future Directions & 495 \\
References & & 500
\end{tabular}

\subsubsection{Introduction}

As new seafloor is created at the ridge crest, it cools and acquires a thermoremanence that captures a record of past geomagnetic field variations. The dominant geomagnetic signal recorded in the ocean crust is the pattern of field reversals; the juxtaposition of normal and reverse polarity crust constitutes a large magnetization contrast that generates readily identifiable variations in the magnetic field measured at the sea surface. The lineated and globally correlatable character of these sea-surface magnetic anomalies has proven remarkably useful in documenting the pattern of geomagnetic reversals since $\sim 160 \mathrm{Ma}$. This reversal pattern, calibrated with suitable numerical ages, provides the basis for the geomagnetic polarity timescale (GPTS) that has broad reaching applications throughout Earth sciences including mapping the age distribution of the ocean floor constituting more than half of Earth's surface area.

The inferred pattern of geomagnetic reversals has changed relatively little since the pioneering work of Heirtzler et al. (1968), who used an assumption of constant seafloor spreading in the South Atlantic to derive the first GPTS. The stability of polarity interval widths in subsequent timescales testifies to the regularity of seafloor spreading, at least for carefully chosen spreading corridors. The anomaly profile in Figure 1, calculated from a simple block model with vertical polarity boundaries and for a full spreading rate of $140 \mathrm{~km} \mathrm{My}^{-1}$, illustrates the optimal resolution that is possible at the fastest spreading known from the present ocean basins. Note that the terms slow-, intermediate-, fast-, and superfast-spreading refer to full spreading rates of $<40 \mathrm{~km} \mathrm{My}^{-1}$, 40-90 km My ${ }^{-1}, 90-140 \mathrm{~km} \mathrm{My}^{-1},>140 \mathrm{~km} \mathrm{My}^{-1}$, respectively. This simple model highlights some important aspects of magnetic anomalies measured at the sea surface. First, the depth of magnetization source (varying from about $2.6 \mathrm{~km}$ at the ridge crest to $5.6 \mathrm{~km}$ for the oldest seafloor (Stein and Stein, 1994) exerts a fundamental control on the wavelengths that can be resolved at the sea surface. The depth and thickness of the magnetized layer act as a bandpass filter (Earth filter of Schouten and McCamy, 1972; with the least attenuation at 

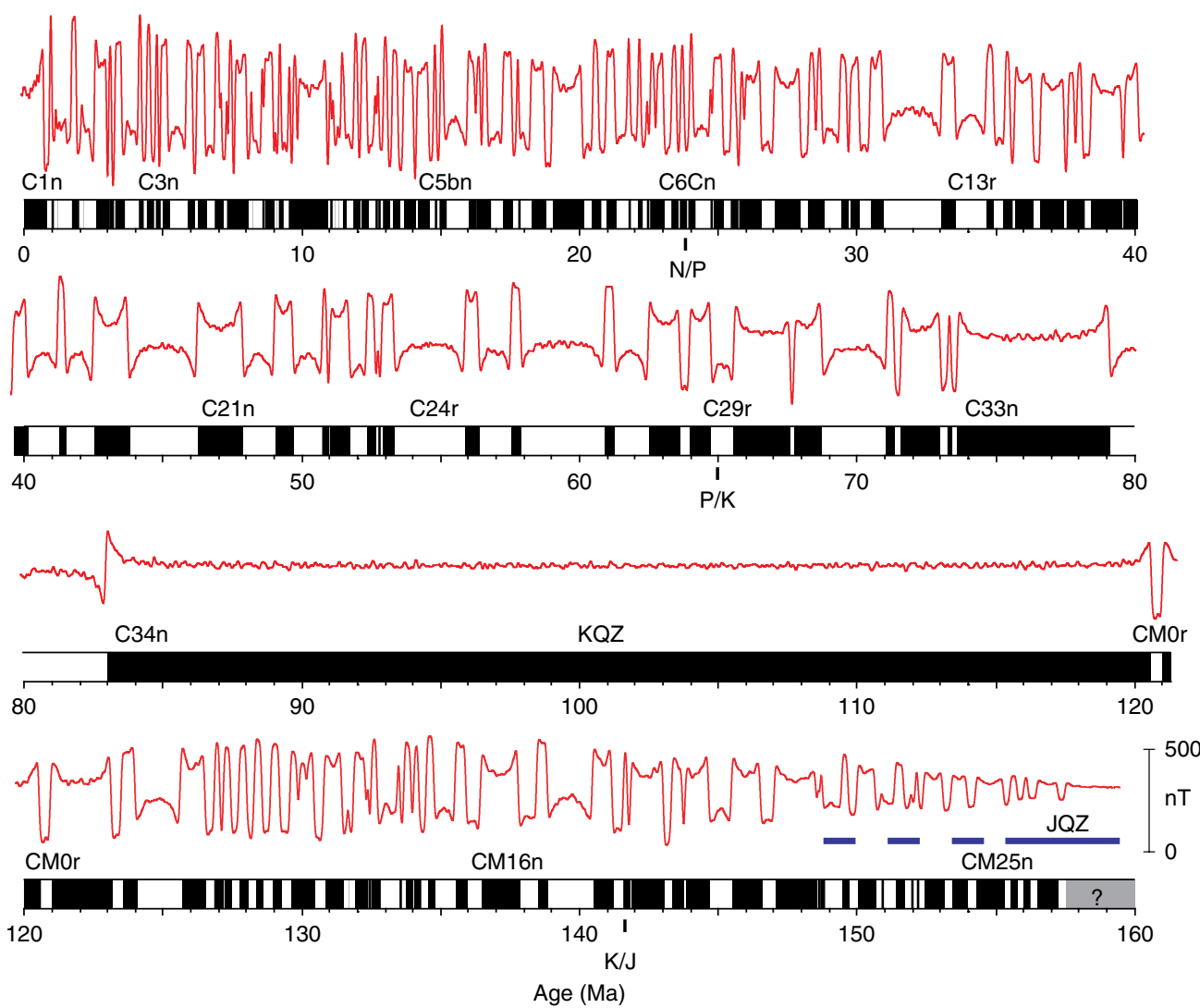

Figure 1 Geomagnetic polarity timescale from marine magnetic anomalies for 0-160 Ma. After Lowrie and Kent (2004); largely based on Cande and Kent (1995) and Channell et al. (1995). Filled and open blocks represent intervals of normal and reverse geomagnetic field polarity. (Table 1); key chrons that were used as calibration tiepoints are identified above the bar graph ( $\mathrm{C} 1 \mathrm{n}, \mathrm{C} 3 \mathrm{n}$, etc.) and correlated positions of geologic period boundaries are indicated by ticks below the bar graph (N/P, Neogene/Paleogene; P/K, Paleogene/Cretaceous, K/J, Cretaceous/Jurassic). Idealized magnetic anomaly profile uses this polarity pattern in a $1 \mathrm{~km}$ thick source layer that has a mean magnetization of $5 \mathrm{Am}^{-1}$ with gaussian variation ( $\sigma=42 \%$ of mean) to mimic paleointensity variations, and vertical magnetization boundaries. The anomaly is calculated at the pole (no skewness, magnetization and ambient field direction vertical) at a full-spreading rate of $140 \mathrm{~km} \mathrm{My}^{-1}$, with depth to the upper surface that increases with age $\mathrm{e}^{0.5}$ (Ma) (Stein and Stein, 1994). Note the amplitude modulation, which primarily reflects the sequence effect since source properties otherwise stay constant other than modest monotonic change in water depth, except for magnetization ramp from JQZ into M-sequence (dashed line; factor of 5 increase from $157 \mathrm{Ma}$ to $143 \mathrm{Ma}$ ) that is likely due to a systematic increase in geomagnetic intensity (Cande et al., 1978; McElhinny and Larson, 2003).

wavelengths of $8-15 \mathrm{~km}$ for typical seafloor depths). Polarity intervals corresponding to these spatial scales $(\sim 100-200 \mathrm{ky}$ for fast-spreading crust) are particularly well represented in the sea-surface anomaly profile (e.g., Anomaly 2; 1.77-1.95 Ma). Significantly shorter polarity intervals $\left(\sim 10^{4}\right.$ years $)$ are also recognizable in high-resolution profiles from fast-spreading ridges, although such brief magnetization changes appear as broader, substantially attenuated anomalies at the sea surface. Thus, the combination of rapid spreading and typical seafloor depths of $3-4 \mathrm{~km}$ is well suited to capture essentially all polarity intervals with durations exceeding $\sim 10^{4}$ years in sea-surface anomaly data. Indeed, independent magnetostratigraphic studies corroborate that the GPTS can be viewed as essentially complete at timescales greater than about $30 \mathrm{ky}$.

Establishing the origin and significance of anomaly fluctuations at scales both longer and shorter than the dominant timescale of reversals $\left(10^{4}-10^{6}\right.$ years $)$ can potentially provide valuable additional insights into geomagnetic field behavior. To the extent that the magnetization of the ocean crust is a thermoremanence, the magnetization of the ocean crust might 
be expected to preserve a broad spectrum of geomagnetic field variations, from brief $\left(<10^{3}\right.$ years $)$ excursions or intensity fluctuations to longerterm variations on the scale of superchrons $\left(10^{7}-10^{8}\right.$ years). Documenting the relative importance of geomagnetic field fluctuations in controlling magnetic anomaly amplitudes has proven difficult, however, since these anomalies are the end product of the recording of a paleofield signal (e.g., paleointensity variations, directional excursions, and polarity reversals), modulated by crustal accretionary processes (e.g., variations in geochemistry or the pattern of lava accumulation), and geometry of the source region(s). Despite limitations in accounting for the recording medium, significant progress has been made in documenting short wavelength anomaly fluctuations that may be attributed to geomagnetic field behavior. A key element in many of these studies is the collection of anomaly data nearer the magnetic source layer to preserve higher frequency variations that are attenuated in sea-surface anomaly data. The coherence among nearbottom anomaly profiles and the similarity of these coherent fluctuations with independent records of field intensity from sediments suggest that a substantial geomagnetic intensity signal may be preserved in the ocean crustal magnetization.

Some longer-term variations in anomaly amplitudes may likewise have a geomagnetic origin although there has been less progress in differentiating this from other causes of variation in source properties. For example, the gradual increase in anomaly amplitudes following the Jurassic Quiet Zone (JQZ; crust older than $\sim 154 \mathrm{Ma}$ ) has been attributed to an increase in paleofield intensity (Cande et al., 1978) whereas the amplitude envelope observed over some ridge axes has long been interpreted as evidence of low-temperature alteration of the source layer (e.g., Bleil and Petersen, 1983; Raymond and LaBrecque, 1987). The particular pattern of polarity reversals and the relative widths of adjacent polarity intervals (sometimes termed the sequence effect) can modulate anomaly amplitudes, for example, the variations in amplitudes that are apparent over the past $40 \mathrm{My}$ in the simple model shown in Figure 1, so recognition of long-term trends is not straightforward. There are also firstorder geomagnetic questions about the marked contrast in the character of magnetic anomalies in the Cretaceous Quiet Zone (KQZ; 83-120.6 Ma) and the JQZ, the former often associated with large amplitude anomalies and the latter with small amplitude anomalies, which may be related to significant differences in mean field strength in the Jurassic and the Cretaceous.

Despite more than 40 years of study, many aspects of the magnetization source responsible for lineated marine magnetic anomalies remain uncertain. Early studies (Atwater and Mudie, 1973; Talwani et al., 1971) indicated that the source layer is thin and dominated by extrusives whereas compilations of lava magnetizations suggest that additional deeper sources may be required and indeed in some cases (e.g., near Ocean Drilling Program (ODP) Hole 735B; Dick et al., 1991) recognizable anomaly lineations are present where only the intrusive portion of the crust is preserved. Since the last review of crustal magnetization (Smith, 1990), there has been significant progress in sampling of the dikes, lower crustal gabbros, and upper mantle material exposed in tectonic windows, and these studies indicate that dikes and gabbros are likely significant contributors to seasurface magnetic anomalies. In addition to the need for a fundamental characterization of possible magnetization sources within the crust, some understanding of the details of the accretionary process (e.g., width of the neovolcanic zone, off-axis volcanism) is also essential since these provide an intrinsic limit on the fidelity of the crustal recording process. As our understanding of geomagnetic field variations improves (particularly over timescales on the order of $10^{4}$ years over which much of the ocean crust is constructed), near-bottom magnetic anomaly data can be used to constrain aspects of crustal accretion. Such studies can, in turn, be useful in evaluating the timescales at which geomagnetic information can be recovered from magnetic anomaly records.

In this chapter we will focus primarily on the promise and limitations of the ocean crust as a recorder of geomagnetic field variations, emphasizing the record of past geomagnetic field variations recorded in anomalies (and therefore in source magnetization) on timescales of $10^{3}$ years (excursions) to $10^{4}-10^{6}$ (reversals) and $10^{7}-10^{8}$ (superchrons). We review the origin of the magnetization in the various crustal source layers responsible for lineated magnetic anomalies and conclude by mentioning some applications to deciphering how oceanic crust formed and by speculating on future directions. The chapter is based mostly on published literature that appeared since the last major review of ocean crust magnetization by Smith (1990). 


\subsubsection{Magnetic Anomalies as Records of Geomagnetic Field Behavior}

\subsubsection{Polarity Reversals and the Geomagnetic Polarity Timescale}

Marine magnetic anomalies (Vine, 1966; Vine and Matthews, 1963) provide a complete record of geomagnetic polarity reversals, making the agecalibrated geomagnetic polarity sequence the basis for global correlations and geochronology for the past $160 \mathrm{My}$ (Figure 1). The relative widths of the magnetic polarity intervals for the Late Jurassic to Recent were determined from magnetic profiles initially by Heirtzler et al. (1968) for the Central Anomaly (Anomaly 1) to Anomaly 32 (C-sequence) and by Larson and Pitman (1972) for Anomalies M1-M22 (M-sequence). Larson and Pitman recognized that the M-sequence anomalies were bracketed by long intervals with apparently few or no reversals: the $\mathrm{KQZ}$ between the $\mathrm{M}$-sequence and the ridge crest $\mathrm{C}$-sequence of Heirtzler et al. (to which Larson and Pitman added Anomalies 33 and 34) and the JQZ prior to the M-sequence (which was soon extended to M0 at the younger end and to M25 at the older end by Larson and Hilde (1975) and to M29 by Cande et al. (1978). Key aspects of the geomagnetic interpretations were verified by magnetostratigraphic studies. For example, Helsley and Steiner (1969) documented an interval of constant normal polarity (the Cretaceous Normal Polarity Superchron, CNPS) corresponding to the KQZ observed in magnetic anomaly profiles. Similarly, Lowrie and Alvarez (1981) verified the overall correspondence between magnetostratigraphic polarity intervals and the $\sim 100 \mathrm{My}$ anomaly record from Anomaly $6 \mathrm{C}$ to Anomaly M3 including the CNPS and KQZ, and Ogg and Lowrie (1986) provided magnetostratigraphic confirmation for the central part of the M-sequence. Correlations between anomaly interpretations and magnetostratigraphy are being refined in land sections and marine cores (e.g., Billups et al., 2004; Channell et al., 2003; Lanci et al., 2004, 2005; Speranza et al., 2005) and provide the linkage to numerical ages based on radioisotopic dates or astronomical cyclicity in stratigraphic sections for age calibration of the anomaly sequence in the construction of geomagnetic polarity timescales.

Standard geomagnetic polarity chron nomenclature is based on the long-standing numbering schemes (sometimes with lettered additions) for prominent but irregularly spaced magnetic anomalies (Larson and Pitman, 1972; Pitman and Heirtzler, 1966; Pitman et al., 1968). Polarity subdivisions for the past $\sim 5 \mathrm{My}$ based on compilations of radiometric dating of discrete lavas (Cox et al., 1964) were initially labeled after prominent geomagneticians (Brunhes, Matuyama, Gauss, and Gilbert for chrons, formerly called epochs; Anonymous, 1979) and type localities (Jaramillo, Olduvai, Mammoth, etc., for subchrons, formerly called events) but this nomenclature system was impractical to be extended to the numerous older polarity intervals delineated by magnetic anomalies. By convention, identifiers usually refer to positive anomalies, which correspond to normal polarity for the C-sequence (Anomalies 1-34) but mostly to reverse polarity intervals for the M-sequence (M0-M29) because they formed in the Southern Hemisphere but are now in the Northern Hemisphere in the Pacific where the M-sequence is well developed. A chron corresponds to the interval from the younger boundary of the eponymous anomaly to the younger boundary of the preceding anomaly and has the prefix ' $\mathrm{C}$ ' (e.g., Chron C3A or Chron CM20). However, each of these chrons is usually subdivided into the two constituent intervals of predominantly normal and reverse polarity, which are designated by adding to the name the suffix ' $n$ ' for normal polarity and ' $\mathrm{r}$ ' for the preceding reverse polarity interval (e.g., Chron C3An and Chron C3Ar, or Chron CM20n and Chron CM20r). When these polarity chrons are further subdivided into shorter polarity intervals they are referred to as subchrons and identified by appending, from youngest to oldest, '.1', '.2', etc., to the polarity chron name, and adding an ' $n$ ' for normal polarity or an ' $r$ ' for reverse polarity (e.g., Chron C3An.1r, or Chron CM20n.1r). Finally, the designation ' -1 ', ' -2 ', etc., is used following a chron or subchron name to denote apparently brief geomagnetic features corresponding to short wavelength anomalies or 'tiny wiggles', which, upon calibration, convert to durations less than $30 \mathrm{ky}$. In view of their uncertain origin, these globally mapped geomagnetic features are referred to as cryptochrons (Cande and Kent, 1992a); they can be elevated to subchron status by the addition of ' $n$ ' for normal polarity and ' $r$ ' for reverse polarity if confirmed as polarity intervals in magnetostratigraphic studies (e.g., Chron C1r.2r-1n).

Anomaly spacings for the Central Anomaly (Anomaly 1) to Anomaly 34 (younger end of KQZ) were comprehensively refined by Cande and Kent (1992a) and for the M-sequence (M0-M29) by 
Channell et al. (1995). Cande and Kent (1992a) used a combination of nine finite rotation poles to describe seafloor spreading in the South Atlantic and 61 stacked profiles distributed over the finite rotation pole intervals to develop a continuous framework for the anomaly sequence; finer scale information was derived from faster spreading rate ridges in the Pacific and Indian Oceans and inserted into the South Atlantic pattern. For age calibration, Cande and Kent (1992a) assumed that spreading rates in the South Atlantic were smoothly varying and fit a cubic interpolation spline function to a set of nine tiepoints that link radioisotopic ages with distances of correlative anomalies from the zero-age ridge axis to derive a GPTS for 0-83 Ma (Anomaly 34). The revised GPTS of Cande and Kent (1995) (CK95) includes astrochronological estimates for polarity reversals for the past 5.23 My (Hilgen, 1991; Shackleton et al., 1990), which are negligibly different (within $0.03 \mathrm{My}$ ) from the most recent retuning by Lourens et al. (2004). For the M-sequence, Channell et al. (1995) compared profiles from the Phoenix, Japanese, and Hawaiian lineation sets and derived a representative anomaly sequence for M0 to M29 from a new block model for the Hawaiian lineations. There are still relatively few age-diagnostic data available for calibration of M-sequence anomalies Channell et al. (1995) used only three tiepoints that were regarded as reliable and consistent with constant spreading on the new model of the Hawaiian lineations to derive a GPTS (referred to by the authors as CENT94) for $120.6 \mathrm{Ma}$ (M0) to $157.53 \mathrm{Ma}$ (M29).

The listing of polarity intervals given in Table 1 is the same as used for statistical analysis by Lowrie and Kent (2004) and is basically a combination of CK95 for the C-sequence and CENT94 for the Msequence. This polarity sequence for the past $160 \mathrm{My}$ is believed to be complete to a resolution of better than $30 \mathrm{ky}$ and includes those relatively few cryptochrons that have been detected as short polarity intervals in high-resolution magnetostratigraphic studies and elevated to subchrons, mostly in the Cenozoic (see summary by Krijgsman and Kent 2004). Small-scale magnetic anomalies have been identified beyond M29 (Handschumacher et al., 1988), most recently to M41 with an apparent age of $\sim 167 \mathrm{Ma}$ (Sager et al., 1998; Tivey et al., 2006). However, the character of the pre-M29 anomalies resembles small-scale magnetic anomalies or tiny wiggles in the Cenozoic, which have generally been attributed to paleointensity variations rather than geomagnetic reversals (e.g., Cande and Kent, 1992b). Accordingly, the pre-M29 anomalies along with the cryptochrons in the Cenozoic that have not been confirmed as polarity intervals are not included in Table 1 or shown in Figure 1.

A recently published timescale (GTS2004: Gradstein et al., 2004) utilizes the distances to anomalies in the South Atlantic from Cande and Kent (1992a, 1995) but with a somewhat different array of age calibration tiepoints. The largest difference between CK95 and GTS2004 is less than $1 \mathrm{My}$ and occurs at chron $\mathrm{C} 6 \mathrm{Cn} .2 \mathrm{n}$, which was set at $23.8 \pm 1 \mathrm{Ma}$ in CK95 but has been recalibrated using astrochronology to $23.03 \pm 0.04 \mathrm{Ma}$ (Lourens et al., 2004; Shackleton et al., 2000). CK95 also maintains age registry with the compilation of Cenozoic cryptochrons by Cande and Kent (1992b), which were not migrated to the chronology of GTS2004. For the M-sequence, age calibration of $\mathrm{M} 0$ is a major difference: GTS2004 sets the age of Chron CM0 (base of Aptian) at about $125 \mathrm{Ma}$, which is $4 \mathrm{My}$ older than in the CENT94 timescale of Channell et al. (1995) and needs to be corroborated because of the profound implications for the rate of seafloor spreading in the KQZ (e.g., Cogné and Humler, 2006).

On a plot of the age of each reversal against the order of its occurrence (Figure 2), the CENT94 data define a straight line whereas the CK95 C-sequence can be divided into two nearly linear segments that intersect near Chron C12r at about $32 \mathrm{Ma}$. The 37.6 My-long CNPS is evident as an abrupt discontinuity between the $\mathrm{C}$-sequence and the $\mathrm{M}$-sequence and is the longest polarity interval in the entire $\sim 160 \mathrm{My}$ long sequence. Polarity intervals $\mathrm{C} 33 \mathrm{n}$ and $\mathrm{C} 33 \mathrm{r}$ that immediately follow the CNPS are the $2^{\text {nd }}$ and $3^{\text {rd }}$ longest chrons and may have a closer affinity to the CNPS than to the rest of the reversal sequence. Linear segments imply that the reversal process is stationary and allow calculation of representative statistical parameters for each of the reversal frequency regimes. According to Lowrie and Kent (2004), mean polarity interval lengths are $0.25 \mathrm{My}$ for $\mathrm{C} 1 \mathrm{n}-\mathrm{C} 12 \mathrm{r}, \quad 0.75 \mathrm{My}$ for $\mathrm{C} 13 \mathrm{n}-\mathrm{C} 32 \mathrm{r}$, and 0.415 My for M0-M29. Despite the large differences in mean polarity interval length and taking into account a finite reversal transition time of a few thousand years, the distributions of chron lengths within each of the regimes are not significantly different from a Poisson or exponential distribution (Lowrie and Kent, 2004), which implies that the reversal process is essentially free of memory (Cox, 
Table 1 Geomagnetic polarity chrons from marine magnetic anomalies

\begin{tabular}{|c|c|c|c|}
\hline Age range (Ma) & Normal polarity Chrons & Age range (Ma) & Reverse polarity chrons \\
\hline $0.000-0.780$ & C1n & $0.780-0.990$ & C1r.1r \\
\hline $0.990-1.070$ & C1r.1n & $1.070-1.201$ & C1r.2r. \\
\hline $1.201-1.211$ & C1r.2r-1n & $1.211-1.770$ & C1r.2r. \\
\hline $1.770-1.950$ & $\mathrm{C} 2 \mathrm{n}$ & $1.950-2.140$ & C2r.1r \\
\hline $2.140-2.150$ & C2r.1n & $2.150-2.600$ & $\mathrm{C} 2 \mathrm{r} .2 \mathrm{r}$ \\
\hline $2.581-3.040$ & C2An.1n & $3.040-3.110$ & C2An.1r \\
\hline $3.110-3.220$ & C2An.2n & $3.220-3.330$ & C2An.2r \\
\hline $3.330-3.580$ & C2An.3n & $3.580-4.180$ & $\mathrm{C} 2 \mathrm{Ar}$ \\
\hline $4.180-4.290$ & C3n.1n & $4.290-4.480$ & C3n.1r \\
\hline $4.480-4.620$ & C3n.2n & $4.620-4.800$ & C3n.2r \\
\hline $4.800-4.890$ & C3n.3n & $4.890-4.980$ & C3n.3r \\
\hline $4.980-5.230$ & C $3 n .4 n$ & $5.230-5.894$ & $\mathrm{C} 3 \mathrm{r}$ \\
\hline $5.894-6.137$ & C3An.1n & $6.137-6.269$ & C3An.1r \\
\hline $6.269-6.567$ & C3An.2n & $6.567-6.935$ & C3Ar \\
\hline $6.935-7.091$ & $\mathrm{C} 3 \mathrm{Bn}$ & $7.091-7.135$ & C3Br.1r \\
\hline $7.135-7.170$ & C3Br.1n & $7.170-7.341$ & $\mathrm{C} 3 \mathrm{Br} .2 \mathrm{r}$ \\
\hline $7.341-7.375$ & $\mathrm{C} 3 \mathrm{Br} .2 \mathrm{n}$ & $7.375-7.432$ & $\mathrm{C} 3 \mathrm{Br} .3 \mathrm{r}$ \\
\hline $7.432-7.562$ & C4n.1n & $7.562-7.650$ & C4n.1r \\
\hline $7.650-8.072$ & C $4 n .2 n$ & $8.072-8.225$ & C4r.1r \\
\hline $8.225-8.257$ & C4r.1n & $8.257-8.606$ & $\mathrm{C} 4 \mathrm{r} .2 \mathrm{r} *$ \\
\hline $8.606-8.664$ & C $4 r .2 r-1 n$ & 8.664-8.699 & $\mathrm{C} 4 \mathrm{r} .2 \mathrm{r} *$ \\
\hline 8.699-9.025 & C4An & $9.025-9.097$ & C4Ar.1r* \\
\hline $9.097-9.117$ & C4Ar.1r-1n & $9.117-9.230$ & C4Ar.1r* \\
\hline $9.230-9.308$ & C4Ar.1n & $9.308-9.580$ & C4Ar.2r \\
\hline $9.580-9.642$ & C4Ar.2n & $9.642-9.740$ & C4Ar.3r \\
\hline $9.740-9.880$ & C5n.1n & $9.880-9.920$ & C5n.1r \\
\hline $9.920-10.949$ & C5n.2n & $10.949-11.052$ & C5r.1r \\
\hline $11.052-11.099$ & C5r.1n & $11.099-11.167$ & C5r.2r* \\
\hline 11.167-11.193 & C5r.2r-1n & $11.193-11.352$ & C5r.2r* \\
\hline $11.352-11.363$ & C5r.2r-2n & $11.363-11.476$ & C5r.2r* \\
\hline $11.476-11.531$ & C5r.2n & $11.531-11.555$ & C5r.3r* \\
\hline $11.555-11.584$ & C5r.3r-1n & $11.584-11.935$ & C5r.3r* \\
\hline $11.935-12.078$ & C5An.1n & $12.078-12.184$ & C5An.1r \\
\hline $12.184-12.401$ & C5An.2n & $12.401-12.678$ & C5Ar.1r \\
\hline $12.678-12.708$ & C5Ar.1n & $12.708-12.775$ & C5Ar.2r \\
\hline $12.775-12.819$ & C5Ar.2n & $12.819-12.991$ & C5Ar.3r \\
\hline 12.991-13.139 & C5AAn & $13.139-13.302$ & C5AAr \\
\hline $13.302-13.510$ & $\mathrm{C} 5 \mathrm{ABn}$ & $13.510-13.703$ & $\mathrm{C} 5 \mathrm{ABr}$ \\
\hline $13.703-14.076$ & C5ACn & $14.076-14.178$ & $\mathrm{C} 5 \mathrm{ACr}$ \\
\hline $14.178-14.612$ & C5ADn & $14.612-14.800$ & C5ADr \\
\hline $14.800-14.888$ & C5Bn.1n & $14.888-15.034$ & C5Bn.1r \\
\hline $15.034-15.155$ & C5Bn.2n & $15.155-16.014$ & $\mathrm{C} 5 \mathrm{Br}$ \\
\hline $16.014-16.293$ & C5Cn.1n & $16.293-16.327$ & C5Cn.1r \\
\hline $16.327-16.488$ & C5Cn.2n & $16.488-16.556$ & C5Cn.2r \\
\hline $16.556-16.726$ & C5Cn.3n & $16.726-17.277$ & $\mathrm{C} 5 \mathrm{Cr}$ \\
\hline $17.277-17.615$ & C5Dn & $17.615-17.793$ & $\mathrm{C} 5 \mathrm{Dr} *$ \\
\hline $17.793-17.854$ & C5Dr-1n & $17.854-18.281$ & $\mathrm{C} 5 \mathrm{Dr} *$ \\
\hline $18.281-18.781$ & C5En & $18.781-19.048$ & C5Er \\
\hline $19.048-20.131$ & C6n & $20.131-20.518$ & C6r \\
\hline 20.518-20.725 & C6An.1n & 20.725-20.996 & C6An.1r \\
\hline 20.996-21.320 & C6An.2n & 21.320-21.768 & $\mathrm{C} 6 \mathrm{Ar}$ \\
\hline 21.768-21.859 & C6AAn & 21.859-22.151 & C6AAr.1r \\
\hline $22.151-22.248$ & C6AAr.1n & $22.248-22.459$ & C6AAr.2r \\
\hline $22.459-22.493$ & C6AAr.2n & $22.493-22.588$ & C6AAr.3r \\
\hline 22.588-22.750 & C6Bn.1n & 22.750-22.804 & C6Bn.1r \\
\hline 22.804-23.069 & C6Bn.2n & 23.069-23.353 & $\mathrm{C} 6 \mathrm{Br}$ \\
\hline 23.353-23.535 & C6Cn.1n & 23.535-23.677 & C6Cn.1r \\
\hline 23.677-23.800 & C6Cn.2n & 23.800-23.999 & C6Cn.2r \\
\hline
\end{tabular}


Table 1 (Continued)

\begin{tabular}{|c|c|c|c|}
\hline Age range (Ma) & Normal polarity Chrons & Age range (Ma) & Reverse polarity chrons \\
\hline 23.999-24.118 & C6Cn.3n & 24.118-24.730 & $\mathrm{C} 6 \mathrm{Cr}$ \\
\hline $24.730-24.781$ & C7n.1n & $24.781-24.835$ & C7n.1r \\
\hline $24.835-25.183$ & C7n.2n & 25.183-25.496 & $\mathrm{C} 7 \mathrm{r}$ \\
\hline $25.496-25.648$ & C7An & $25.648-25.678$ & C7Ar* \\
\hline 25.678-25.705 & C7Ar-1n & 25.705-25.823 & C7Ar* \\
\hline 25.823-25.951 & C8n.1n & 25.951-25.992 & C8n.1r \\
\hline 25.992-26.554 & C8n.2n & $26.554-27.027$ & $\mathrm{C} 8 \mathrm{r}$ \\
\hline 27.027-27.972 & C9n & 27.972-28.283 & C9r \\
\hline 28.283-28.512 & C10n.1n & 28.512-28.578 & C10n.1r \\
\hline $28.578-28.745$ & C10n.2n & $28.745-29.401$ & C10r \\
\hline 29.401-29.662 & C11n.1n & 29.662-29.765 & C11n.1r \\
\hline 29.765-30.098 & C11n.2n & $30.098-30.479$ & C11r \\
\hline $30.479-30.939$ & C12n & 30.939-33.058 & $\mathrm{C} 12 \mathrm{r}$ \\
\hline $33.058-33.545$ & C13n & $33.545-34.655$ & $\mathrm{C} 13 \mathrm{r}$ \\
\hline $34.655-34.940$ & C15n & $34.940-35.343$ & C15r \\
\hline $35.343-35.526$ & C16n.1n & $35.526-35.685$ & C16n.1r \\
\hline $35.685-36.341$ & C16n.2n & $36.341-36.618$ & C16r \\
\hline $36.618-37.473$ & C17n.1n & $37.473-37.604$ & C17n.1r \\
\hline $37.604-37.848$ & C17n.2n & $37.848-37.920$ & C17n.2r \\
\hline $37.920-38.113$ & C17n.3n & $38.113-38.426$ & $\mathrm{C} 17 \mathrm{r}$ \\
\hline $38.426-39.552$ & C18n.1n & $39.552-39.631$ & C18n.1r \\
\hline $39.631-40.130$ & C18n.2n & $40.130-41.257$ & C18r \\
\hline $41.257-41.521$ & C19n & $41.521-42.536$ & C19r \\
\hline $42.536-43.789$ & C20n & $43.789-46.264$ & $\mathrm{C} 2 \mathrm{Or}$ \\
\hline $46.264-47.906$ & $\mathrm{C} 21 \mathrm{n}$ & $47.906-49.037$ & $\mathrm{C} 21 \mathrm{r}$ \\
\hline $49.037-49.714$ & C22n & $49.714-50.778$ & $\mathrm{C} 22 \mathrm{r}$ \\
\hline $50.778-50.946$ & C23n.1n & $50.946-51.047$ & C23n.1r \\
\hline $51.047-51.743$ & C23n.2n & $51.743-52.364$ & $\mathrm{C} 23 \mathrm{r}$ \\
\hline $52.364-52.663$ & C24n.1n & $52.663-52.757$ & C24n.1r \\
\hline $52.757-52.801$ & C24n.2n & $52.801-52.903$ & C24n.2r \\
\hline $52.903-53.347$ & C24n.3n & $53.347-55.904$ & $\mathrm{C} 24 \mathrm{r}$ \\
\hline $55.904-56.391$ & $\mathrm{C} 25 \mathrm{n}$ & $56.391-57.554$ & $\mathrm{C} 25 \mathrm{r}$ \\
\hline $57.554-57.911$ & C26n & $57.911-60.920$ & $\mathrm{C} 26 \mathrm{r}$ \\
\hline $60.920-61.276$ & $\mathrm{C} 27 \mathrm{n}$ & $61.276-62.499$ & $\mathrm{C} 27 \mathrm{r}$ \\
\hline $62.499-63.634$ & C28n & 63.634-63.976 & $\mathrm{C} 28 \mathrm{r}$ \\
\hline $63.976-64.745$ & C29n & $64.745-65.578$ & $\mathrm{C} 29 \mathrm{r}$ \\
\hline $65.578-67.610$ & C30n & $67.610-67.735$ & C30r \\
\hline $67.735-68.737$ & C31n & $68.737-71.071$ & C31r \\
\hline $71.071-71.338$ & C32n.1n & $71.338-71.587$ & C32n.1r \\
\hline $71.587-73.004$ & C32n.2n & $73.004-73.291$ & C32r.1r \\
\hline $73.291-73.374$ & C32r.1n & 73.374-73.619 & C32r.2r \\
\hline 73.619-79.075 & C33n & $79.075-83.000$ & $\mathrm{C} 33 \mathrm{r}$ \\
\hline $83.00-120.60$ & C34n (CNPS) & $120.60-121.00$ & CMOr \\
\hline $121.00-123.19$ & CM1n & $123.19-123.55$ & CM1r \\
\hline $123.55-124.05$ & $\mathrm{CM} 2 \mathrm{n}$ & $124.05-125.67$ & $\mathrm{CM} 3 \mathrm{r}$ \\
\hline $125.67-126.57$ & $\mathrm{CM} 4 \mathrm{n}$ & $126.57-126.91$ & $\mathrm{CM} 5 \mathrm{r}$ \\
\hline $126.91-127.11$ & CM6n & $127.11-127.23$ & CM6r \\
\hline $127.23-127.49$ & $\mathrm{CM} 7 \mathrm{n}$ & $127.49-127.79$ & $\mathrm{CM} 7 \mathrm{r}$ \\
\hline $127.79-128.07$ & CM8n & $128.07-128.34$ & $\mathrm{CM} 8 \mathrm{r}$ \\
\hline $128.34-128.62$ & CM9n & $128.62-128.93$ & CM9r \\
\hline $128.93-129.25$ & CM10n & $129.25-129.63$ & CM10r \\
\hline $129.63-129.91$ & CM10Nn.1n & $129.91-129.95$ & CM10Nn.1r \\
\hline $129.95-130.22$ & CM10Nn.2n & $130.22-130.24$ & CM10Nn.2r \\
\hline $130.24-130.49$ & CM10Nn.3n & $130.49-130.84$ & $\mathrm{CM} 10 \mathrm{Nr}$ \\
\hline $130.84-131.50$ & CM11n & $131.50-131.71$ & CM11r.1r \\
\hline $131.71-131.73$ & CM11r.1n & $131.73-131.91$ & CM11r.2r \\
\hline $131.91-132.35$ & CM11An.1n & $132.35-132.40$ & CM11An.1r \\
\hline $132.40-132.47$ & CM11An.2n & $132.47-132.55$ & $\mathrm{CM} 11 \mathrm{Ar}$ \\
\hline
\end{tabular}


Table 1 (Continued)

\begin{tabular}{|c|c|c|c|}
\hline Age range (Ma) & Normal polarity Chrons & Age range (Ma) & Reverse polarity chrons \\
\hline $132.55-132.76$ & CM12n & $132.76-133.51$ & CM12r.1r \\
\hline $133.51-133.58$ & CM12r.1n & 133.58-133.73 & CM12r.2r \\
\hline $133.73-133.99$ & CM12An & 133.99-134.08 & $\mathrm{CM} 12 \mathrm{Ar}$ \\
\hline $134.08-134.27$ & CM13n & $134.27-134.53$ & CM13r \\
\hline $134.53-134.81$ & CM14n & $134.81-135.57$ & CM14r \\
\hline $135.57-135.96$ & CM15n & $135.96-136.49$ & CM15r \\
\hline $136.49-137.85$ & CM16n & $137.85-138.50$ & CM16r \\
\hline $138.50-138.89$ & $\mathrm{CM} 17 \mathrm{n}$ & $138.89-140.51$ & CM17r \\
\hline $140.51-141.22$ & CM18n & $141.22-141.63$ & CM18r \\
\hline $141.63-141.78$ & CM19n.1n & $141.78-141.88$ & CM19n.1r \\
\hline $141.88-143.07$ & CM19n & 143.07-143.36 & CM19r \\
\hline $143.36-143.77$ & CM20n.1n & $143.77-143.84$ & CM20n.1r \\
\hline $143.84-144.70$ & CM20n.2n & $144.70-145.52$ & CM20r \\
\hline $145.52-146.56$ & $\mathrm{CM} 21 \mathrm{n}$ & $146.56-147.06$ & $\mathrm{CM} 21 \mathrm{r}$ \\
\hline $147.06-148.57$ & CM22n.1n & $148.57-148.62$ & CM22n.1r \\
\hline $148.62-148.67$ & CM22n.2n & 148.67-148.72 & CM22n.2r \\
\hline $148.72-148.79$ & CM22n.3n & $148.79-149.49$ & CM22r \\
\hline $149.49-149.72$ & CM22An & $149.72-150.04$ & CM22Ar \\
\hline 150.04-150.69 & CM23n.1n & 150.69-150.91 & CM23n.1r \\
\hline $150.91-150.93$ & CM23n.2n & $150.93-151.40$ & CM23r \\
\hline $151.40-151.72$ & CM24n.1n & $151.72-151.98$ & CM24n.1r \\
\hline $151.98-152.00$ & CM24n.2n & $152.00-152.15$ & $\mathrm{CM} 24 \mathrm{r}$ \\
\hline $152.15-152.24$ & CM24An & $152.24-152.43$ & CM24Ar \\
\hline $152.43-153.13$ & CM24Bn & $153.13-153.43$ & $\mathrm{CM} 24 \mathrm{Br}$ \\
\hline $153.43-154.00$ & CM25n & $154.00-154.31$ & CM25r \\
\hline $154.31-155.32$ & CM26n & 155.32-155.55 & CM26r \\
\hline $155.55-155.80$ & $\mathrm{CM} 27 \mathrm{n}$ & $155.80-156.05$ & $\mathrm{CM} 27 \mathrm{r}$ \\
\hline $156.05-156.19$ & CM28n & $156.19-156.51$ & CM28r \\
\hline $156.51-157.27$ & CM29n & $157.27-157.53$ & CM29r \\
\hline
\end{tabular}

Geomagnetic polarity time scale tabulated from Cande and Kent (1995), with additional short subchrons summarized by Lowrie and Kent (2004), for after the Cretaceous Normal Polarity Superchron (CNPS), which corresponds to the Cretaceous Quiet Zone, and from Channell et al. (1995) for before the CNPS. The names of chrons marked by asterisks are repeated because the reverse polarity intervals contain one or two cryptochrons that have been elevated to the status of new normal polarity subchrons.

1968). It has been suggested that the CNPS may represent part of a continuous, long-term evolution of reversal rate (McFadden and Merrill, 2000). However, the lack of precursory field behavior that might have heralded this superchron (Gallet and Hulot, 1997; Lowrie and Kent, 2004) suggests that the CNPS may represent either an abrupt perturbation of the reversal process or a separate (non)reversal regime.

\subsubsection{Geomagnetic Intensity Fluctuations}

Sea-surface magnetic anomaly profiles from fastspreading ridges allow recognition of polarity intervals as short as $\sim 30 \mathrm{ky}$. Yet the geomagnetic field is known to fluctuate on significantly shorter timescales. For example, direct observations indicate that the dipole field is decreasing at $15 \mathrm{nT} \mathrm{yr}^{-1}$ so that $g_{1}^{0}$ has decreased about $8 \%$ since 1832 when Gauss first estimated the field intensity from a spherical harmonic analysis (Jackson et al., 2000). Absolute paleointensities from archeomagnetic materials suggest that field intensities at $1-3 \mathrm{ka}$ were approximately $40-50 \%$ higher than the present field (Yang et al., 2000) although nondipolar field variations undoubtedly result in considerable spatial variability (Korte and Constable, 2005). On somewhat longer timescales, more sparse absolute intensity data from volcanic materials (see Chapter 1.13) provide evidence for extremely low field values ( $\sim 20 \%$ or less of the present value) at approximately $40 \mathrm{ka}$ associated with the Laschamp excursion (Levi et al., 1990; Roperch et al., 1988).

Short-term $\left(\sim 10^{2}-10^{3}\right.$ years $)$ fluctuations in geomagnetic intensity, even if quite substantial, will 

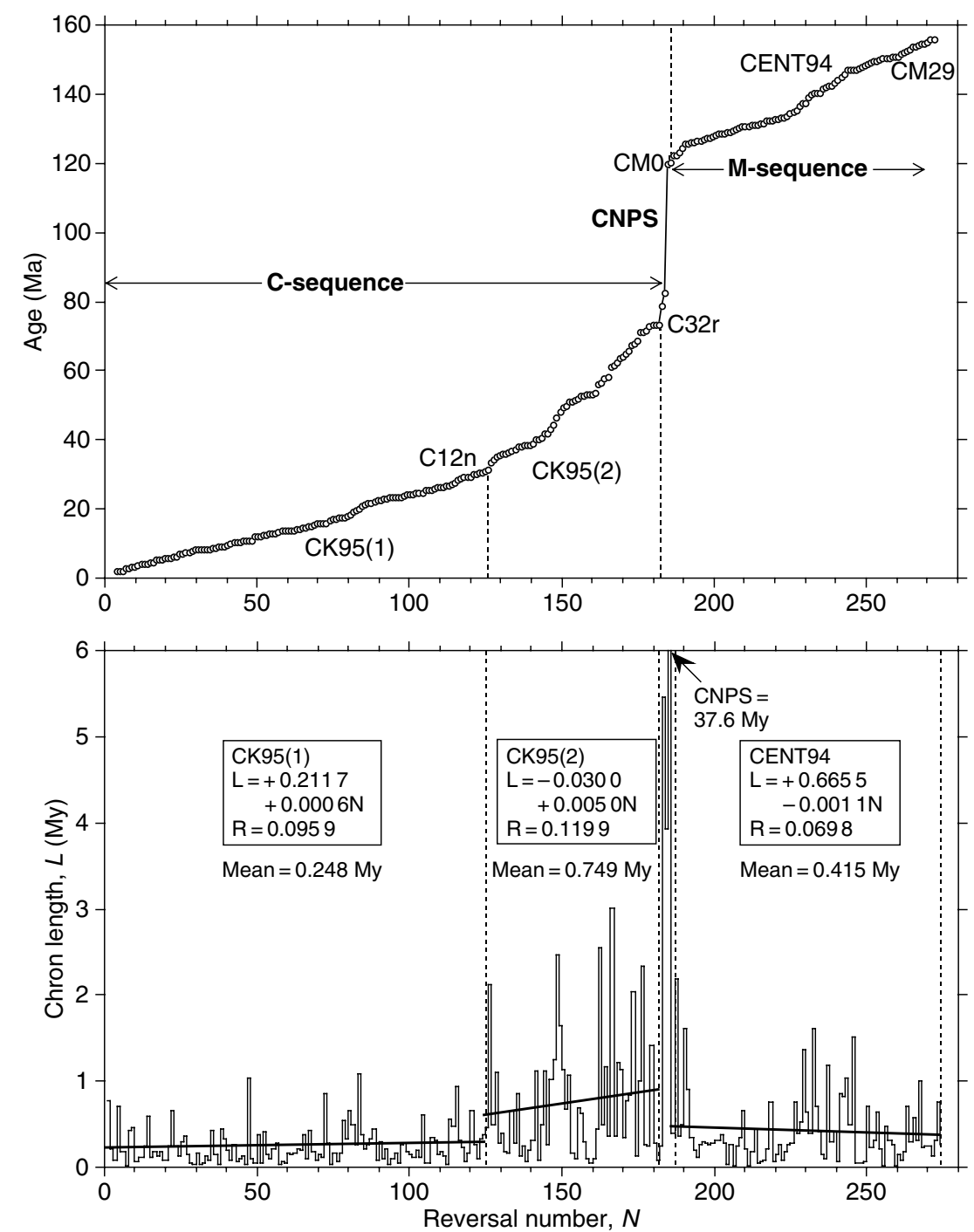

Figure 2 Top, ages of magnetic reversals (Ma), and bottom, polarity chron lengths (My) in the Cenozoic and Mesozoic oceanic anomaly sequences plotted against their age order (from Lowrie and Kent, 2004). Statistical properties are shown for two segments of the CK95 timescale and the CENT94 timescale in which linear fits have slopes not distinct from zero. CNPS, Cretaceous normal polarity superchron.

hardly be evident in sea-surface anomaly data. Intensity variations on timescales of $10^{4}$ years may be detectable in sea-surface profiles from fast-spreading ridges but will have greatly reduced amplitudes and longer wavelengths as dictated by the Earth filter. In order to document these higher-frequency anomaly variations (some of which may reflect geomagnetic field behavior), it is useful to make magnetic field observations nearer the magnetic source (Larson and Spiess, 1969). One might well ask whether much additional information can be gained from these near-bottom records since even polarity intervals as short as $10^{4}$ may be recorded, albeit in filtered form, in sea-surface profiles from the fastestspreading ridges in the present ocean basins. The answer is twofold. First, comparison of sea-surface and near-bottom data can sometimes differentiate between short wavelength anomalies due to short reversals and those arising from intensity fluctuations. For example, Bowers et al. (2001) have documented that many of the coherent tiny wiggles in sea-surface profiles from Anomaly 5 evolve into more complex, but still lineated, anomalies near the seafloor, suggesting these short wavelength anomalies represent 
geomagnetic intensity fluctuations rather than discrete short polarity events (which should be manifest by a higher amplitude and simpler anomaly pattern). A second benefit of near-bottom data is that two closely spaced short events (whether intensity variations or reversals) can be resolved as distinct features but must be much more widely separated to be differentiated in sea-surface anomaly data.

Near-bottom magnetic anomaly data from near the axis of fast-spreading ridges are particularly useful for assessing any geomagnetic signal, since they can provide high temporal resolution over a time period where independent estimates of geomagnetic intensity fluctuations are best known. Such anomaly data from fast-spreading ridges often show a short wavelength $(2-4 \mathrm{~km})$ axial anomaly high with a superimposed anomaly minimum or notch of even shorter wavelength (Gee et al., 2000; Perram et al., 1990; Shah et al., 2003). Possible mechanisms that have been advanced to explain this notch in the axial anomaly include: (1) variations in the thickness of the magnetized layer, (2) variations in magnetization intensity as a result of alteration, and (3) geomagnetic intensity fluctuations (Gee and Kent, 1994; Perram et al., 1990; Tivey and Johnson, 1987). Variations in the thickness of the extrusive magnetic source layer might arise from an axial keel of less magnetic dikes or from elevated temperature that may exceed the Curie point of the Ti-rich titanomagnetite in the extrusives (Shah et al., 2003). The magnetization of seafloor basalts can be substantially reduced by alteration in localized hydrothermal upflow zones (e.g., Tivey et al., 1996; Tivey and Johnson, 2002). As will be discussed further in Section 5.12.3.1, the longstanding notion that low-temperature alteration of the magnetic source is the dominant process in controlling crustal magnetization has significantly influenced interpretation of magnetic anomaly data both in the near-ridge environment (e.g., Schouten et al., 1999), as well as on much longer timescales (e.g., Bleil and Petersen, 1983; Zhou et al., 2001).

Although a variety of mechanisms undoubtedly influence magnetic anomaly amplitudes, near-bottom anomaly data and associated absolute paleointensities from the superfast-spreading southern East Pacific Rise (EPR) illustrate that geomagnetic intensity variations are likely sufficient to account for much of the near-ridge anomaly signal (Figure 3). Models of crustal alteration predict a monotonic decrease in magnetization intensity away from the ridge axis. The initial increase in anomaly amplitudes on the ridge flanks is thus apparently at odds with lowtemperature alteration being the dominant process
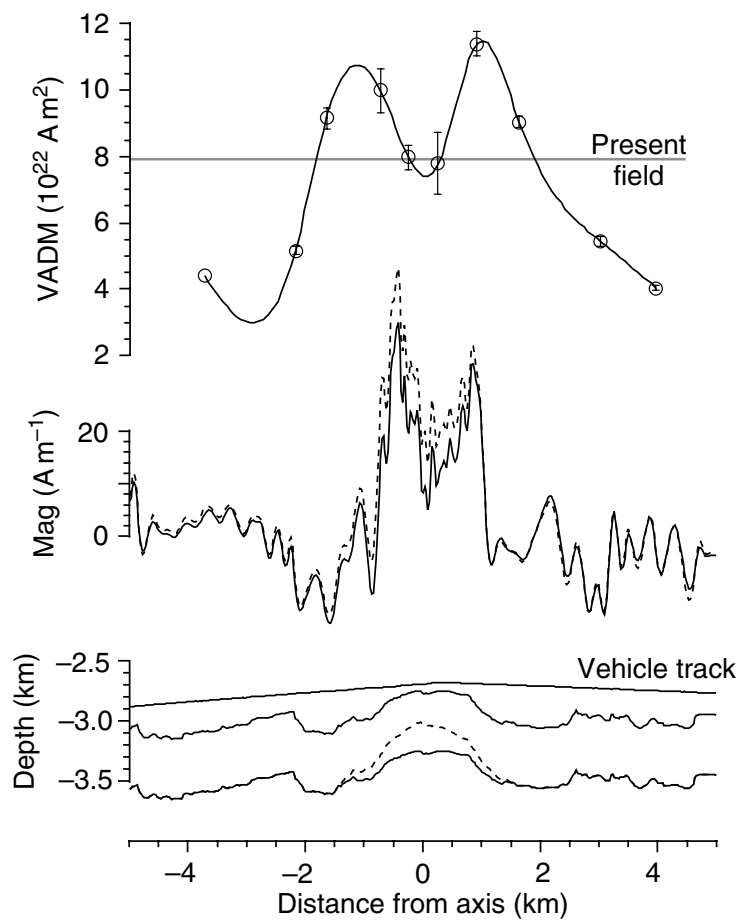

Figure 3 Comparison of glass paleointensities (top) and inversion magnetization solution (middle) for near-bottom magnetic profile across East Pacific Rise at $19.75^{\circ} \mathrm{S}$. For source-layer geometries (bottom), both a constantthickness source (solid line) and a variable-thickness source (dashed line) approximating off-axis doubling of seismic layer $2 \mathrm{~A}$ thickness produce inversions indicating that a lower magnetization is required on-axis with flanking areas of high magnetization. Modified from Gee et al. (2000).

controlling crustal magnetization. Thinning of the extrusive magnetic source layer at the ridge axis may also contribute to the axial anomaly notch (Shah et al., 2003). However, even a factor of 2 thinner extrusive source at the ridge axis, as suggested by seismic data (e.g., Christeson et al., 1992; Vera and Diebold, 1994), is apparently not sufficient to account for the lower axial magnetization (Figure 3). Absolute paleointensity data from surface glass samples near the ridge axis reveal a substantial variation in paleointensity (Bowles et al., 2006; Gee et al., 2000; Mejia et al., 1996), with moderate paleointensity values at the ridge axis higher values $1-2 \mathrm{~km}$ off-axis and much lower values farther from the ridge. This pattern is remarkably similar to independent estimates of field intensity variations established from archeomagnetic and volcanic materials, which document a substantial dipole moment increase from a low of $\sim 2 \times 10^{22} \mathrm{~A} \mathrm{~m}^{2}$ at $\sim 40$ ka to a peak of $\sim 11 \times 10^{22} \mathrm{Am}^{2}$, followed by a rapid decrease to the present value of $7.9 \times 10^{22} \mathrm{~A} \mathrm{~m}^{2}$ 
(e.g., Merrill et al., 1996). The similarity of these paleointensity data, both in magnitude and pattern, and the near-bottom anomaly data strongly suggests that geomagnetic intensity fluctuations are an important, if not the dominant, factor controlling anomaly amplitudes at many ridges.

Comparison of geomagnetic intensity variations over the past $800 \mathrm{ky}$ from sedimentary records and near-bottom magnetic anomalies from the EPR at $19^{\circ} \mathrm{S}$ (Gee et al., 2000) (Figure 4) also points to the potential importance of geomagnetic intensity variations in producing tiny wiggles. Absolute intensity information from well-dated archeomagnetic and

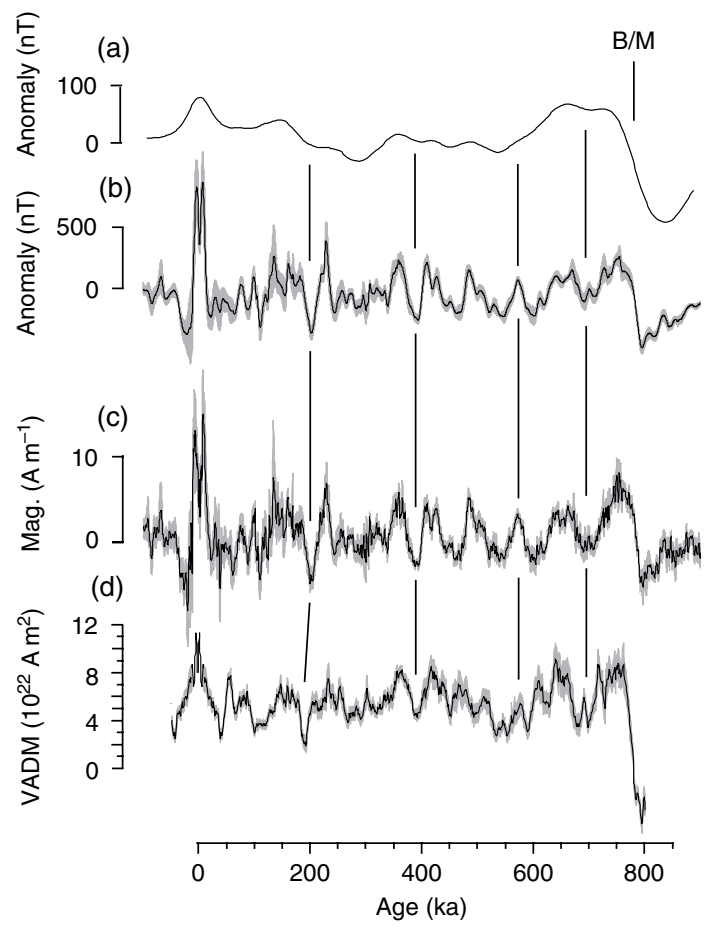

Figure 4 Comparison of geomagnetic intensity variations over the past $800 \mathrm{ky}$ from sedimentary records and in seasurface and near-bottom magnetic anomalies from the East Pacific Rise at $19^{\circ}$ S. (a) Stack of sea-surface anomaly profiles coincident with near-bottom magnetic anomaly (b) and inversion solution (c) stacks (see Gee et al., 2000 for details of inversion). Ages calculated assuming constant spreading rate and an age of $780 \mathrm{ky}$ for Brunhes/Matuyama $(B / M)$ boundary. Lower panel (d), shows Sint800 sedimentary relative paleointensity stack for 10-800 ky (Guyodo and Valet, 1999) combined with global archeomagnetic data for past $10 \mathrm{ky}$ (Merrill et al., 1996), all scaled as virtual axial dipole moment (VADM). Modified from Gee JS, Cande SC, Hildebrand JA, Donnelly K, and Parker $\mathrm{RL}$ (2000) Geomagnetic intensity variations over the past 780 kyr obtained from near-seafloor magnetic anomalies. Nature 408: 827-832. volcanic materials are too sparse prior to about 50 ka to allow construction of a time series of field intensity fluctuations. However, marine sediments can provide continuous, globally distributed records of relative paleointensity ( $\mathrm{see}$ Chapter 5.12 for a discussion of these relative intensity records) over longer timescales. A stack of sedimentary relative paleointensity records spanning the Brunhes (Guyodo and Valet, 1999) shows many similarities with coherent anomaly (and magnetization) fluctuations on eight profiles from the southern EPR. Because these anomaly profiles are separated by up to $60 \mathrm{~km}$, it is unlikely that crustal accretionary variables (variations in the source thickness or geochemistry) would result in coherent anomaly variations. Thus, variations in geomagnetic intensity are the most likely cause of the coherent fluctuations in the near-bottom anomaly profiles.

The pattern of geomagnetic intensity fluctuations in the near-bottom data is also recognizable in many sea-surface anomaly profiles across the Central Anomaly. At the superfast spreading southern EPR, sea-surface anomalies reveal two broad minima at $\sim 300$ and $\sim 550 \mathrm{ky}$ (Figure 4). A similar pattern is discernible in many sea-surface profiles, particularly from intermediate- and fast-spreading ridges (Figure 5). The systematic variation of profiles of the Central Anomaly with spreading rate and their similarity to progressively smoothed records of sediment-derived paleointensity suggest that the short wavelength anomalies within the Central Anomaly are global features representing filtered variations in geomagnetic dipole intensity.

Near-bottom anomaly profiles of Anomaly 5 in the northeast Pacific (Bowers et al., 2001) and comparison with the corresponding sea-surface anomaly data provide additional evidence that many short wavelength anomalies reflect paleointensity variations rather than short polarity reversals (Figure 6). Although the tiny wiggles in sea-surface anomaly profiles can conveniently be modeled as due to short reverse polarity intervals (Blakely, 1974), these anomaly minima in the sea-surface data correspond to more complex but still lineated anomalies in the near-bottom data. For example, the sea-surface minima labeled 5.4 corresponds to a local anomaly maximum within a broader low in the near-bottom data (Bowers et al., 2001). Numerous lineated magnetic lows were found in the 12 near-bottom profiles from the northeast Pacific. If modeled as short polarity reversals, the approximately $\sim 1$ My duration normal polarity interval would be interrupted by 26 reverse polarity 


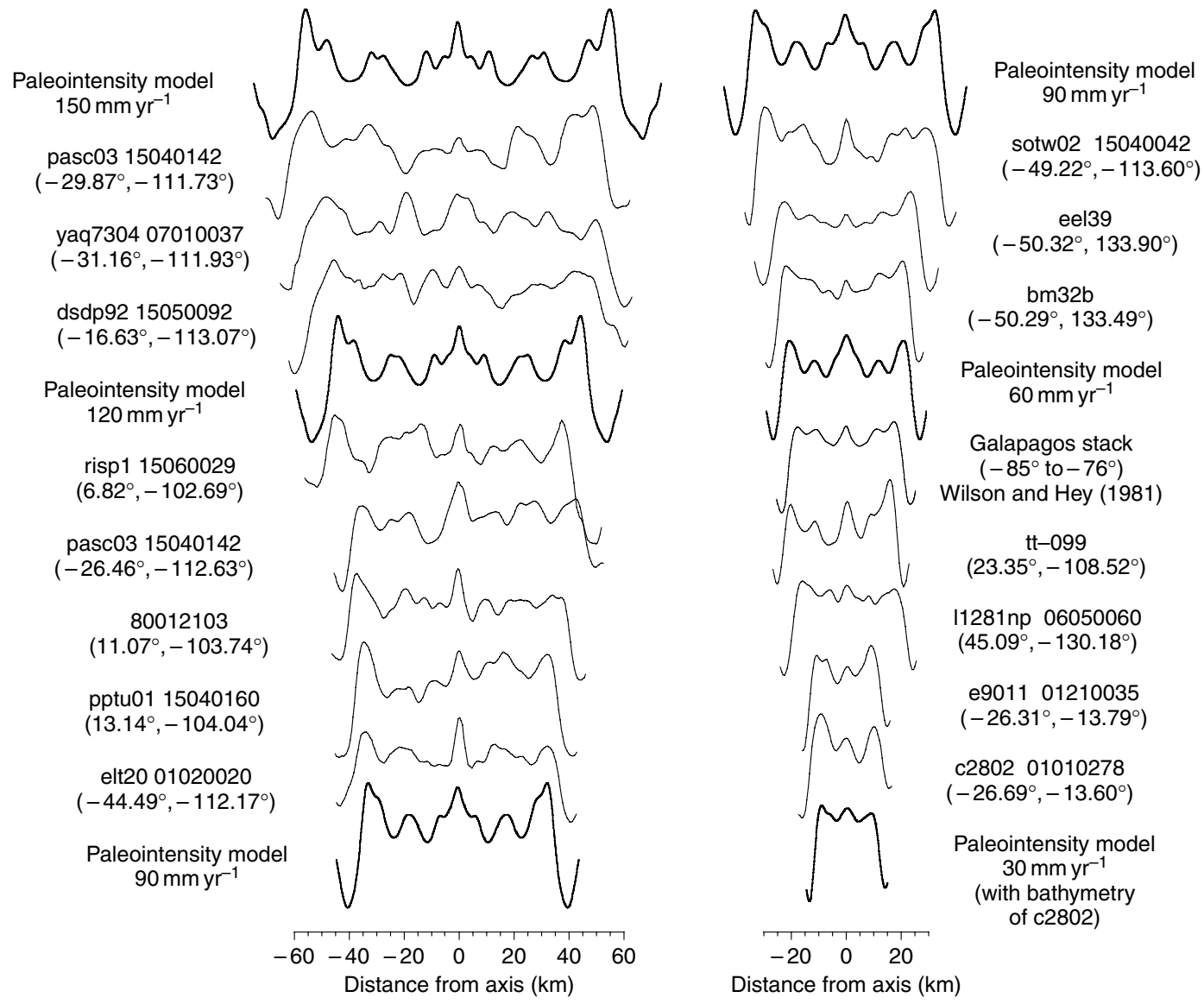

Figure 5 Sea-surface magnetic anomaly profiles illustrating the character of the Central Anomaly at different full spreading rates and the similarity to synthetic profiles (heavier lines) based on sedimentary paleointensity variations. All profiles have been reduced to the pole; actual profiles are identified by the location of the ridge crossing and the NDGC designations where available. Modified from Gee J, Schneider DA, and Kent DV (1996) Marine magnetic anomalies as recorders of geomagnetic intensity variations. Earth and Planetary Science Letters 144: 327-335.

intervals ranging from 1.2 to $19 \mathrm{ky}$ in duration (Bowers et al., 2001). More than three-quarters of these would have durations less than $10 \mathrm{ky}$ and so would be comparable to or less than the time needed for two reversals (average reversal duration $7 \mathrm{ky}$; Clement, 2004). The implausibly large number and short duration of required reversed polarity intervals suggest that most of the near-bottom anomaly fluctuations reflect geomagnetic intensity fluctuations rather than short polarity intervals. This interpretation is also supported by the fact that some correlative sedimentary records show no polarity reversals and yet have relative intensity variations that appear to correlate with the short wavelength anomaly features (Bowles et al., 2003). Other sedimentary records, however, reveal a small number of polarity fluctuations within Chron C5n (e.g., Evans and Channell, 2003; Evans et al., 2004; Roberts and Lewin-Harris, 2000) though the number, duration, and timing of these features is often conflicting. In some cases, the inferred long duration (e.g., 23 and $28 \mathrm{ky}$ events identified by Roberts and Lewin-Harris, 2000) is incompatible with magnetic anomaly data (such long polarity intervals would be readily apparent in profiles from fastspreading ridges). In other cases, proposed events are sufficiently brief (5-11 ky) to not conflict with existing anomaly data, though these events may represent excursions rather than polarity subchrons (Evans et al, 2004). While the sedimentary data provide evidence for a small number of polarity fluctuations, the bulk of the variations evident in near-bottom anomaly records are likely to reflect intensity variations rather than short polarity reversals. A linkage between directional excursions and low intensities is also suggested by a statistical model of the geomagnetic field (Tauxe and Kent, 2004). 


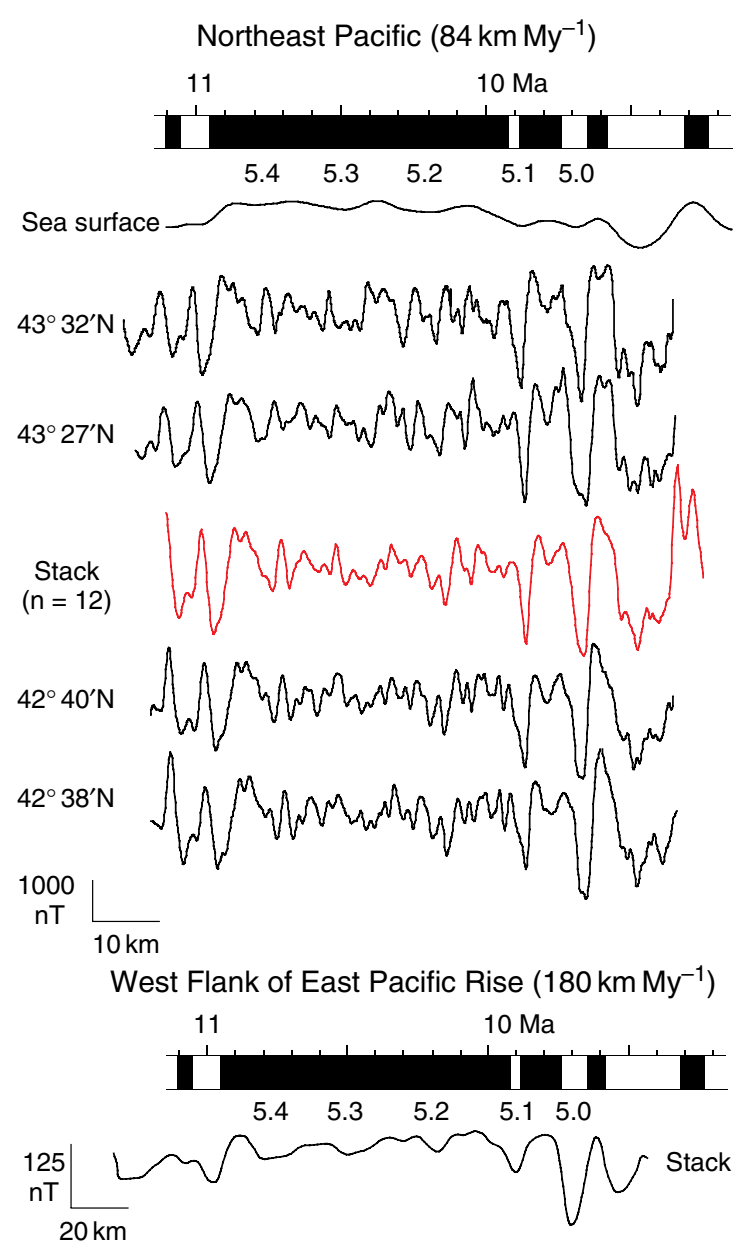

Figure 6 Magnetic anomaly profiles for Anomaly 5. Top shows sea-surface stack compared to representative nearbottom profiles and coincident near-bottom stack from moderate (84 $\mathrm{km} \mathrm{My}^{-1}$ full-rate) spreading seafloor in Northeast Pacific; bottom shows sea-surface stack from fast (180 $\mathrm{km} \mathrm{My}^{-1}$ full-rate) spreading seafloor on west flank of the southern East Pacific Rise. Modified from Bowers NE, Cande SC, Gee JS, Hildebrand JA, and Parker RL (2001) Fluctuations of the paleomagnetic field during chron C5 as recorded in near-bottom marine magnetic anomaly data. Journal of Geophysical Research 106: 26379-26396.

The geomagnetic intensity signal documented in the Central Anomaly and Anomaly 5 is likely to be a more general feature of marine magnetic anomalies, since the thermoremanence in the ocean crust should record geomagnetic intensity as well as polarity information. Apparently lineated, short-wavelength magnetic anomalies that most plausibly represent geomagnetic intensity fluctuations have indeed been documented within several portions of the C-sequence, for example, in sea-surface anomaly profiles from Anomalies 12-13 (Cande and
LaBrecque, 1974) and Anomalies 24-27 (Cande and Kent, 1992b). They are mostly attributed to intensity fluctuations because attempts to find corresponding short polarity intervals in sedimentary records have generally not been successful (e.g., Bowles et al., 2003; Evans and Channell, 2003; Hartl et al., 1993; Lanci and Lowrie, 1997; Schneider, 1995); these magnetostratigraphic data were summarized by Krijgsman and Kent (2004). Although the detailed pattern of preBrunhes intensity variations is not known, the statistical properties of the recent field (with $\sim 40 \%$ intensity fluctuations about the mean; Merrill et al., 1996) provide a plausible model for generating short wavelength anomaly variations (Cande and Kent, 1992b). The models shown in Figure 7 illustrate that coherent short wavelength anomaly variations are likely to be present throughout the marine magnetic anomaly sequence.

The amplitude and character of such short wavelength anomaly fluctuations, particularly in anomalous intervals such as the KQZ and JQZ, may therefore provide important clues about the origin of the geomagnetic field (e.g., by testing proposed links between reversal rate and geomagnetic intensity; Tauxe and Hartl, 1997). Sea-surface magnetic anomalies within the JQZ, arbitrarily delineated as older than anomaly M25, typically have very low amplitudes and there is a gradual increase in amplitude, extending from at least M29 to around M19, which may be field related (Cande et al., 1978; McElhinny and Larson, 2003) (Figure 8(a)). Although the lineated nature of even older M-sequence anomalies has been documented over fast spreading crust and used for tectonic reconstructions (Handschumacher et al, 1988; Nakanishi et al., 1989; 1992; Nakanishi and Winterer, 1998), magnetostratigraphic evidence for polarity reversals over the time interval represented by the JQZ, that is, prior to $\sim \mathrm{M} 25$, is still ambiguous (e.g., Channell et al., 1984; Juarez et al., 1994; Steiner et al., 1985). These older anomalies resemble the kind of shortwavelength, low-amplitude anomalies observed in the Cenozoic that have been attributed to paleointensity variations (Cande and Kent, 1992b). In contrast, magnetic anomalies in the KQZ can often be of high amplitude (e.g., Figure 8(b)) even though magnetostratigraphic studies and paleomagnetic compilations provide strong evidence that the KQZ formed during predominantly normal geomagnetic polarity (e.g., Irving and Pullaiah, 1976; Lowrie and Alvarez, 1981). It is not clear whether the anomalies in the KQZ are field related (e.g., Cronin et al., 2001) but their large amplitude does suggest that the field 
(a)

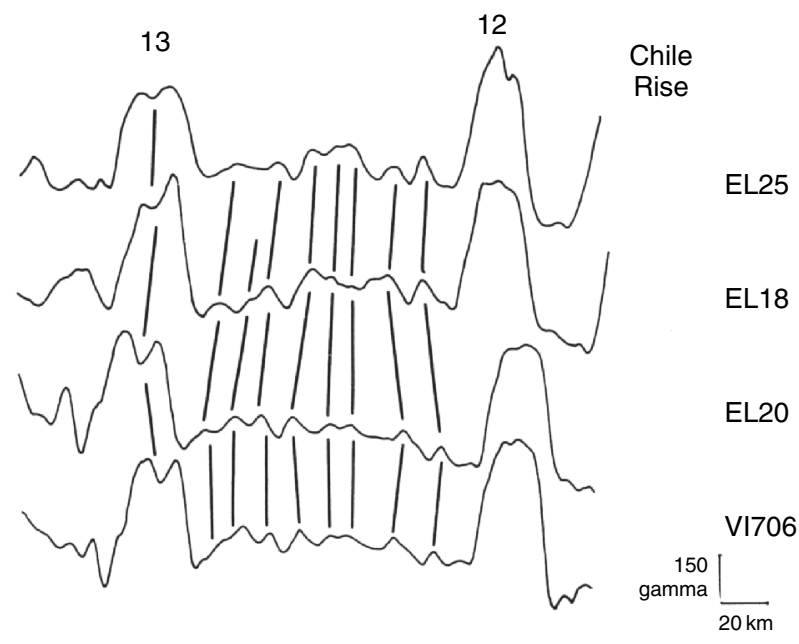

(b)

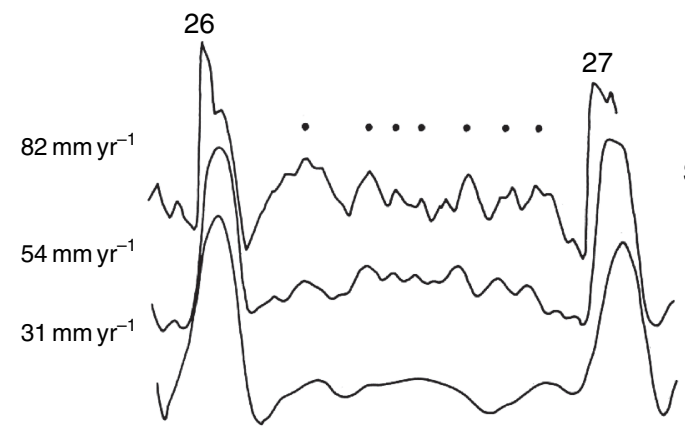

$T_{0}^{250} \mathrm{nT}$

Southeast Pacific $25 \mathrm{~km}$ Indian Ocean $\stackrel{25 \mathrm{~km}}{\longmapsto}$

North Pacific

$25 \mathrm{~km}$

(c)

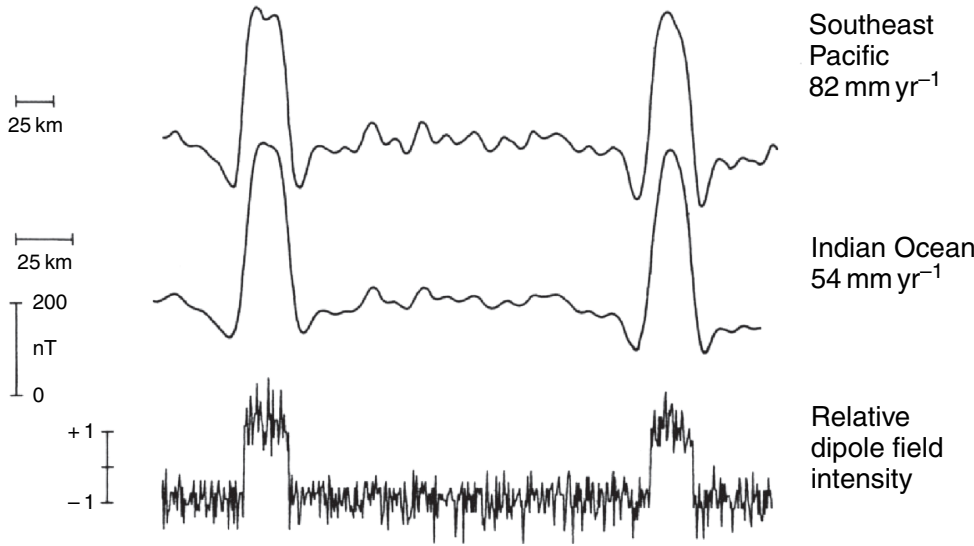

Figure 7 Further examples of short wavelength magnetic anomalies in sea-surface profiles (a) from between Anomalies 12 and 13 on Chile Rise and (b) at various spreading rates from between Anomalies 26 and 27. A model for the source of the short wavelength magnetic anomalies between Anomalies 26 and 27 at different spreading rates is shown in (c) and assumes that the anomalies are due to random fluctuations in the dipole field paleointensity whose statistical properties are compatible with observed paleointensity variations over the past $5 \mathrm{My}$. (a) Modified from Cande SC and LaBrecque JL (1974) Behaviour of the Earth's paleomagnetic field from small scale marine magnetic anomalies. Nature 247: 26-28. (b,c) Modified from Cande SC and Kent DV (1992b) Ultrahigh resolution marine magnetic anomaly profiles: A record of continuous paleointensity variations. Journal of Geophysical Research 97: 15075-15083. 


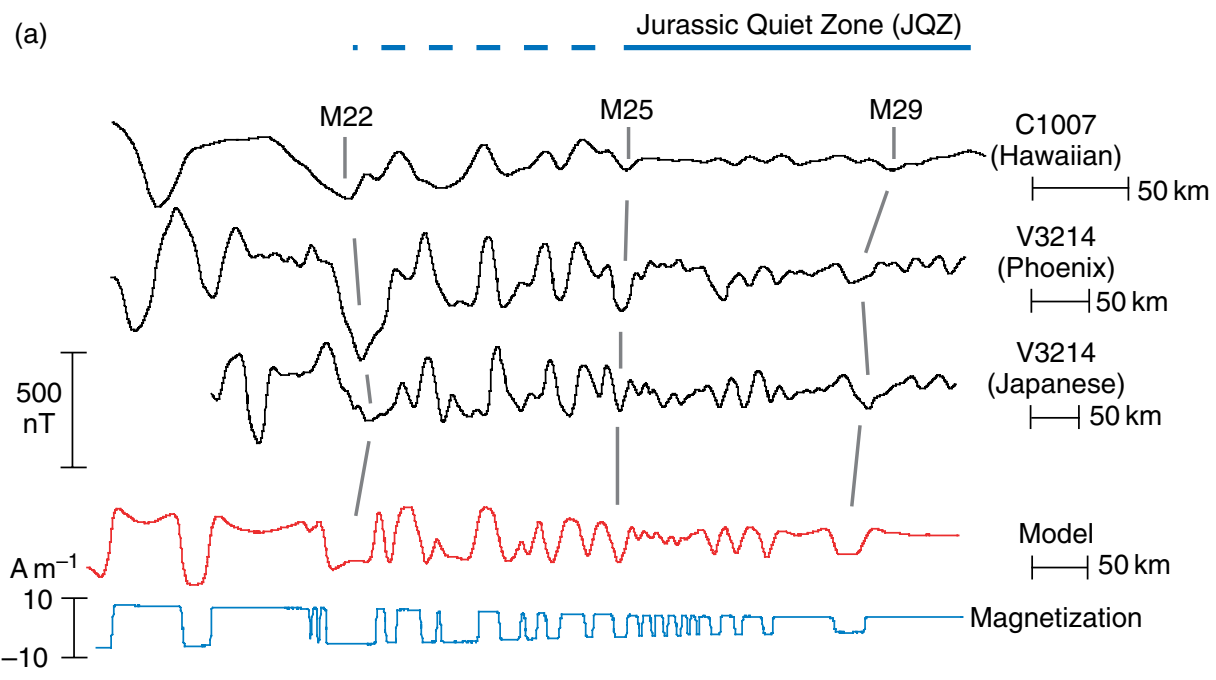

(b) Cretaceous Quiet Zone (KQZ)

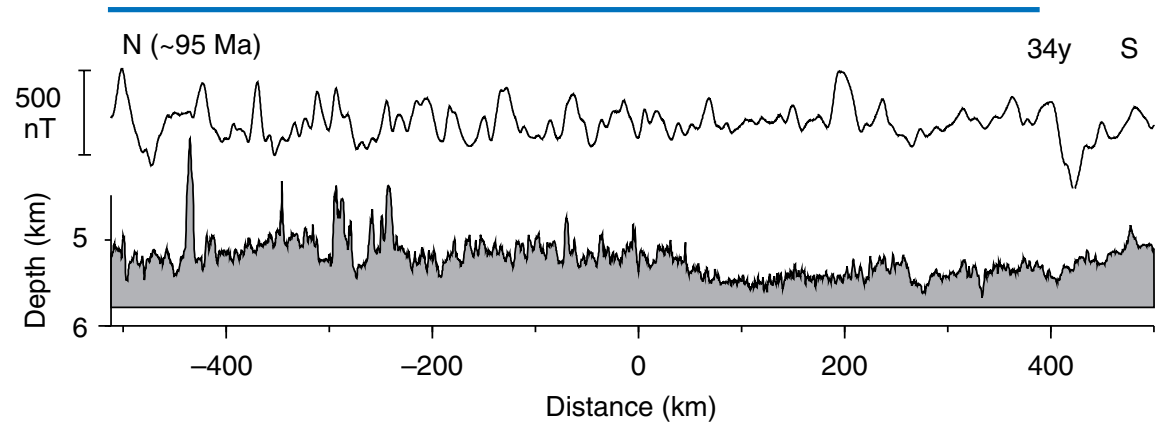

Figure 8 A comparison of sea-surface magnetic profiles from the Jurassic Quiet Zone (JQZ) in the western Pacific (top; after Cande et al., 1978) and the Cretaceous Quite Zone (KQZ) from the southwest Pacific (bottom; data from Pockalny et al., 2002). Representative anomaly profiles from the JQZ from the Hawaiian, Phoenix, and Japanese lineation sets have been reduced to the pole. Note the pronounced decrease in amplitude from anomaly M22 to M29, and the low ( $<100 \mathrm{nT})$ amplitudes prior to M29. In contrast, many anomaly profiles within the KQZ show large amplitude variations that in some cases are as large as known polarity reversals (e.g., anomaly 34y - young end of anomaly 34 (as for chrons in Table 1)).

intensity during the KQZ may have been high (Tarduno et al., 2001; Tauxe and Staudigel, 2004), especially compared to the JQZ, whose low-amplitude anomalies might be indicative of low average field intensity in the Jurassic (McElhinny and Larson, 2003; Prévot et al., 1990).

\subsubsection{Anomaly Skewness and Nondipole Field}

In addition to the wealth of information on geomagnetic intensity and polarity reversals, the shape (skewness) of magnetic anomalies can also provide an estimate of remanent inclination that can, in turn, be used for tectonic or geomagnetic studies. The skewness of a magnetic anomaly is a function of the effective inclinations (i.e., those projected in a plane perpendicular to the azimuth of the magnetized blocks) of the ambient field and of the remanence of the source blocks (Schouten and Cande, 1976). Skewness amounts to a uniform phase shift as a measure of the deviation in shape between the observed magnetic anomalies and the ideal symmetric profile that would be produced in a vertical field by vertically oriented magnetizations separated by vertical source boundaries. Determination of the skewness from anomaly profiles, together with the known geometry of the spreading lineation and ambient field, allows the remanent inclination to be estimated. For the Central Anomaly, Schneider (1988) applied this type of skewness analysis to 14 magnetic 
anomaly profiles from the Galapagos Ridge to derive a precise estimate of the mean remanent inclination, which was found to differ by several degrees from the expected field inclination and indicated that there is a small but significant $(\sim 5 \%)$ long-term nondipole (mainly axial quadrupole) contribution to the geocentric axial dipole field (Figure 9). This result was confirmed by an analysis of skewness in 203 profiles of the
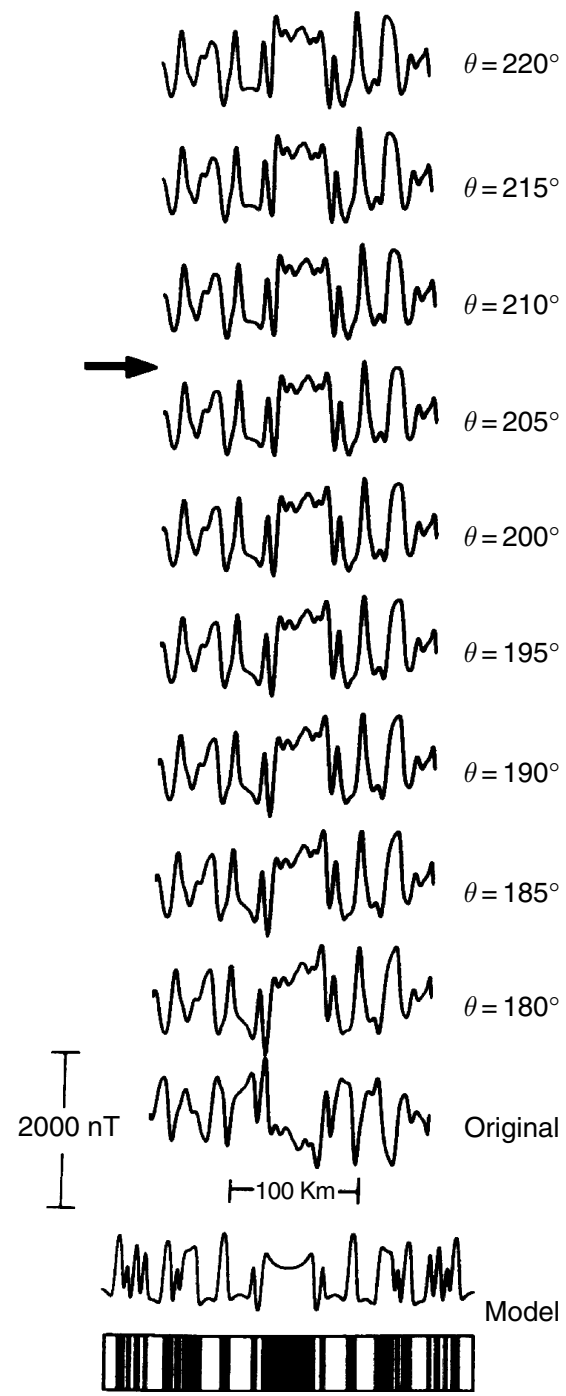

Figure 9 Representative sea-surface magnetic anomaly profile from Galapagos spreading center illustrating technique used to determine skewness of Central Anomaly. Arrow points to approximate phase shift $\left(\theta=207.5^{\circ}\right)$ required to match the shape of the Central Anomaly to the model profile formed at the pole (bottom). Modified from Schneider DA (1988) An estimate of the long-term nondipole field from marine magnetic anomalies. Geophysical Research Letters 15: 1105-1108.
Central Anomaly from the global ridge system (Acton et al., 1996).

In applications of the skewness method outside of the Central Anomaly (or Brunhes), where both isochronous boundaries of the source block contribute and thus simplify interpretation of the anomaly shape, other aspects of the source that may not be symmetrically distributed to cancel out (e.g., sloping polarity boundaries, tectonic rotations) need to be considered for interpretation of field behavior (Cande and Kent, 1976). The skewness of magnetic anomalies that is not accounted for by a simple block model is termed anomalous skewness (Cande, 1976). While such anomalous skewness is a complicating factor in extracting geomagnetic or tectonic information from magnetic anomalies (e.g., Petronotis et al., 1992), the details of the anomaly shape provide strong constraints on the geometry and tectonic deformation of the magnetization source that will be discussed further in Section 5.12.4. Assessing the fidelity of the geomagnetic field record in anomalies requires an understanding of both these nonfield related variations in source properties (e.g., transition zone width, geometry of polarity boundaries), as well as the intrinsic magnetic properties of the various source layers. The nature and origin of the remanent magnetization of these layers are the subject of the following section.

\subsubsection{Magnetic Source Regions}

Analysis of sea-surface and near-bottom magnetic anomalies suggest that most of the signal comes from the extrusive layer (Figure 10). For example, Talwani et al. (1971) determined the mean magnetization of basement topography from sea-surface magnetic surveys made along strike, which allowed an estimate of the thickness of the layer responsible for the acrossstrike (seafloor spreading) magnetic anomalies. The analysis was made on the slow-spreading Reykjanes Ridge and yielded a thickness of about $500 \mathrm{~m}$, approximately the thickness of the volcanic layer. Atwater and Mudie (1973) did a comparable analysis using near-bottom magnetic profiles on the Gorda Rise in the Pacific. They also found that a $500 \mathrm{~m}$ thick source layer could account for the seafloor spreading magnetic anomalies. Dredged and drilled samples of oceanic basalts have remanent magnetizations that are more or less compatible with a relatively thin source layer but firm conclusions are inhibited by the several orders of magnitude range in the magnetization values (Lowrie, 1977). 


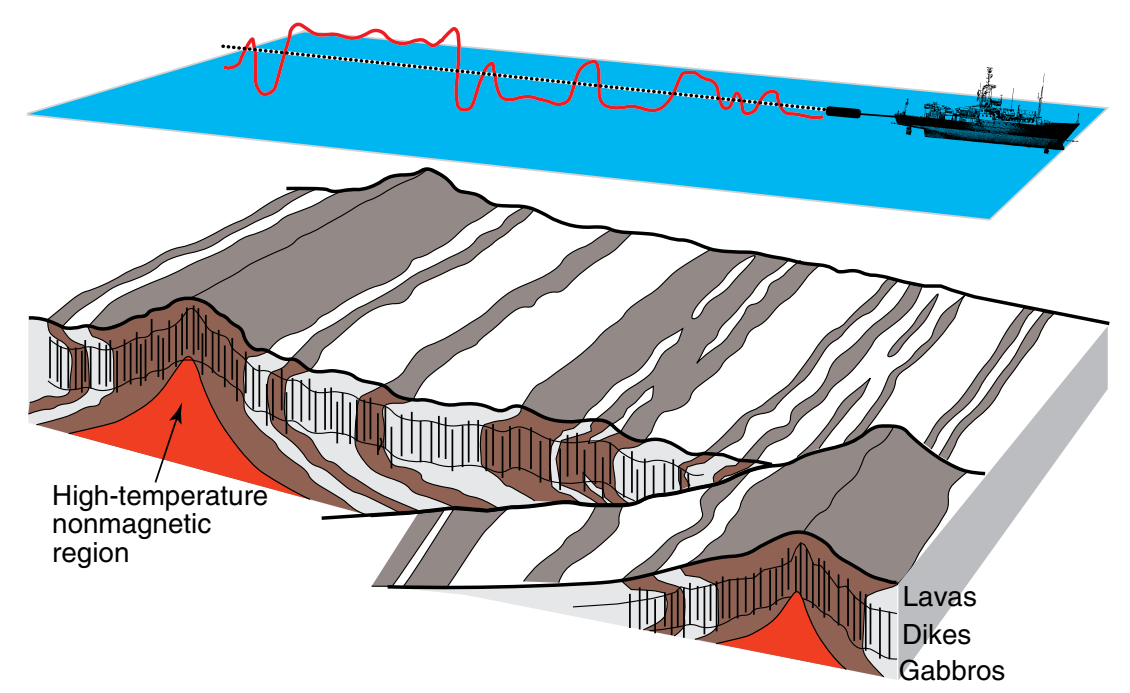

Figure $103-D$ perspective cartoon of ocean crust (after Johnson et al., 1997), showing spreading centers separated by a transform fault. Crust generated during normal/reverse geomagnetic polarity (shown as shaded/unshaded regions) can be inferred from magnetic anomalies, for example, as measured from ship-towed magnetometers. Magnetization polarity boundaries are expected to be vertical in sheeted dikes and are likely to slope but in opposite directions in extrusive basalt layer (due to successive emplacement of lavas) and in intrusive gabbroic layer (due to progressive cooling with depth of gabbros).

Thicker and even deeper sources have also been invoked, usually as a counterbalance to supposedly altered and diminished shallower sources to explain the apparent loss of fidelity in earlier Cenozoic anomaly sequences (e.g., Blakely, 1976) or to produce anomalous skewness from sloping blocking temperature isotherms (Cande and Kent, 1976). Although broader transition zone widths (and consequently some loss of short polarity events) might be expected if the slowly cooled gabbroic layer is a substantial contributor, the still older (M-sequence) anomalies do not have markedly broader transition zone widths (e.g., Cande et al., 1978) and magnetostratigraphic data confirm that the reversal frequency in the earlier Cenozoic was in fact lower (Lowrie and Alvarez, 1981; Lowrie and Kent, 2004). Similarly, the general absence of anomalous skewness for Anomalies M0-M4 (Cande, 1978; Larson, 1977; Larson and Chase, 1972) places limits on the contribution from the gabbroic layer. These observations suggest that contributions from deeper source layers are not necessarily required, although they are also not precluded (Harrison, 1987). Magnetic data from samples of these deeper layers suggest that they do indeed contribute significantly to magnetic anomalies.

Below we summarize the magnetization of the oceanic crust according to the main subdivisions: extrusives, sheeted dikes, and gabbros, plus serpentinized mantle peridotites, and show that sample remanence and anomaly data can be reconciled by a three-layer model, with relatively narrow transition zones in lavas and dikes and broader polarity boundaries in the gabbros. Oceanic basement rocks acquire a thermal remanent magnetization (TRM) during initial cooling. The magnitude of the TRM is proportional to the strength of ambient geomagnetic field but also depends on the geochemistry (e.g., iron content) of the rocks and magnetic grain size. The rocks may alter with age, which may also modify the TRM. The resultant magnetization measured on rock samples in the laboratory is referred to as the natural remanent magnetization (NRM). In order to facilitate comparison of magnetization values from different locations (dipole intensity varies by a factor of 2 from equator to pole), all magnetization values are reported as equatorial values. Although the arithmetic mean is most pertinent for comparison with magnetic anomalies, most large magnetization data sets are characterized by approximately lognormal distributions. Geometric mean values are used where possible (many authors do not specify how mean values were calculated) for comparisons since these are less influenced by extreme values in smaller data sets that are typical of many studies of oceanic rocks. 


\subsubsection{Magnetization of Lavas}

Mid-ocean ridge basalts that constitute the oceanic extrusive layer have a magnetization that is characteristically dominated by a strong stable remanence compared to an induced component, making these shallow seated rocks a traditional prime source of seafloor spreading magnetic anomalies. Titaniumrich titanomagnetite $\left(\mathrm{Fe}_{3-\mathrm{x}} \mathrm{Ti}_{\mathrm{x}} \mathrm{O}_{4}\right.$, where $\left.\mathrm{x} \sim 0.6\right)$ that has often undergone variable degrees of lowtemperature oxidation (maghemitization) is the principal magnetic mineral. However, it was recognized early on that the very wide range of observed NRM intensities could not be explained by a mere variation in low-temperature oxidation; instead, it is necessary to invoke substantial variations in titanomagnetite composition, concentration, and grain size (Lowrie, 1977).

\subsection{Initial grain size and composition}

The rapidly chilled margins of submarine lavas produce a large gradient in cooling rate-dependent grain size and compositional effects (Marshall and Cox, 1971). For example, detailed sampling perpendicular to the chilled margin shows that the NRM and magnetic hysteresis parameters can vary systematically by an order of magnitude on centimeter scales (Gee and Kent, 1997, 1998, 1999; Kent and Gee, 1996; Marshall and Cox, 1971) (Figure 11). Near the chilled margin, hysteresis parameters indicate grain sizes spanning the superparamagnetic/single domain boundary ( $30 \mathrm{~nm}$; Özdemir and O'Reilly, 1981). The presence of stable single domain grains, associated with a peak in NRM intensity, presumably accounts for much of the strong, stable remanence associated with the extrusive layer. The pronounced grain-size variation, however, presents a practical problem in characterizing the magnetic properties of oceanic basalts because random sampling of such large within-flow variations can seriously bias estimates of between-flow and between-site variations.

Unblocking temperatures of NRM as well as Curie temperatures can also show a large systematic variation with depth in a flow (Grommé et al., 1979; Ryall and Ade-Hall, 1975), even in a zero-age pillow such as is illustrated in Figure 11. The within-flow variation in Curie temperatures in these and other studies has usually been interpreted as reflecting progressive low-temperature oxidation of an originally homogeneous titanomagnetite host (e.g., Kent and Gee, 1996). However, transmission electron microscopic (a)

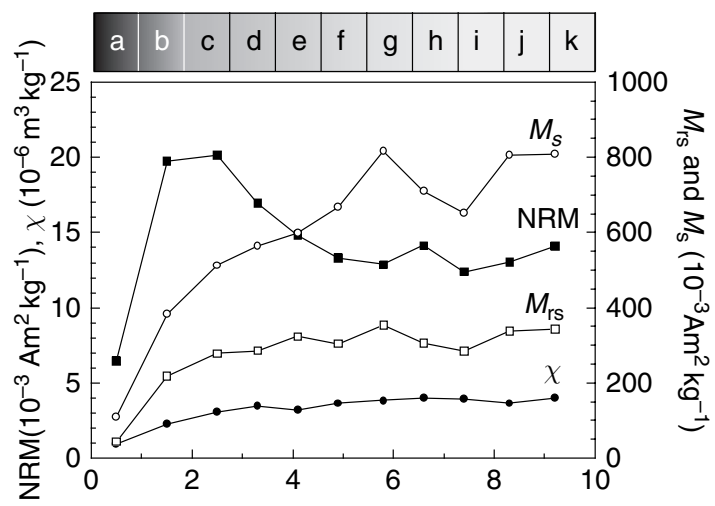

(b)

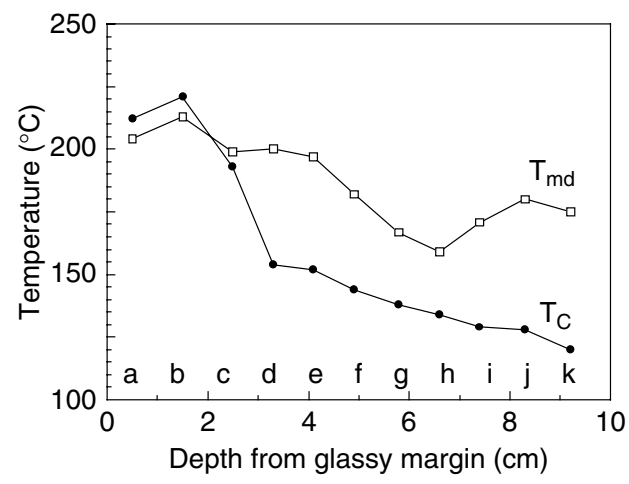

Figure 11 Within-lava flow variability in magnetic properties that can be ascribed to cooling rate-dependent grain size effects. (a) Variation in NRM, susceptibility $(\chi)$, saturation remanence $\left(M_{\mathrm{rs}}\right)$ and saturation magnetization $\left(M_{\mathrm{s}}\right)$ as a function of distance from glassy chilled margin in New Flow (erupted 1993) pillow fragment R-1 from the Juan de Fuca Ridge. (b) Variation in Curie temperature $\left(T_{c}\right)$ and median demagnetizing temperature of NRM (Tmd) in the same samples. Similar cooling-rate dependent variations in magnetic properties in oceanic basalts have been documented by Marshall and Cox (1971), Gee and Kent (1997), and others. Modified from Kent DV and Gee J (1996) Magnetic alteration of zero-age oceanic basalt. Geology 24: 703-706.

observations (Zhou et al., 2000) on a zero-age pillow fragment from the Juan de Fuca Ridge show no oxidation and that the titanium content of titanomagnetite grains varies as a function of distance from the chilled margin (Figure 12). The larger grains in the interior have a more uniform composition of around $x=0.6$ whereas the smaller grains toward the glassy margin have more variable compositions with a lower average $x$ value of $\sim 0.45$. Ultrafine magnetite $(x \sim 0)$ has been documented both in interstitial glass, as well as in the chilled glassy 


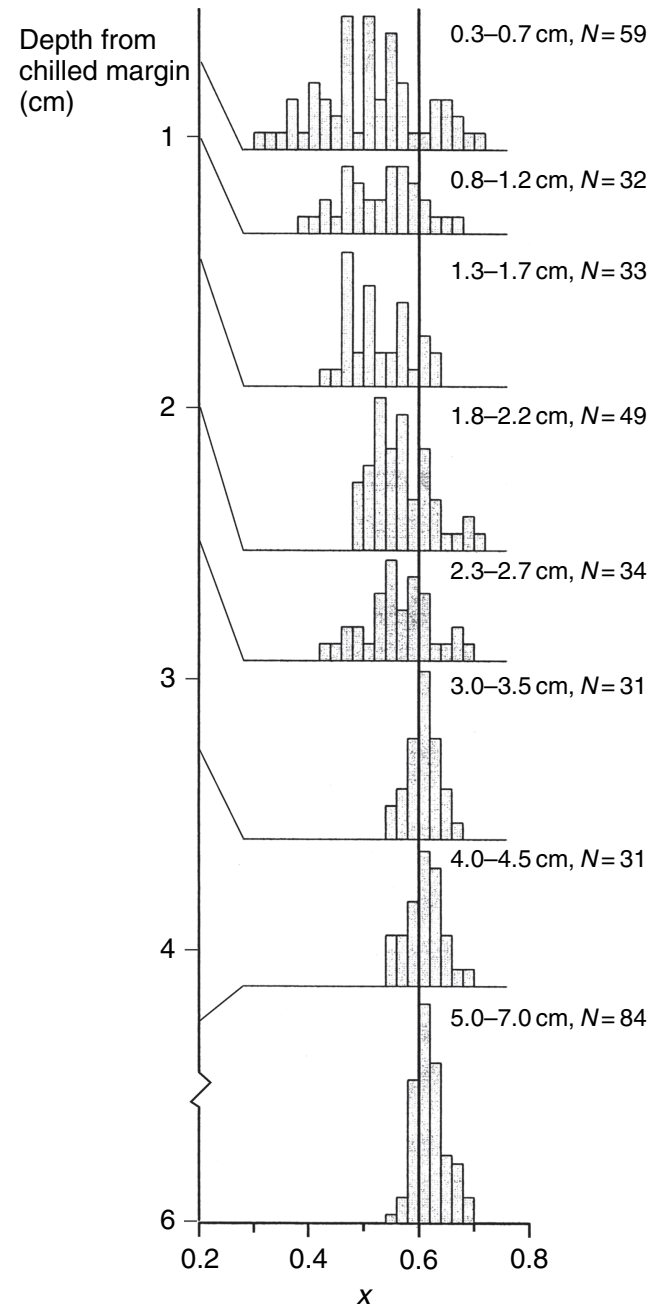

Figure 12 Variation of composition parameter, $x$, of titanomagnetite as a function of depth from the glassy chilled margin in a New Flow (erupted 1993) pillow fragment from the Juan de Fuca Ridge. Modified from Zhou W, Van der Voo R, Peacor DR, and Zhang Y (2000) Variable Ti-content and grain size of titanomagnetite as a function of cooling rate in very young MORB. Earth and Planetary Science Letters 179: 9-20.

margin (Pick and Tauxe, 1994; Zhou et al., 1999b) and these grains may remain unaltered for tens of millions of years (Zhou et al., 1999b). Kent and Gee (1996) also documented trace amounts of low-Ti magnetite in the crystalline interiors of very young flows.

A more general geochemical factor, iron and titanium enrichment of basaltic melts, is expected to exert a fundamental control on the magnetization of oceanic basalts and has been conveniently cast in terms of the magnetic telechemistry hypothesis (Vogt and Johnson, 1973). The iron content of basaltic melts increases during low-pressure fractionation (e.g., Juster et al., 1989) and this iron enrichment should be accompanied by increased abundance of titanomagnetite, resulting in higher NRM and thus in enhanced magnetic anomaly amplitudes. Several attempts to test the magnetic telechemistry hypothesis produced uncertain results, largely because of large scatter in the magnetization data. For example, Johnson and Tivey (1995) found a poor correlation $(R \sim 0.2)$ between $\mathrm{FeO}^{*}$ (total iron expressed as $\mathrm{FeO}$ ) and NRM from the Juan de Fuca Ridge. However, good linear correlations ( $R$ up to $\sim 0.8$ ) between NRM and $\mathrm{FeO}^{*}$ were obtained from data from the southern East Pacific Rise (EPR) (Gee and Kent, 1997, 1998) (Figure 13(a)). The greatly improved correlations can be attributed to detailed sampling that spanned the full range of cooling-related magnetization changes within a flow, as well as to the young age of the axial samples, which effectively minimized agedependent magnetization changes. An inversion of the axial magnetic anomaly profile shows a close correspondence between the magnitude of the magnetization solution and the range of intensities observed in the axial samples (Figure 13(b)). The equivalent NRM values calculated from the mean $\mathrm{FeO}^{*}$ content of each dredge using the linear regression also provide confirmation of the predicted link between geochemistry and anomaly amplitude.

The geochemical dependence demonstrated on the southern EPR indicates that the magnetization of oceanic basalts can vary by up to a factor of $\sim 4$ as a function of their iron contents alone, from around $12 \mathrm{~A} \mathrm{~m}^{-1}$ for $9 \% \mathrm{FeO}^{*}$ to more than $50 \mathrm{Am}^{-1}$ for the highest $\mathrm{FeO}^{*}$ values $(\sim 15 \%$; separation of early crystallizing phases cause $\mathrm{FeO}^{*}$ to increase but at higher degrees of fractionation $\mathrm{FeO}^{*}$ decreases as $\mathrm{FeTi}$ oxide phenocrysts begin crystallizing). Geochemical variation is thus expected to exert a fundamental control on the magnetization of basalt and the source of magnetic anomalies, which should vary more or less proportionately in amplitude as has been observed on the southern EPR. Ridge crest discontinuities, where enhanced fractionation is expected, are often accompanied by higher amplitude magnetic anomalies (Bazin et al., 2001; Wilson and Hey, 1995). In addition, the average degree of fractionation of lavas appears to vary with spreading rate (Sinton and Detrick, 1992). Slow-spreading ridges, which lack steady magma chambers, have systematically less-evolved magmas with lower $\mathrm{FeO}^{*}$ than faster-spreading ridges, differences that might be reflected in overall values of basalt magnetizations and anomaly amplitudes. 
(a)

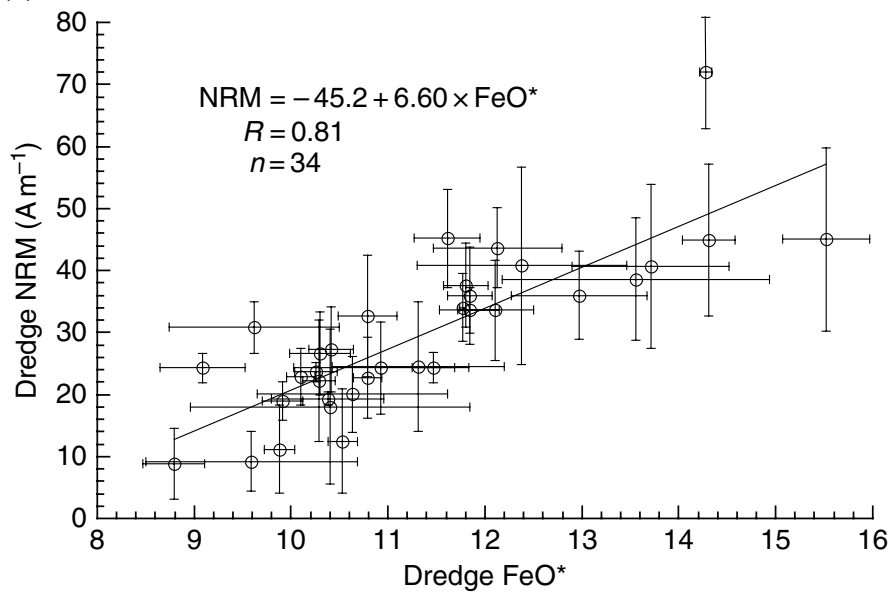

(b)

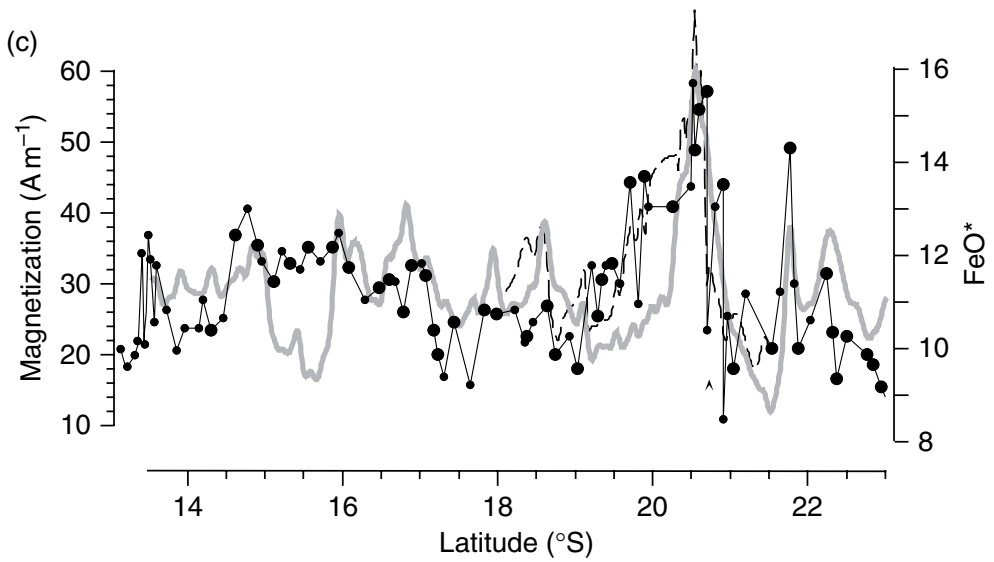

Figure 13 Magnetic and geochemical variations along the axis of the southern East Pacific Rise. (a) Variation in NRM as a function of $\mathrm{FeO}^{*}$ (total $\mathrm{Fe}$ as $\mathrm{FeO}$ ) for dredges from the southern East Pacific Rise. NRM values represent the arithmetic mean intensity ( \pm s.d.) of three or more flows/pillows, each with multiple subspecimens (Gee and Kent, 1997). Dredge mean FeO* content ( \pm s.d.) calculated from microprobe analysis of glass chips (Sinton et al., 1991) from samples used for magnetic study. (b) Composite axial magnetic anomaly (prior to reduction to pole). (c) Magnetization inferred from profile inversion (heavy grey line) and grid inversion (dashed, both left scale) is compared to $\mathrm{FeO}^{*}$ content (filled circles, with larger circles indicating dredges for which sample magnetizations are available), with the scaling and offset between the axes determined by the regression result from panel (a). Prior to inversion, the axial anomaly was reduced to pole using an effective source thickness of $375 \mathrm{~m}$, corresponding to an extrusive layer that thickens from 250 to $500 \mathrm{~m}$ within approximately $2.5 \mathrm{~km}$ of the ridge crest. A cosine-tapered band-pass filter was applied where wavelengths $<10 \mathrm{~km}$ and $>600 \mathrm{~km}$ were cut and wavelengths $>20 \mathrm{~km}$ and $<300 \mathrm{~km}$ were passed unattenuated. Modified from Gee J and Kent DV (1998) Magnetic telechemistry and magmatic segmentation on the southern East Pacific Rise. Earth and Planetary Science Letters 164: 379-385.

\subsection{Low-temperature alteration}

Low-temperature oxidation of stoichiometric titanium-rich titanomagnetite is widely considered to be the dominant process of magnetic alteration of oceanic basalts. The magnetic consequences of such low-temperature alteration include a fourfold reduction in the saturation magnetization (for complete oxidation; O'Reilly, 1984), as well as a significant increase in the Curie temperature (Xu et al., 1996), with the possible acquisition of a chemical remanent 
magnetization (CRM) that might replace the initial TRM (Raymond and LaBrecque, 1987). Substantial (up to an order of magnitude) changes in the magnetization of the extrusive layer and the amplitude of the associated magnetic anomalies have been attributed to low-temperature alteration (Bleil and Petersen, 1983; Irving, 1970). As documented below, zero-age lavas do have a remanence that is higher, by a factor of 4 , than that of older lava samples. However, magnetic anomaly data and direct determination of the degree of low-temperature oxidation suggest that this process is responsible for only about half of this decrease in magnetization, with the remaining discrepancy plausibly attributed to higher paleofield intensity in the axial lavas. Moreover, the heterogeneity of alteration makes definitive resolution of the relevant timescales difficult.

Sea-surface magnetic profiles and inversion solutions from fast-spreading ridges like the PacificAntarctic Ridge (Figure 14(a)) record a short $(\sim 10 \mathrm{~km})$ wavelength axial Central Anomaly magnetic high (CAMH) (Klitgord, 1976). Near-bottom anomaly data from fast-spreading ridges indicate that the width of this high magnetization zone is $\sim 2-3 \mathrm{~km}$ (Figure 3). At slow-spreading ridges, the $\mathrm{CAMH}$ occupies a larger proportion of the Central Anomaly and consequently may not be readily distinguishable in sea-surface profiles from the Central Anomaly (Figure 14(b)). In concert with a dominant Central Anomaly (e.g., Vine, 1966), the evidence for a decay in basalt magnetizations has traditionally come from the slow-spreading ridges in the Atlantic Ocean where oceanic basalts have been thought to suffer decay related to aging and alteration with a time constant on the order of 0.5 My (Irving, 1970; Johnson and Atwater, 1977). Alteration-induced magnetization decay has also often been linked to the CAMH (Klitgord, 1976), although this would require very different time constants for fast- and slow-spreading ridges. For example, profiles from the fast spreading EPR at $12^{\circ} \mathrm{N}$ suggest that the magnetization contrast must occur over a much shorter timescale to balance a presumed negative magnetic anomaly that would result from the thickening of Layer 2A deduced from seismic imaging (Figure 15).

Although originally interpreted as reflecting lowtemperature alteration on rapid timescales (Gee and Kent, 1994), remanence data from near-ridge basalts at the EPR at $12^{\circ} \mathrm{N}$ do not require a substantial decay in magnetization related to alteration. This is because low NRM intensities and magnetic (a)

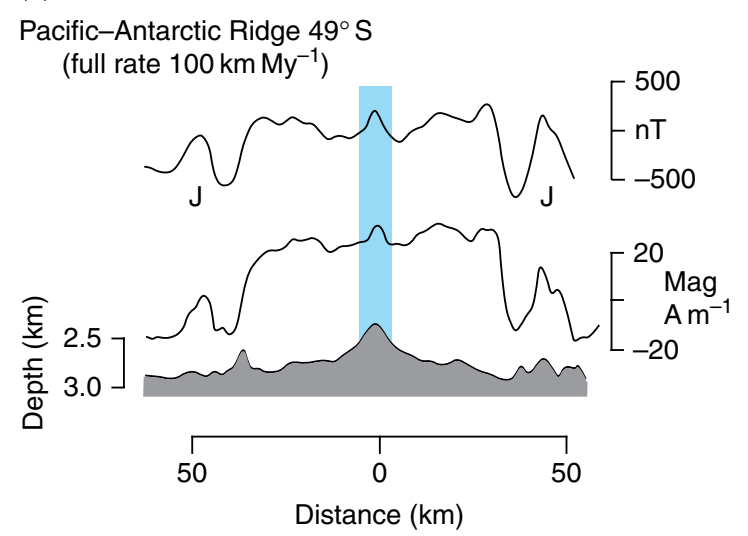

(b)

Gorda Rise $41^{\circ} \mathrm{N}$

(full rate $24 \mathrm{~km} \mathrm{My}^{-1}$ )

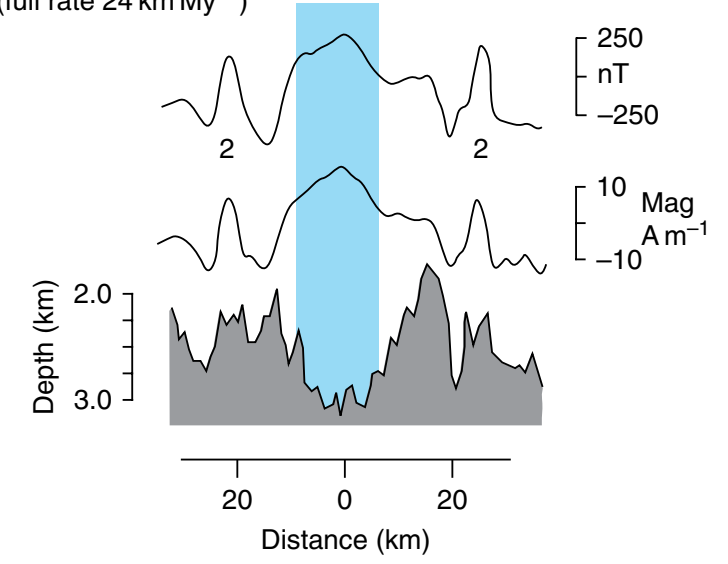

Figure 14 Sea-surface magnetic profiles, inversion solutions, and bathymetric profiles from (a) the fastspreading Pacific-Antarctic Ridge and (b) the slowspreading Gorda Rise illustrating the short ( $10 \mathrm{~km})$ wavelength axial Central Anomaly magnetic high $(\mathrm{CAMH}$, vertical shading). The CAMH occupies a larger proportion of the Central Anomaly at slow-spreading ridges where it is not readily distinguishable in sea-surface profiles from the Central Anomaly because the wavelengths become similar. Modified from Klitgord KD (1976) Sea-floor spreading: The central anomaly magnetization high. Earth and Planetary Science Letters 29: 201-209.

susceptibilities and high Curie temperatures, which might be an indication of alteration, occur at the ridge axis (zero age) and as well as off-axis (Figure 16). Indeed, efforts to induce alteration of young oceanic basalts in the laboratory have generally failed (e.g., Kent and Gee, 1994). Instead, it now appears that the high magnetization values on-axis producing the contrast that accounts for the CAMH on fast-spreading ridges is mostly due to a paleointensity signal, which is also suggested by the central 

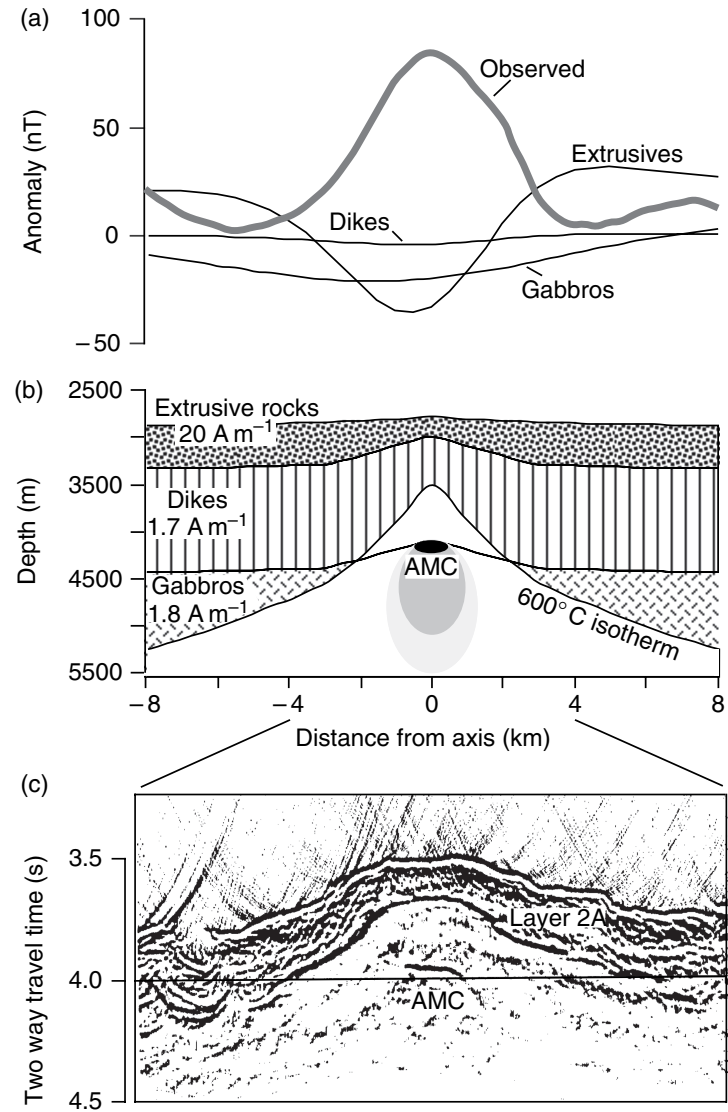

Figure 15 (a) Forward models illustrating the axial magnetic anomaly minimum generated by off-axis thickening of a uniformly magnetized extrusive layer or cooling of deeper layers as shown in (b), compared to the observed sea-surface profile at $19.5^{\circ} \mathrm{S}$ on the East Pacific Rise. (b) Source models based on seismic data from near $19.5^{\circ}$ S. (c) Wide aperture seismic profile from East Pacific Rise near $14^{\circ} \mathrm{S}$ (Detrick et al., 1993) that illustrates rapid thickening of Layer $2 \mathrm{~A}$ and presence of axial magma chamber (AMC). Modified from Gee J and Kent DV (1994) Variations in layer $2 \mathrm{~A}$ thickness and the origin of the centra anomaly magnetic high. Geophysical Research Letters 21: 297-300.

notch in the CAMH in near-bottom profiles over faster-spreading rate ridges (Gee et al., 2000; Perram et al., 1990) (Figure 3).

Evidence has also been sought for longer-term changes in oceanic basalt magnetic properties that could be attributed to the effects of alteration to explain an apparent envelope of decreasing anomaly amplitudes with distance from the ridge axis. Several magnetic anomaly inversion studies have suggested a decrease in magnetization by a factor of $2-3$ within about $10 \mathrm{My}$ of the ridge axis (Sayanagi and Tamaki, 1992; Wittpenn et al., 1989). However, it is difficult to
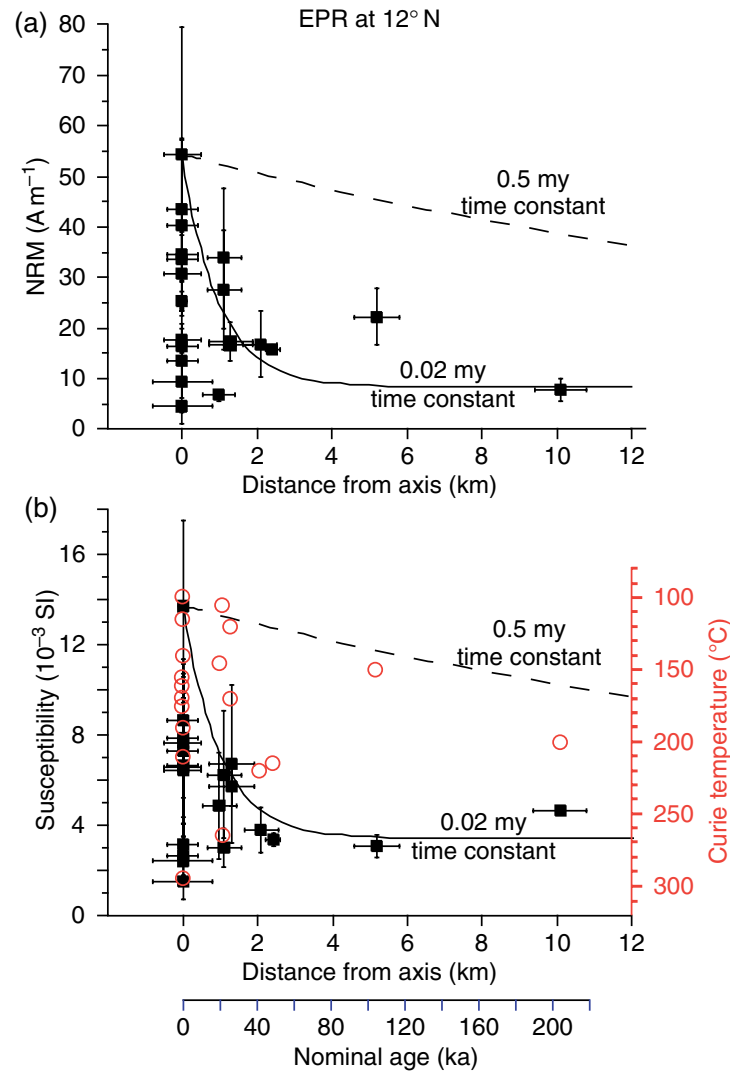

Figure 16 (a) Natural remanent magnetization (NRM), and (b) magnetic susceptibility for samples of dredged oceanic basalts from $12^{\circ} \mathrm{N}$ on the East Pacific Rise as a function of distance from the ridge axis (or nominal age based on full spreading rate of $\left.98 \mathrm{~km} \mathrm{My}^{-1}\right)$. Each data point ( \pm s.d.) is the average of 3-6 specimens collected within $5-8 \mathrm{~cm}$ of the glassy margin. Exponential magnetization decay curves with time constants of $0.5 \mathrm{My}$ and $0.02 \mathrm{My}$ are shown for reference but the large variability in the magnetization data, as well as in the previously unpublished Curie temperature data shown in (b) for these samples do not make a compelling case for any simple decay scheme. Modified from Gee J and Kent DV (1994) Variations in layer 2A thickness and the origin of the central anomaly magnetic high. Geophysical Research Letters 21: 297-300.

evaluate the effects of various potential artifacts associated with data processing (filtering, gridding) and the sequence effect in biasing the results, for example, in producing the apparent substantial (factor of 3-5) increase in magnetization with increasing age beyond $10 \mathrm{Ma}$ and into the KQZ. An influential and more direct analysis in this regard was the compilation of oceanic basalt magnetizations from Deep Sea Drilling Project (DSDP) sites by Bleil and Petersen (1983), who proposed that the data showed an initial sharp decrease in NRM to minimum values at 
around $20 \mathrm{Ma}$ followed by a gradual increase to ages of around $120 \mathrm{Ma}$. Subsequent compilations (Furuta, 1993; Johnson and Pariso, 1993) (Figure 17) show a similar pattern of variation with age although the data quality is highly variable with more than onethird of the sites represented by 10 or fewer samples (e.g., six sites have only one sample!). The overall arithmetic mean NRM intensity for all 64 site means reduced to the equator is $4.4 \mathrm{~A} \mathrm{~m}^{-1}$; high values of around $10 \mathrm{~A} \mathrm{~m}^{-1}$ occur at both very young ages as well as at around $120 \mathrm{Ma}$, whereas values of $1 \mathrm{~A} \mathrm{~m}^{-1}$ or less occur at around $40 \mathrm{Ma}$. There is considerable scatter throughout with only a handful of sites older than $40 \mathrm{Ma}$ penetrating more than $50 \mathrm{~m}$ of basalt or represented by more than a nominal number (20-30) of samples. Because of the typically small number of samples, as well as the lack of control on geochemical variations, within-flow grain size variations, or geomagnetic intensity fluctuations that strongly influence remanent intensity, suggestions of any temporal trends in magnetization intensity of seafloor lavas from such plots should be regarded as tentative.

A more robust estimate of age-dependent changes can be obtained by comparing the distribution of
NRM values for a large collection of near-axis (zero-age) samples from the southern EPR with histograms of NRM values for the best characterized DSDP/ODP drill sites that have the deepest penetration and are represented by about 100 or more samples (Figure 18). The NRM distributions are reasonably approximated by log-normal distributions. The zero-age southern EPR samples have a geometric mean NRM of $18.9 \mathrm{~A} \mathrm{~m}^{-1}$. This is virtually identical to the geometric mean NRM intensity of $18 \mathrm{~A} \mathrm{~m}^{-1}$ for the axial samples from $12^{\circ} \mathrm{N}$ on the EPR, which were mostly taken within about $3 \mathrm{~km}$ of the axis and thus are less than $\sim 50 \mathrm{ky}$ old (Gee and Kent, 1994). Published data from the youngest drill site with significant penetration (DSDP Site 482, which was sited on $\sim 0.4$ Ma crust; Lewis et al., 1983) indicate NRM intensities of about $5 \mathrm{~A} \mathrm{~m}^{-1}$, almost a factor of 4 less than the axial samples. Still older drill sites have geometric mean NRM intensities that range from $2.3 \mathrm{~A} \mathrm{~m}^{-1}$ for Site $395(7.8 \mathrm{Ma})$ to $14.1 \mathrm{~A} \mathrm{~m}^{-1}$ for Site $1256(15.4 \mathrm{Ma})$ although the data at this latter site may be biased to higher NRM values by a particularly strong drilling remanence (Wilson et al., 2003). Nevertheless, there

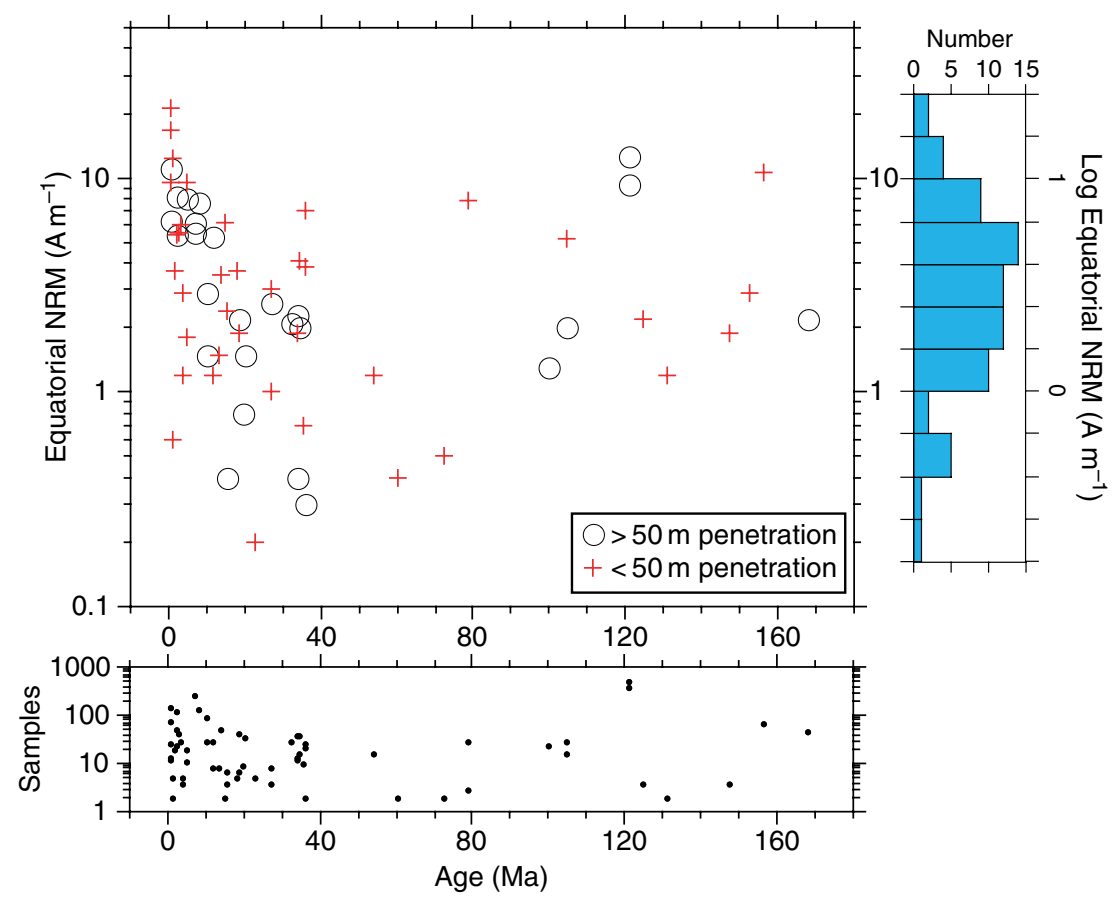

Figure 17 Compilation of equatorial NRM of oceanic basalts recovered from DSDP and ODP drill sites as a function of crustal age and sorted by depth of basement penetration. Lower plot shows number of sample measurements available for calculation of site mean (from references listed in Johnson and Pariso, 1993); histogram at right is for all site mean NRM values. NRM data are from compilation of Johnson and Pariso (1993) with some corrections (e.g., deletion of data for samples from sills). Ages are based on updated anomaly or biostratigraphic assignments and the timescales of Berggren et al. (1995) and Channell et al. (1995). 

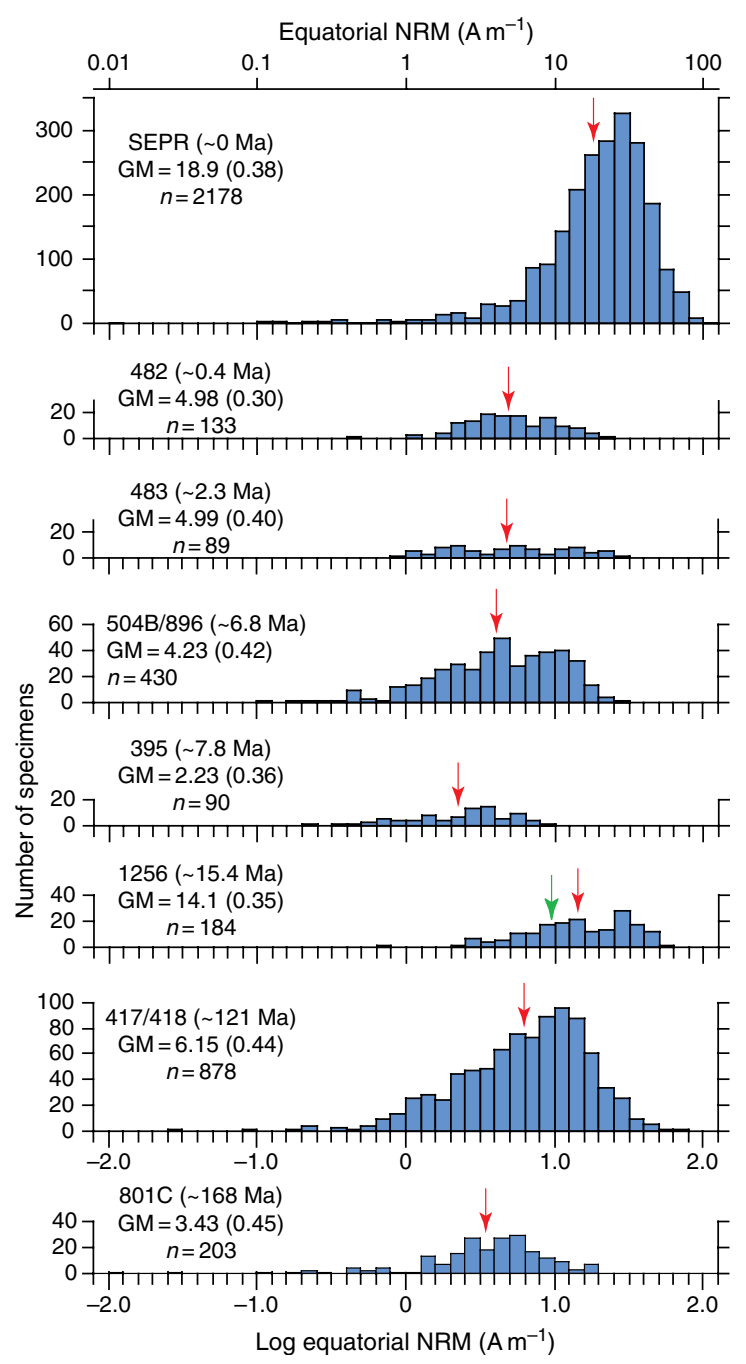

Figure 18 Histograms of equatorial NRM for oceanic basalts for sites with largest datasets, including from the axial zone of the southern EPR versus off-axis drill sites Sites 482, 483, 504B/896, 395, 1256, 417/418, and 801C (see Table 2 for data sources). Geometric mean (GM) is indicated by red arrow for each distribution. The green arrow for Hole 1256D indicates average NRM for samples with initial inclinations $<30^{\circ}$ and $>-30^{\circ}$ that should be least affected by drilling remanence.

does not appear to be an obvious age-dependent trend in the drillsite-mean NRM values since the oldest sites (Site $417 / 418$ at $121 \mathrm{Ma}$ and Hole $801 \mathrm{C}$ at $169 \mathrm{Ma}$ ) have about the same average NRM intensities as some of the youngest drill sites (e.g., Sites 482,483 at $2.3 \mathrm{Ma}$, and Hole $504 \mathrm{~B}$ at $\sim 6.8 \mathrm{Ma}$ ), which are all between about $4-6 \mathrm{~A} \mathrm{~m}^{-1}$. What does seem significant is the factor of almost 4 decrease in mean NRM intensity from the axial zone to older sites; if the entire reduction is ascribed to alteration, the time constant must be considerably shorter than about 0.4 My, the age of the youngest off-axis site (Site 482) with reduced magnetization. A similar pattern of magnetization change was observed in the FAMOUS area $\left(37^{\circ} \mathrm{N}\right.$ on the slow-spreading Mid-Atlantic Ridge) based on the magnetization of topography derived from near-bottom observations (Macdonald, 1977).

Direct observations of the degree of lowtemperature alteration suggest that the fourfold difference in intensity of axial lavas and older drill sites cannot be attributed solely to maghemitization. The oxidation parameter $(0<z<1$, where 1 indicates complete oxidation to titanomaghemite; O'Reilly, 1984) has now been estimated from lattice spacing and composition using transmission and analytical electron microscopy on small titanomagnetite grains in fine-grained oceanic basalts over a broad age range (Wang et al., 2005; Wang et al., 2006; Zhou et al., 2001). The development and application of microanalytical techniques (Zhou et al., 1999a) represent a major advance in the study of oceanic basalts because they allow more direct characterization of the important fine-grained magnetic carriers that previously had to be inferred from larger magnetic grains or bulk properties. Although there is considerable scatter (Figure 19), the oxidation parameter data are consistent with an initial, very rapid increase in alteration such that $z$ values up to 0.8 occur in basalts less than $1 \mathrm{My}$ old, as suggested by Bleil and Petersen (1983). Much less convincing is any systematic long-term trend because although values of $\mathrm{z}$ greater than 0.8 do tend to occur in samples older than about $30 \mathrm{Ma}$, the oldest sample measured (Hole $801 \mathrm{C}, 169 \mathrm{Ma}$ ) has a $z$ value of only $\sim 0.2$. Thus, while low-temperature alteration evidently can occur rapidly, the extrusive layer is not uniformly oxidized even for the oldest seafloor.

Since complete oxidation would be required to account for a factor of 4 reduction in saturation magnetization (O'Reilly, 1984), some additional parameter is apparently required to explain the factor of 4 difference in magnetization of axial lavas and older drilled basalts. Paleofield changes might explain the difference if the present field is unusually high and it is worth noting that magnetization variations over long timescales have been attributed by some authors to paleofield variations (e.g., Wang et al., 2005; Juarez et al., 1998). Even the traditional model of alteration-related variations in saturation magnetization (Ms) is still 

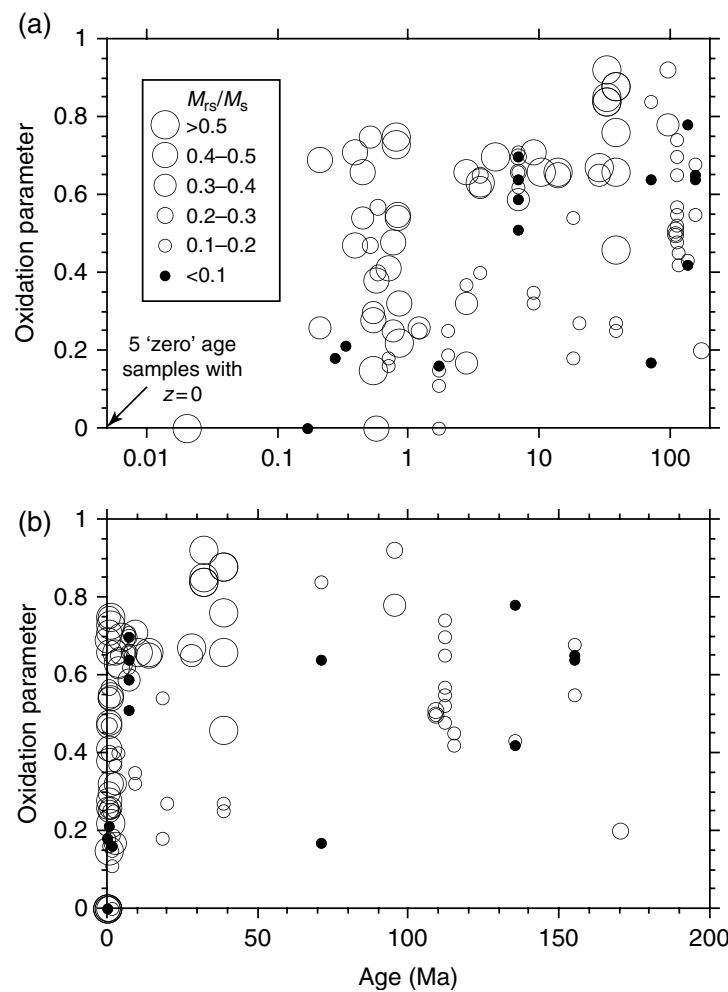

Figure 19 Variation in oxidation parameter (and hysteresis ratio, $M_{\mathrm{rs}} / M_{\mathrm{s}}$ ) of oceanic basalts samples as a function of crustal age (log scale in (a) and linear scale in (b)). Data are from Wang et al. $(2005,2006)$ and Zhou et al. (2001). The plot shows no obvious evidence of any systematic evolution of magnetic properties that could be ascribed to lowtemperature alteration, for example, the basalt samples from Site $801 \mathrm{C}$, which are the oldest at $169 \mathrm{Ma}$, have an oxidation parameter value of only 0.2 .

possible, for example, Matzka et al. (2003) argue that the low NRM values for $10-40$ Ma samples are primarily due to the reduction in saturation magnetization accompanying maghemitization, similar to the model of Bleil and Petersen (1983). Some other alternative explanations are described below.

Xu et al. (1997c) have suggested a model of preferential dissolution with time of the finest-grained titanomagnetites as the major process contributing to long-term temporal changes in remanent intensity of mid-ocean ridge basalts. If widespread, such dissolution could enhance the effect of the reduction in saturation magnetization accompanying low-temperature oxidation. However, the data in Figure 19 show no obvious coarsening in magnetic grain size with age or alteration, for example, some of the highest $M_{\mathrm{rs}} / M_{\mathrm{s}}$ values (i.e., high ratios of saturation remanence to saturation magnetization indicate the finest magnetic grain sizes) are associated with the highest $z$ values (greatest low-temperature oxidation) in $\sim 30$-My-old samples. Instead, the results in Figure 19 are consistent with the more voluminous hysteresis data shown in Figure 20 that illustrate that substantial intra-sample variability in oceanic basalts precludes recognition of any systematic trend in magnetic grain size with age from DSDP/ODP drill sites (Gee and Kent, 1999).

Directional changes associated with low-temperature alteration might also contribute to reduction in seafloor basalt magnetization with time if a CRM is acquired in a direction that opposes the initial thermoremanence. Several early studies (e.g. Ryall and Ade-Hall, 1975; Marshall and Cox, 1972) concluded that the remanence direction was unaffected by lowtemperature alteration since the oxidized titanomaghemite would inherit the original TRM direction. These results are not conclusive, however, since these studies were conducted on young Brunhes-age samples where no large directional difference would be expected. More extensive studies on altered lavas from a range of ages (Beske-Diehl, 1990) were also interpreted as reflecting no alteration-related directional changes since the observed directional shifts could also be attributed to viscous remanence acquisition. Although the low Curie point of TM60 makes direct experimental investigation of seafloor oxidation difficult, Kelso et al. (1991) found that CRM in synthetic TM40 grains was acquired parallel to the applied field direction, with secondary magnetizations particularly enhanced at lower $\mathrm{pH}$ values. If broadly applicable, such field-parallel CRM acquisition coupled with the pattern of geomagnetic polarity reversals could provide a mechanism for long-term variations in NRM intensity as suggested by Raymond and Labrecque (1987).

In addition, low-temperature oxidation has been suggested as a possible mechanism by which partial self-reversal might occur, leading to the acquisition of an antipodal overprint that could significantly reduce the NRM intensity (Doubrovine and Tarduno, 2004). These authors found that the majority of thermally demagnetized samples from Detroit Seamount had two nearly antipodal remanence components. Some samples showed a maximum in the $\mathrm{Ms}(\mathrm{T})$ curves above room temperature that might be indicative of N-type ferromagnetic behavior and partial self-reversal (Doubrovine and Tarduno, 2004). A similar peak in $\mathrm{Ms}(\mathrm{T})$ and importantly a corresponding reversible peak in NRM above room temperature were reported for 10-40 Ma oceanic basalts (Matzka 


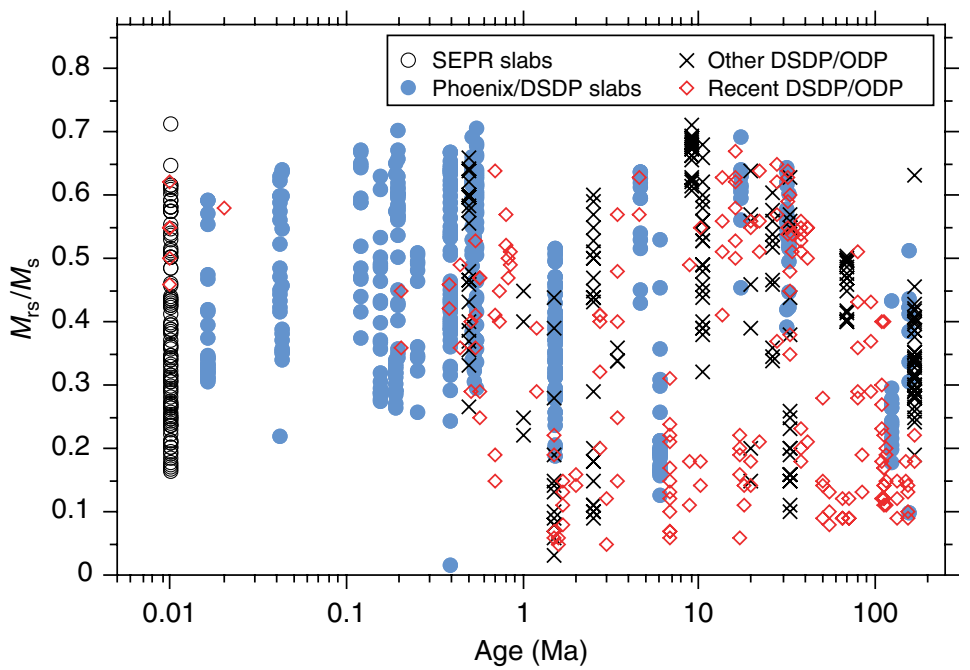

Figure 20 Variation of $M_{\mathrm{rs}} / M_{\mathrm{s}}$ with age in oceanic basalt samples. Data acquired from systematic sampling relative to the chilled flow margin (labeled slabs) include samples from the southern East Pacific Rise (SEPR), Phoenix dredge collection, and DSDP sites (see Gee and Kent, 1999 and references therein). Other DSDP/ODP designates additional hysteresis data from isolated samples used in this same compilation. More recent hysteresis data (Recent DSDP/ODP) includes data from Wang et al. (2005, 2006) and Zhou et al. (2001).

et al., 2003). Krasa et al. (2005) provided compelling documentation for partial self-reversal associated with titanomaghemite in subaerial lavas, although they argue that the 'low-temperature' oxidation occurred at temperatures above the blocking temperatures of the original titanomagnetite phase during initial cooling. Thus, while such partial selfreversals may occur, the importance of this process in generating long-term changes in seafloor magnetization remains to be demonstrated.

A common motivation for seeking evidence of a time-dependent change in the magnetization of oceanic basalts is the widespread perception of a decreasing amplitude envelope for ridge crest anomalies. This concept stems largely from longstanding observations that the Central Anomaly in the slow-spreading Atlantic and Indian Oceans tends to be anomalously high (e.g., Vine, 1966). For example, Bleil and Petersen (1983) show a magnetic profile across the North Atlantic as evidence of this phenomenon, which had also been described to occur over some sectors of the Australia-Antarctic Ridge by Weissel and Hayes (1972). However, the Central Anomaly is not such a pronounced feature in magnetic profiles from the faster-spreading sectors of the East Pacific, which are also typically described as showing only a gradual decrease in amplitude on the ridge flanks (e.g., Pitman and Heirtzler, 1966; Pitman et al., 1968). Indeed, the prominence of the
Central Anomaly (and the associated amplitude envelope) appears to be closely tied to spreading rate (Figure 21; Cande and Gee, 2001).

The fact that neither a prominent Central Anomaly nor a pronounced anomaly envelope are present on all ridge systems places limits on systematic timedependent processes that are expected to affect the magnetization of all oceanic basalts, such as long-term changes in paleointensity and alteration. Suggested time constants of magnetic alteration, assuming an exponential decay, have ranged over several orders of magnitude, from $\sim 0.05 \mathrm{My}$ (Gee and Kent, 1994) to $\sim 0.5 \mathrm{My}$ (Johnson and Atwater, 1977; Macdonald, 1977 ), and to $\sim 5 \mathrm{My}$ or longer (Bleil and Petersen, 1983; Raymond and LaBrecque, 1987; Xu et al., 1997b; Zhou et al., 2001). We use these order of magnitude increments in the estimated time constants to model the expected effects on magnetic anomalies in Figure 22. For fast-spreading ridges (Figure 22(a)), models using a factor of 4 decay in magnetization, corresponding to the nominal decrease in NRM from the ridge axis to off-axis drill sites (Figure 18), are virtually precluded over the various timescales. These models produce either a very prominent axial high at a short $(0.05 \mathrm{My})$ decay constant or an obvious amplitude envelope at a long (5 My) decay constant, but neither of these features is compatible with the representative Pacific-Antarctic Ridge profile shown in Figure 21. This comparison suggests that the effective 

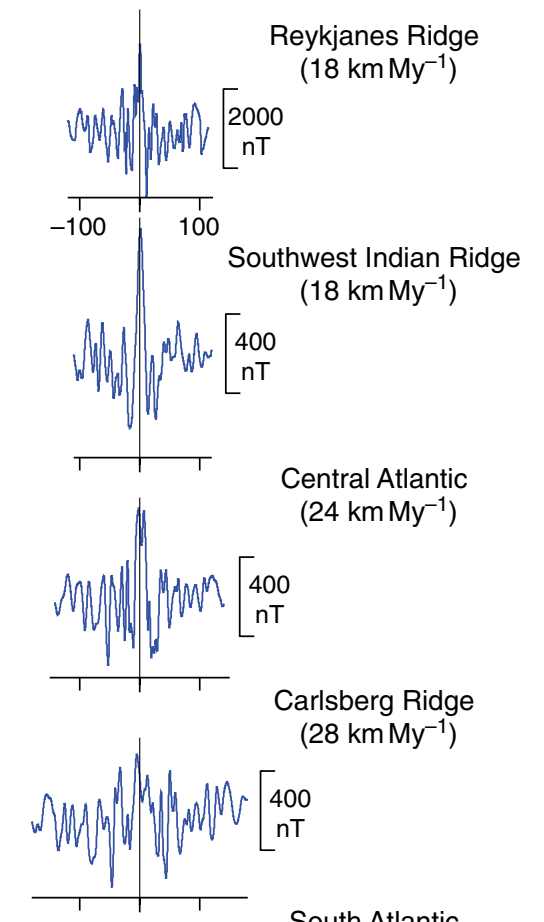

$\left(28 \mathrm{~km} \mathrm{My}^{-1}\right)$

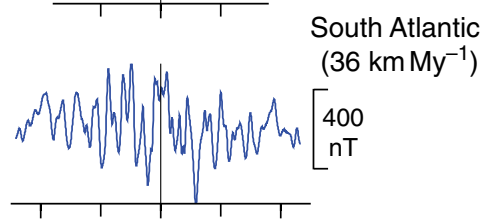

Southeast Indian Ridge
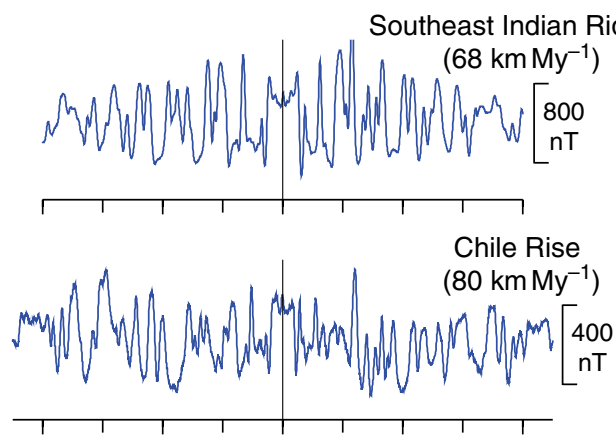

Pacific-Antarctic Ridge $\left(82 \mathrm{~km} \mathrm{My}^{-1}\right)$

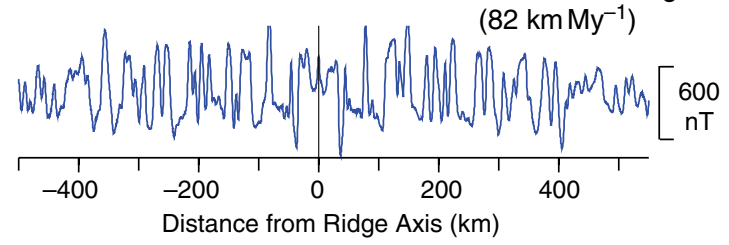

Figure 21 Representative sea-surface anomaly profiles illustrating the spreading rate dependence of the amplitude of the Central Anomaly. All profiles extend approximately to Anomaly 5 and have been reduced to the pole. The Central Anomaly has notably higher amplitude only at full spreading rates less than $\sim 30 \mathrm{~km} \mathrm{My}^{-1}$. magnetization reduction from alteration is likely much smaller than a factor of 4 , perhaps reflecting the heterogeneous nature of low-temperature oxidation in the crust. Indeed, models using a $2 \mathrm{x}$ factor of decay in magnetization at a variety of decay constants for fastspreading ridges (Figure 22(a)) cannot be excluded as resembling the observed Pacific-Antarctic Ridge profile. Models for different decay factors and time constants for a slow-spreading ridge (Figure 22(b)), on the other hand, seem to favor a larger decay (e.g., compare $4 \mathrm{x}$ models to observed Central Atlantic or Southwest Indian Ridge profiles in Figure 21).

The independent evidence for rapid changes in oxidation parameter (Figure 19) favors a fast decay time constant, although the entire observed decrease in NRM intensity may not be entirely due to alteration. For example, the NRM of the near-axis samples may be biased by high paleointensities over the past few thousand years that were up to a factor of 2 higher than today's field and perhaps a factor of 4 higher than the average long-term paleofield intensity (Selkin and Tauxe, 2000). Absolute paleointensity data, which show a $3 \mathrm{x}$ change near the ridge axis (Bowles et al., 2006; Gee et al., 2000), are a powerful indication that a large part of that near-ridge signal is field-related. A factor of 2 decrease in NRM intensity due to alteration might be a reasonable estimate for oceanic basalts, with a possibly larger contrast in the slow-spreading ridges due to more intense near-axis tectonics, for example.

\subsubsection{Magnetization of Dikes}

One of the most significant changes in our understanding of the magnetization of oceanic crust since the review by Smith (1990) has been in the role of dikes, which some earlier compilations based on ophiolites and dredge metabasalt samples from fracture zones suggested were characterized by weak, rather unstable remanences (e.g., Kent et al., 1978). The penetration, albeit with limited recovery, of $\sim 1000 \mathrm{~m}$ section of dike rocks at Site 504B (Figure 23) has allowed the documentation of the physical and magnetic properties of this important constituent of oceanic crust in a more typical setting. An $\sim 100$ m-thick transition between pillow lavas and dikes (at $\sim 1000 \mathrm{mbsf}$ ) does have weak magnetizations, $0.1 \mathrm{~A} \mathrm{~m}^{-1}$ and less, although they have very high coercivities. Deeper levels in the sheeted dike complex have moderate NRM $\left(\sim 2 \mathrm{~A} \mathrm{~m}^{-1}\right)$ and moderate median demagnetizing fields. Moreover, analysis of logging data suggests that, due to void 
(a)

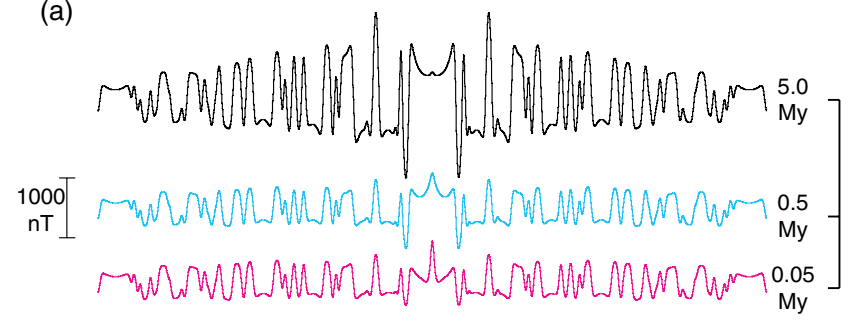

(b)

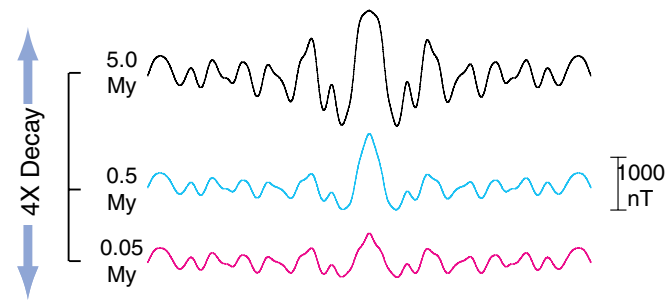

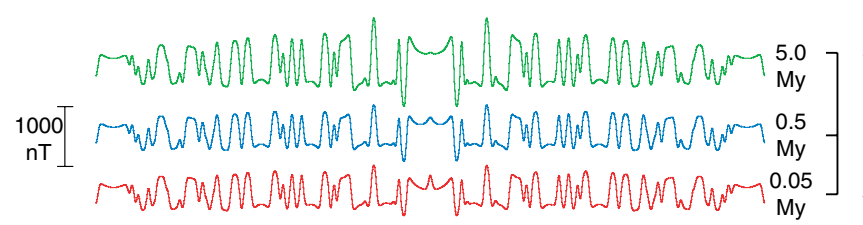
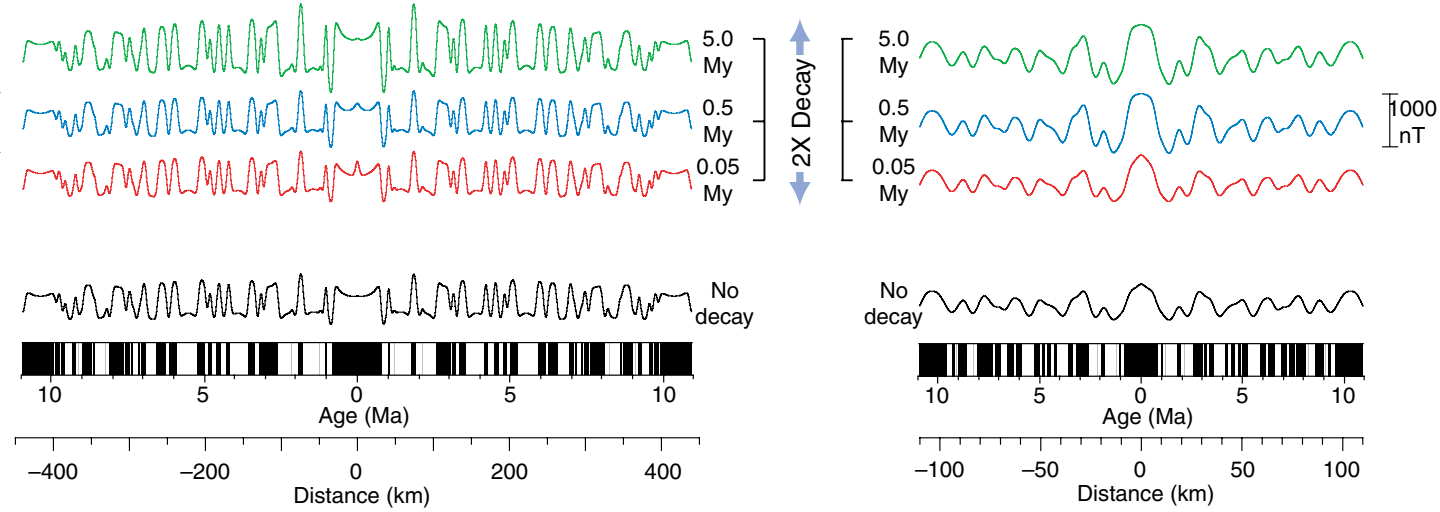

Figure 22 Magnetic anomaly models illustrating the effect of alteration-related exponential decay in magnetization for (a) intermediate-spreading crust (full rate of $80 \mathrm{~km} \mathrm{My}^{-1}$ ) and (b) slow-spreading crust (full rate of $20 \mathrm{~km} \mathrm{My}^{-1}$ ). For each spreading rate, anomaly profiles are shown for a fourfold decrease in magnetization $\left(20 \mathrm{~A} \mathrm{~m}^{-1}\right.$ to $\left.5 \mathrm{Am}^{-1}\right)$ and a twofold decrease in magnetization $\left(10 \mathrm{~A} \mathrm{~m}^{-1}\right.$ to $5 \mathrm{~A} \mathrm{~m}^{-1}$ ) for a range of decay time constants. The magnetization model (block diagram) and model with constant remanence intensity are shown for comparison. In all models, the anomaly is calculated for a $1 \mathrm{~km}$ thick source layer, with the depth to the upper surface that increases with age ${ }^{0.5}$ (Ma) (Stein and Stein, 1994). A gaussian filter has been applied to the magnetization $(\sigma=0.5 \mathrm{~km}$ and $\sigma=1.0 \mathrm{~km}$ for the intermediate- and slow-spreading ridges, respectively) to simulate the transition zone width in the extrusive layer.

spaces, the effective NRM of the lavas from Hole 504B may be only $3 \mathrm{~A} \mathrm{~m}^{-1}$ rather than the $5 \mathrm{~A} \mathrm{~m}^{-1}$ based on sample measurements (Worm et al., 1996), which would further reduce the magnetization contrast with the dike complex.

Dike samples obtained by both dredges and submersible sampling also highlight the importance of dikes to crustal magnetization. Submersible sampling of $\sim 1.2$ my-old fast-spread crust exposed at Hess Deep provides a direct comparison of magnetic properties of extrusives, dikes, and gabbros (Figure 24). Here, lavas and dikes have comparable NRM values $\left(\sim 4 \mathrm{~A} \mathrm{~m}^{-1}\right)$. Dredged dike samples from $\sim 2$ my crust exposed along the Blanco Fracture Zone also have moderately strong magnetizations $\left(\sim 1.7 \mathrm{~A} \mathrm{~m}^{-1}\right.$ when reduced to equatorial value; Johnson and Salem, 1994), although this is substantially less than the magnetization of extrusives $\left(\sim 6.4 \mathrm{~A} \mathrm{~m}^{-1}\right)$ inferred from near-bottom magnetic anomaly surveys in this area (Tivey, 1996; Tivey et al., 1998a). Although samples of the dike complex are still limited, it appears that they may have a remanence that is significant relative to that of the extrusive layer.

A major difference from the pillows, however, is the magnetic mineralogy, which in pillows is variably maghemitized titanomagnetite (Curie temperatures typically $200-400^{\circ} \mathrm{C}$ ) whereas in the dikes it is dominated by nearly pure magnetite (Curie temperatures $>550^{\circ} \mathrm{C}$; Figures 23 and 24 ). The origin of the magnetite is critical to assessing role of dikes as a source of seafloor spreading magnetic anomalies. If magnetite is primarily produced by alteration at temperatures below the Curie point, as some have suggested, then the remanence may be largely chemical in origin and may be acquired significantly later than that of the extrusive layer (e.g., Hall and Muzzatti, 1999). Based on a transmission electron microscopy study of dike samples from Hole 504B, Shau et al. (2000) documented multiple pathways for formation of magnetite (Figure 25). Initial oxyexsolution, at temperatures $>600^{\circ} \mathrm{C}$, would have produced only slightly $\mathrm{Ti}$-depleted titanomagnetite, with a Curie temperature too low to acquire a 


\section{Author's personal copy}

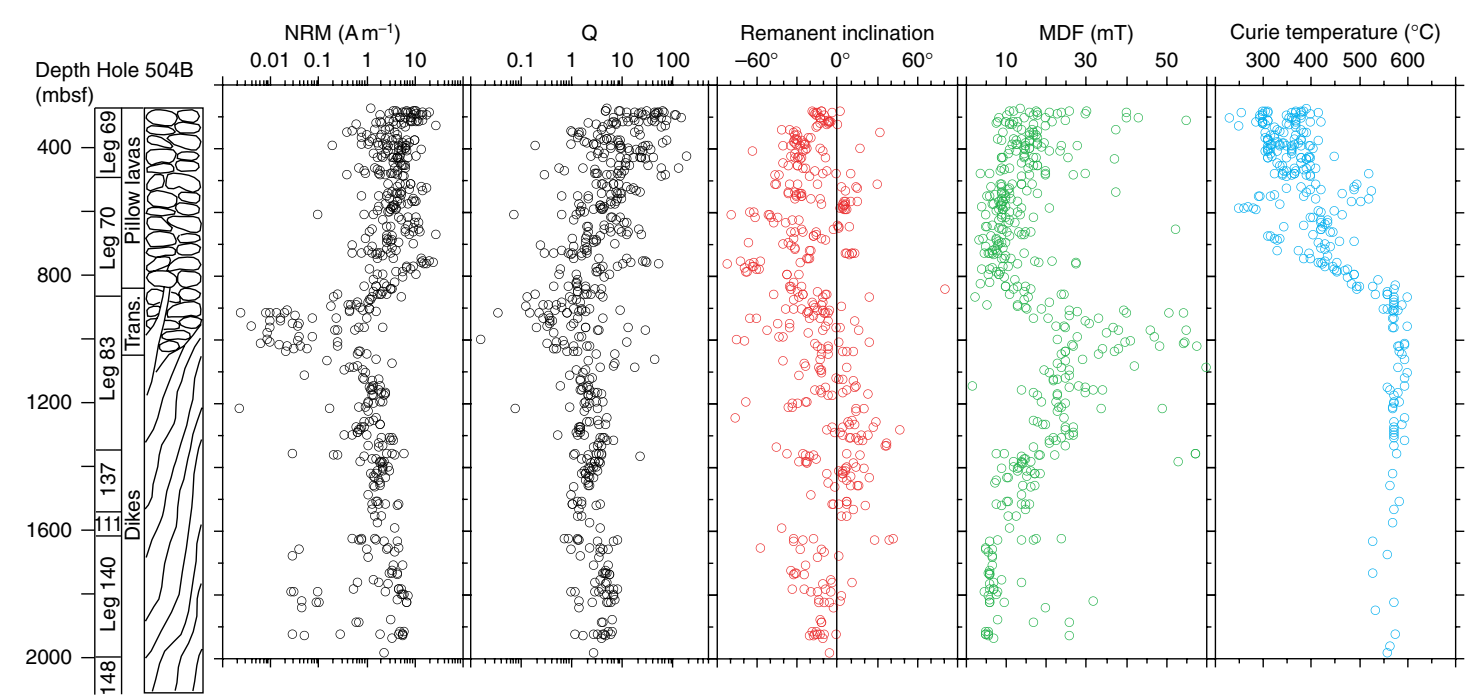

Figure 23 Depth variation in magnetic properties (NRM, Q calculated for $40 \mathrm{~A} \mathrm{~m}^{-1}$ field, stable remanent inclination, median demagnetization field (MDT), and Curie temperature) of samples of Miocene ( 6.8 Ma) oceanic basement at Site 504B on the Galapagos spreading center. Schematic lithology and penetration during seven drilling legs shown at left. Data compiled from Facey et al. (1985); Furuta (1983); Furuta and Levi (1983); Kinoshita et al. (1985); Pariso and Johnson (1989); Pariso et al. (1995); Pechersky et al. (1983a); Smith and Banerjee $(1985,1986)$.
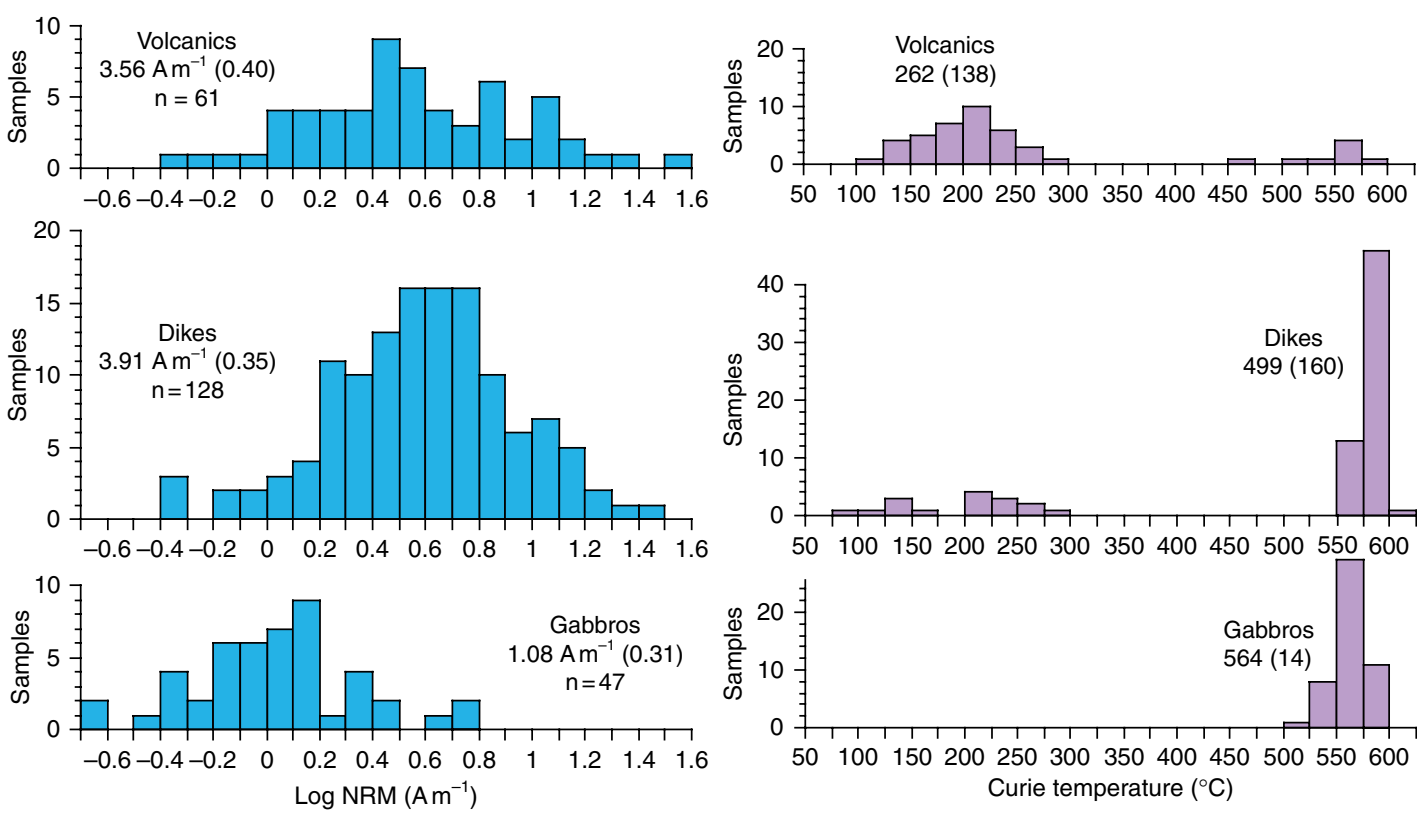

Figure 24 Histograms of NRM intensities (left) and Curie temperatures (right) for dive samples of volcanics, dikes and gabbros from 1.2 Ma fast-spread oceanic crust at Hess Deep (data from Gee et al., 1992; Varga et al., 2004). Note that the mean NRM intensity for dikes is higher than reported at Hole 504B and is more similar to the volcanics, suggesting that the dikes are an important source of magnetic anomalies at least in the Hess Deep area.

remanence at these elevated temperatures. Further oxidation or true exsolution and reduction, likely at temperatures of $\sim 500-400^{\circ} \mathrm{C}$, then produces the fine Ti-poor magnetite that acquires a thermal and/or chemical remanence (Shau et al., 2000). While the remanence in dikes maybe, at least in part, chemical in origin, the temperatures at which the alteration occurs imply that remanence would be acquired very 


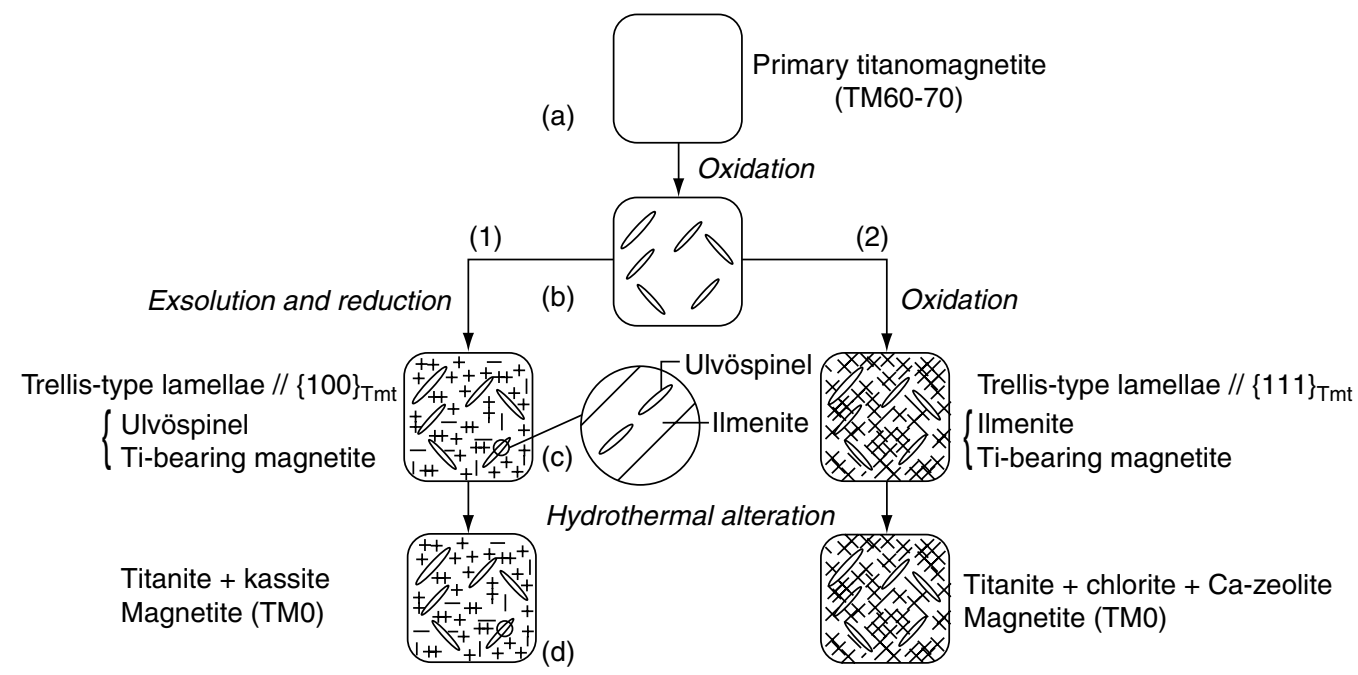

Figure 25 Alteration pathways for primary titanomagnetite in sheeted dikes. From Shau et al., 2000. Either oxyexsolution or true exsolution and reduction may produce fine-grained magnetite $(x \sim 0)$ that is distinct from primary titanomagnetite in the extrusives.

near the ridge axis. This result is confirmed by the consistent (reverse) polarity in the lavas and dikes inferred from magnetic logging data at Hole 504B (Worm and Bach, 1996).

\subsubsection{Magnetization of Gabbros}

Early estimates of the gabbroic contribution to marine magnetic anomalies relied on dredged samples and studies of ophiolites, with the results from ophiolites yielding variable and sometimes contradictory results (Banerjee, 1980). For example, Swift and Johnson (1984) concluded from the low remanent intensities and Königsberger ratios (the ratio of remanent to induced magnetization) of unaltered gabbros from the Bay of Islands ophiolite that only the altered intrusive portion of the crust (characterized by higher magnetization values) would contribute to magnetic anomalies. In contrast, results from dredges and other ophiolites (Kent et al., 1978; Vine and Moores, 1972) indicated that gabbros had significant magnetization $\left(\sim 1 \mathrm{~A} \mathrm{~m}^{-1}\right)$ and high Königsberger ratios and likely would contribute to magnetic anomalies.

At the time of the last review of ocean crustal magnetization (Smith, 1990), relatively little direct information was available on the magnetic properties of oceanic gabbros. Initial results from the first significant drillcore penetration of gabbros $(500 \mathrm{~m}$ at Hole 735B; Robinson et al., 1989) indicated highly variable NRM intensities, with some FeTi oxide gabbros having extremely high values. With only a single drillcore, however, it was difficult to evaluate whether these magnetic (and petrologic) results were generally applicable. In the intervening time, lower crustal gabbros have been sampled by drilling at three portions of the slow-spreading Mid-Atlantic Ridge (Mid-Atlantic Ridge near the Kane Fracture Zone or MARK area at $23^{\circ} \mathrm{N}$ (Cannat et al., 1995), near the $15^{\circ} 20^{\prime}$ Fracture Zone (Kelemen et al., 2004), Atlantis Massif (Blackman et al., 2006)), at fast-spreading crust at Hess Deep (Gillis et al., 1993), and Hole 735B has been deepened by an additional kilometer (Dick et al., 1999) and supplemented by additional drilling on the Atlantis Bank (Allerton and Tivey, 2001; Pettigrew et al., 1999). Although these sites all made use of tectonic exposures, recent drilling in the Guatemala Basin (Wilson et al., 2006) penetrated lavas, dikes, and a small amount of gabbro; continued drilling at this site could provide the first in situ gabbroic section from the ocean crust.

These various drill sites into lower crustal gabbros provide a remarkably consistent average magnetization of $\sim 1-2 \mathrm{~A} \mathrm{~m}^{-1}$ (Table 2), suggesting that these rocks should constitute an important magnetization source for magnetic anomalies. Although average magnetic properties are similar, gabbroic sections (particularly at slow-spreading ridges) exhibit substantial variability both in lithology and magnetic properties as exemplified by results from Hole 735B (Figure 26). $\mathrm{FeTi}$ oxide gabbros with $>2 \%$ (and occasionally $>10 \%$ ) oxide minerals constitute a significant fraction of the core from Hole 735B. Magnetic susceptibility 
Table 2 Equatorial natural remanent magnetization values for oceanic crustal rocks

\begin{tabular}{|c|c|c|c|c|c|c|c|c|}
\hline Site & Sample type & $\begin{array}{l}\text { Age } \\
(\mathrm{Ma})\end{array}$ & $\mathbf{n}$ & $\begin{array}{l}\text { A.M. } \\
\left(\mathbf{A ~ m}^{-1}\right)\end{array}$ & $\begin{array}{l}\text { std. } \\
\left(\mathbf{A ~ m}^{-1}\right)\end{array}$ & $\begin{array}{l}\text { G.M. } \\
\left(\mathbf{A} \mathbf{m}^{-1}\right)\end{array}$ & $\begin{array}{l}\text { std } \\
(\log )\end{array}$ & Ref. \\
\hline \multicolumn{9}{|l|}{ Lavas } \\
\hline EPR & Dredge & 0 & 2178 & 24.68 & 15.54 & 18.94 & 0.38 & 1 \\
\hline Hess Deep & Dive & 1.2 & $61^{a}$ & 5.37 & 5.70 & 3.56 & 0.40 & 2,3 \\
\hline Site 482 & Drill & 0.4 & 133 & 6.20 & 4.19 & 4.98 & 0.30 & 4,5 \\
\hline Site 483 & Drill & 2.3 & 89 & 7.42 & 6.49 & 4.99 & 0.40 & 4,5 \\
\hline Hole 504B/896 ${ }^{b}$ & Drill & 6.8 & 430 & 6.15 & 4.95 & 4.23 & 0.42 & $6-12$ \\
\hline Site $395^{c}$ & Drill & 7.8 & 90 & 2.95 & 2.01 & 2.23 & 0.35 & 15 \\
\hline Site $1256^{d}$ & Drill & 15.4 & 184 & 18.36 & 12.22 & 14.06 & 0.35 & 16 \\
\hline Sites $417 / 418$ & Drill & 121 & 878 & 9.22 & 8.03 & 6.15 & 0.44 & 17 \\
\hline Hole $801 C^{e}$ & Drill & 168 & 203 & 4.92 & 3.89 & 3.43 & 0.45 & 18,19 \\
\hline Deep Drillholes & Drill & - & 7 & 7.89 & 5.01 & 4.92 & 0.25 & \\
\hline \multicolumn{9}{|l|}{ Dikes } \\
\hline Hess Deep & Dive & 1.2 & $128^{a}$ & 5.27 & 4.50 & 3.91 & 0.35 & 2,3 \\
\hline Hole $504 B^{f}$ & Drill & 6.8 & 171 & 2.11 & 1.67 & 1.32 & 0.53 & $9-14$ \\
\hline All & - & - & 2 & 3.69 & 2.23 & 2.27 & 0.33 & \\
\hline \multicolumn{9}{|l|}{ Gabbros } \\
\hline Hess Deep & Dive & 1.2 & $47^{a}$ & 1.40 & 1.17 & 1.08 & 0.31 & 2,3 \\
\hline Hole 735B & Drill & 12 & 600 & 3.34 & 8.42 & 1.19 & 0.57 & 20,21 \\
\hline $\operatorname{Leg} 209^{g}$ & Drill & $0.5-2.0$ & 61 & 6.15 & 6.23 & 2.36 & 0.78 & 22 \\
\hline Leg $153^{h}$ & Drill & $\sim 1$ & 252 & 1.19 & 1.74 & 0.62 & 0.53 & 23,24 \\
\hline Hole $894 \mathrm{G}^{i}$ & Drill & $\sim 1$ & 87 & 2.25 & 1.56 & 1.65 & 0.41 & 25 \\
\hline Exp. 304/305 & Drill & $\sim 1$ & 472 & 3.11 & 6.28 & 0.56 & 0.97 & 26 \\
\hline All Drillholes & Drill & - & 5 & 2.91 & 1.81 & 1.09 & 0.24 & \\
\hline \multicolumn{9}{|l|}{ Peridotites } \\
\hline Oufi compilation $^{k}$ & Drill & - & 234 & 5.84 & 5.05 & 3.15 & 0.62 & 27 \\
\hline $\operatorname{Leg} 209^{\prime}$ & Drill & $0.5-2.0$ & 99 & 2.75 & 3.57 & 0.79 & 0.99 & 22 \\
\hline All & Drill & - & 333 & 4.92 & 4.86 & 2.09 & 0.79 & \\
\hline
\end{tabular}

${ }^{a}$ Each sample value based on three or more specimens.

${ }^{b}$ Average based on Hole 504B lava samples above 898 mbsf (corresponding to low-temperature altered zone of Pariso and Johnson, 1991) and all lava samples from Site 896.

${ }^{c}$ Excludes gabbro and peridotites recovered at this site.

${ }^{d}$ Average based on shipboard data from 252-749 mbsf. Wilson et al. (2003) note particularly large drilling induced remanence.

${ }^{e}$ Average based on samples from 551-933 mbsf (excluding younger alkalic lavas and hydrothermal deposits).

${ }^{f}$ Average based on samples deeper than 1055 mbsf (dike/lava transition zone [878-1055 mbsf] excluded).

${ }^{9}$ Average based on all gabbroic samples from Sites 1268-1275 (near 152 $20^{\prime}$ N Fracture Zone).

${ }^{h}$ Average based on all gabbroic samples from Sites 921-924 (MARK Area).

'Minor recovery of gabbroic material in other drillsites at Hess Deep not included.

Includes gabbroic samples from Holes 1309B and 1309D (excluding diabase and ultramafic samples).

${ }^{k}$ Compilation of peridotite samples from DSDP/ODP drilling up to and including Leg 153.

'Average based on all peridotite samples from Sites 1268-1274 (near $15^{\circ} 20^{\prime} \mathrm{N}$ Fracture Zone).

A.M., arithmetic mean; G.M., geometric mean.

References: 1, Gee and Kent (1997); 2, Varga et al. (2004); 3, Gee et al. (1992); 4, Day et al. (1983); 5, Pechersky et al. (1983b); 6, Allerton et al. (1996); 7, Furuta and Levi (1983); 8, Pechersky et al. (1983a); 9, Kinoshita et al. (1985); 10, Facey et al. (1985); 11, Smith and Banerjee (1985); 12, Smith and Banerjee (1986); 13, Pariso and Johnson (1989); 14, Pariso et al. (1995); 15, Johnson (1978); 16, JANUS database for ODP Leg 206 (Wilson et al., 2003); 17, Levi (1980); 18, JANUS database for ODP Legs 129 (Lancelot et al., 1990) and 185 (Plank et al., 2000); 19, Wallick and Steiner (1992); 20, Kikawa and Pariso (1991); 21, Dick et al. (1999); 22, Kelemen et al. (2004); 23, Gee et al. (1997); 24, Cannat et al. (1995); 25, Pariso et al. (1996a); 26, Blackman et al. (2006); 27, Oufi et al. (2002).

data indicate the presence of several hundred oxide-rich zones, ranging from centimeter to several meters in thickness, throughout the core (Natland, 2002). These oxide-rich intervals may be associated with extremely high NRM values (in some cases $>10^{3} \mathrm{~A} \mathrm{~m}^{-1}$; Robinson et al., 1989) though these high values likely reflect a substantial drilling induced overprint and thus are not representative of the in situ magnetization. Borehole magnetic data from the upper $500 \mathrm{~m}$ of Hole $735 \mathrm{~B}$ indicate an in situ equatorial remanence of $4.4 \mathrm{~A} \mathrm{~m}^{-1}$ for oxide-rich gabbros and $1.8 \mathrm{~A} \mathrm{~m}^{-1}$ for other gabbroic rocks (Pariso and Johnson, 1993a). Although NRM 


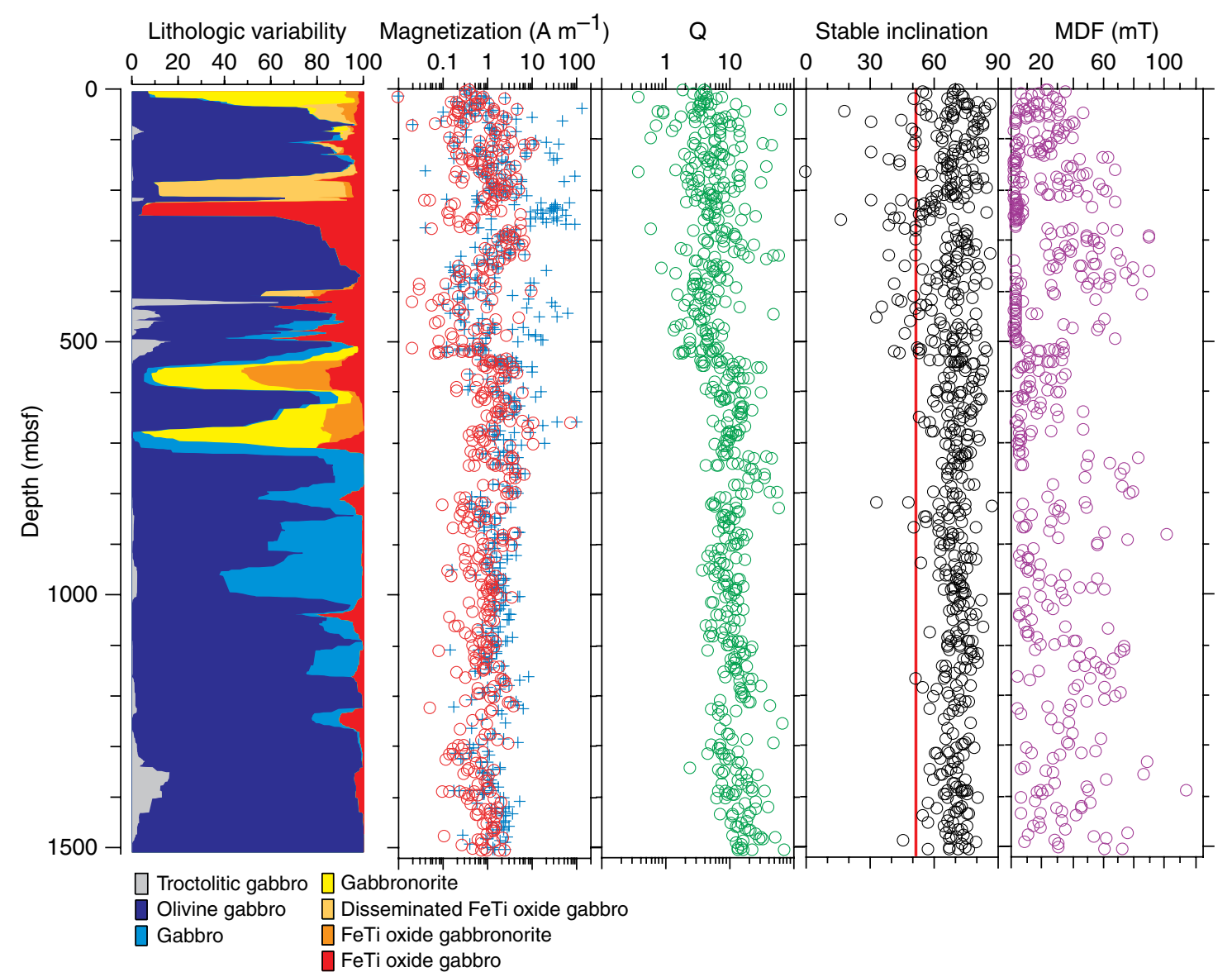

Figure 26 Depth variation in lithology and magnetic properties (NRM, Q calculated for $30 \mathrm{Am}^{-1}$ field, stable remanent inclination and MDF, median demagnetization field) for samples of gabbroic section in oceanic crust at ODP Hole $735 \mathrm{~B}$. Magnetic data compiled from Kikawa and Pariso (1991) and Dick et al. (1999); lithology column from Dick et al. (2000). Heavy line in inclination plot is expected dipole value. Magnetization data have not been reduced to equatorial values (open circles and + symbols represent the intensity after removal of the drilling-induced remanence and NRM, respectively).

intensities show significant variability, results from both drillcore and submersible samples (Table 2) suggest that an average intensity of $\sim 1 \mathrm{~A} \mathrm{~m}^{-1}$ is typical for oceanic gabbroic rocks.

Although less compelling than for lavas, there appears to be a weak correlation between more fractionated (Fe-rich) gabbros and higher NRM intensities (Gee et al., 1997; Kikawa and Ozawa, 1992). For a subset of gabbroic rocks from the MARK area, Hess Deep, and Hole 735B (Figure 27(a)), the lowest NRM values are exclusively associated with the least evolved gabbros (with high $\mathrm{Mg} \#=\mathrm{Mg}^{2+} /\left(\mathrm{Fe}^{2+}+\mathrm{Mg}^{2+}\right)$ ). Kikawa and Ozawa (1992) have noted a comparable broad increase in remanent intensity from Hole 735B samples as fractionation proceeds from troctolite to olivine gabbro. These same authors have suggested that gabbro magnetization values also may be reduced by up to an order of magnitude as a result of alteration (as measured by the percentage of secondary mafic minerals). This trend is less obvious in a more qualitative comparison of NRM and shipboard estimates of alteration from MARK area gabbros (Figure 27(b)). Nonetheless, it appears that earlier suggestions of increasing remanent intensity with degree of alteration (Swift and Johnson, 1984) are not generally applicable to oceanic gabbros.

Curie temperatures of gabbroic samples are uniformly near $580^{\circ} \mathrm{C}$ (e.g., Gee et al., 1997; Pariso and Johnson, 1993b; Worm, 2001), indicating that Ti-poor magnetite is the dominant remanence carrying phase. Primary discrete magnetite (associated with more abundant ilmenite) is abundant in $\mathrm{FeTi}$ oxide gabbros 
(a)
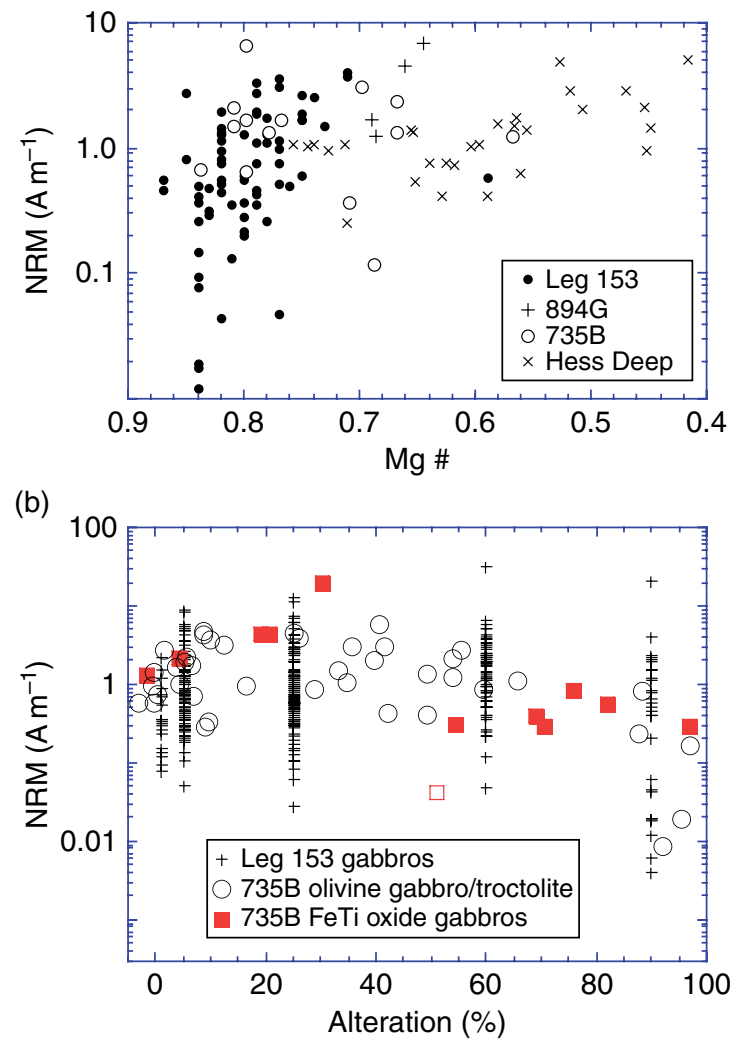

Figure 27 Variation of NRM of oceanic gabbros as a function of $\mathrm{Mg} \#$ (whole rock $\mathrm{Mg}^{2+} /\left(\mathrm{Mg}^{2+}+\mathrm{Fe}^{2+}\right)$ ) and alteration (after Gee et al., 1997, with additional data from Kikawa and Ozawa, 1992). Qualitative alteration data for Leg 153 gabbros are from shipboard descriptions; percent alteration for Hole 735B gabbros (Kikawa and Ozawa, 1992) is based on pyroxene alteration. NRM data have not been reduced to equatorial values. but rare in the less-evolved rocks that constitute the bulk of the gabbroic material. In these latter samples, much of the stable remanence may be carried by finegrained magnetite enclosed in silicate grains. Finegrained oxides are present in olivine, pyroxene, and plagioclase in nearly all troctolites and olivine gabbros from Hole 735B (Natland, 2002). Magnetite along cracks in olivine is attributed to amphibolite-granulite facies alteration at temperatures of $500-700^{\circ} \mathrm{C}$ (Pariso and Johnson, 1993b). Crystallographically oriented elongate magnetite within pyroxene is demonstrably a high temperature $\left(\sim 800^{\circ} \mathrm{C}\right)$ 'exsolution' product in some cases (Renne et al., 2002). A similar exsolution origin for crystallographically controlled magnetite in plagioclase has also been suggested (Natland, 2002; Selkin et al., 2000; Xu et al., 1997a). Silicate-hosted magnetite, at least in plagioclase and pyroxene, appears to be a common feature in oceanic gabbros (Gee and Meurer, 2002) and may be responsible for much of the stable remanence in these rocks. Hysteresis and Curie temperature data from single plagioclase crystals from gabbros at the MARK area and from Leg 209 (Figure 28) illustrate that these fine-grained magnetite grains may have substantial coercivities.

With the exception of FeTi oxide gabbros, most oceanic gabbros have high stability magnetizations and Königsberger ratios $(\mathrm{Q})>1$, indicating that they may constitute an ideal magnetization source. For example, Königsberger ratios for gabbros from Hole 735B are essentially all $>1$ and exceed 10 for much of the lower kilometer of the section (Figure 26). The increase in $\mathrm{Q}$ downhole is paralleled by a general increase in coercivity, as measured by the median
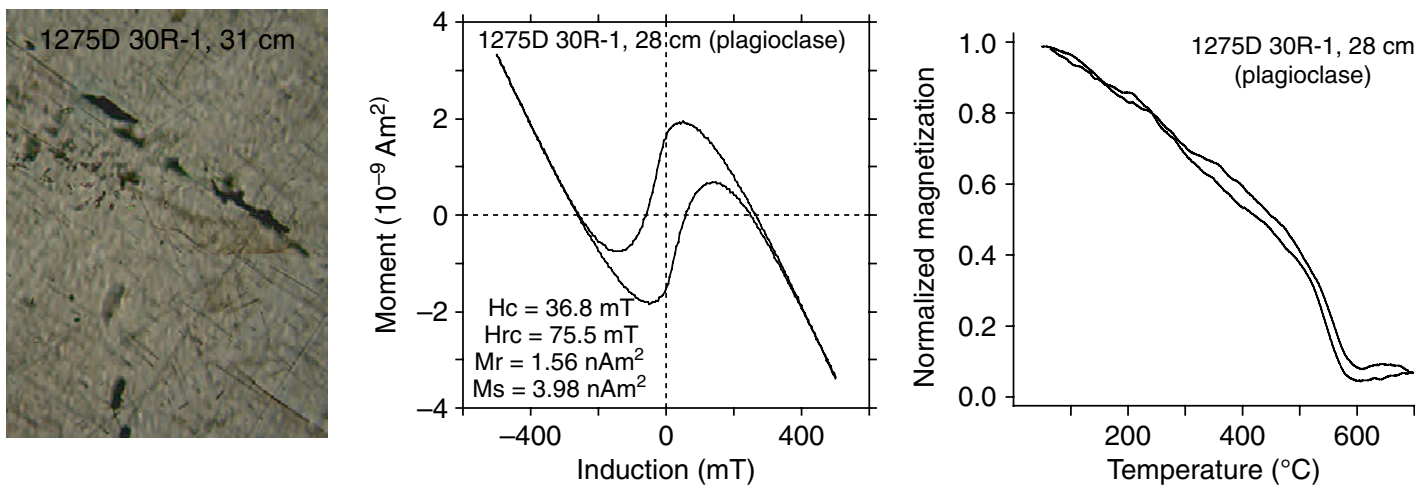

Figure 28 Example of silicate hosted magnetite in plagioclase from gabbro sampled during Leg 209, near $15^{\circ} 20^{\prime} \mathrm{N}$ Fracture Zone Left, photomicrograph (25X, oil immersion) of plagioclase with elongate magnetite; center, hysteresis loop; and right, Curie temperature curve for a single plagioclase crystal. 
destructive field (MDF). Oxide-rich gabbros are characterized by lower stabilities, as might be expected from the abundance of coarse-grained magnetite grains that are particularly susceptible to acquiring a drilling-induced remanence. The olivine gabbros and gabbros that constitute the bulk of the material from Hole 735B are characterized by significantly higher MDF values (several 10's mT). Comparable MDF values (average $\sim 30 \mathrm{mT}$ ) have been reported for gabbros from Hess Deep (Pariso et al., 1996b) and for the $\sim 1400 \mathrm{~m}$ of gabbro sampled from the Atlantis Massif (Blackman et al., 2006).

The variability of inclination values in gabbroic rocks (Figure 26) is considerably less than for extrusive sections and presumably reflects significant averaging of secular variation during slow cooling. For the lowermost $1000 \mathrm{~m}$ of Hole 735B sampled during Leg 176, the directional dispersion parameter (kappa $=59, \mathrm{n}=339)$ is approximately 1.6 times the value expected from the paleosecular variation model of McFadden et al. (1988). The higher value of kappa indicates tighter grouping of the inclination data and the implied time averaging during slow cooling is a necessary prerequisite for using the average inclination data to infer tectonic tilts. Although the inclinations from Hole $735 \mathrm{~B}$ are offset from the expected dipole value due to tilting, the uniform polarity and relatively high magnetization of this $1500 \mathrm{~m}$ gabbroic section (where lavas and dikes have been tectonically removed) are sufficient to account for the sea-surface anomaly amplitudes at the site (Dick et al., 2000). While uniform polarity is likely the norm, it should be noted that complex multicomponent remanences and dual polarities within a site have been reported from gabbros from the MARK area and the Atlantis Massif (Cannat et al., 1995; Gee and Meurer, 2002; Blackman et al., 2006). These complex remanence characteristics have been attributed to crustal accretion and cooling spanning multiple polarity intervals (Gee and Meurer, 2002) and, if more generally applicable, would serve to reduce the gabbroic contribution to the magnetic anomalies.

\subsubsection{Mantle-Derived Peridotites}

Although pristine ultramafic rocks are nonmagnetic (containing only paramagnetic silicates and spinels), serpentinization results in the production of magnetite (e.g., Toft et al., 1990) and magnetizations that are sufficient to constitute a potential significant source for marine magnetic anomalies (e.g., Nazarova, 1994).
Well-documented exposures of serpentinized peridotite at slow-spreading ridges (Cannat, 1993; Cannat et al., 1997) indicate that such upper mantle material undoubtedly contributes, at least locally, to magnetic anomalies. Serpentinization of peridotites and lower crustal gabbros has also been suggested as the cause of higher anomalous skewness of anomalies at slow-spreading ridges (Dyment and ArkaniHamed, 1995; Dyment et al., 1997). In addition, the enhanced positive magnetization (both for normal and reverse polarity crust) at the ends of slowspreading ridge segments has been attributed to induced magnetization of serpentinized peridotites and gabbros (Pariso et al., 1996b; Pockalny et al., 1995; Tivey and Tucholke, 1998).

As with sampling of the gabbroic portion of the ocean crust, drilling at tectonic exposures (Site 895 at Hess Deep (Gillis et al., 1993); Sites 670 and 920 in the MARK area (Cannat et al., 1995; Detrick et al., 1988); and near the $15^{\circ} 20^{\prime}$ Fracture Zone (Kelemen et al., 2004)) has significantly enhanced our understanding of the magnetic properties of oceanic ultramafic rocks. Minor amounts of serpentinized peridotite were also (unexpectedly) recovered from a number of Atlantic drillsites (Sites 334, 395, 556, 558, 560) designed to sample oceanic lavas. Oufi et al. (2002) provide a thorough analysis and review of magnetic studies on serpentinized peridotites up to and including Leg 153 drilling in the MARK area. These results and the more recent remanence data from Leg 209 (Kelemen et al., 2004) are summarized in Table 2.

Magnetizations of serpentinized peridotites, whether obtained by dredging or drilling, vary from $<0.1 \mathrm{~A} \mathrm{~m}^{-1}$ to values higher than $30 \mathrm{~A} \mathrm{~m}^{-1}$ that are comparable to typical values for older oceanic basalts (Figure 29; Table 2). The magnetite content, susceptibility, and magnetization of ultramafic rocks increases with the degree of serpentinization, though this increase is not linear and depends on the particular alteration phases produced (Toft et al., 1990). The degree of serpentinization may be estimated from the sample density (Miller and Christensen (1997), with a correction for the amount of substantially denser magnetite (Oufi et al., 2002)), and Figure 30 shows that relatively little magnetite is produced until the serpentinization exceeds $50 \%$. This nonlinear behavior may be attributed to the $\mathrm{FeO}$ content of the silicate alteration phases. For $<75 \%$ serpentinization, early $\mathrm{FeO}$-rich lizardite is formed and with continued alteration this lizardite is replaced by more $\mathrm{FeO}$-poor chrysotile, with a concomitant release of iron and production of 


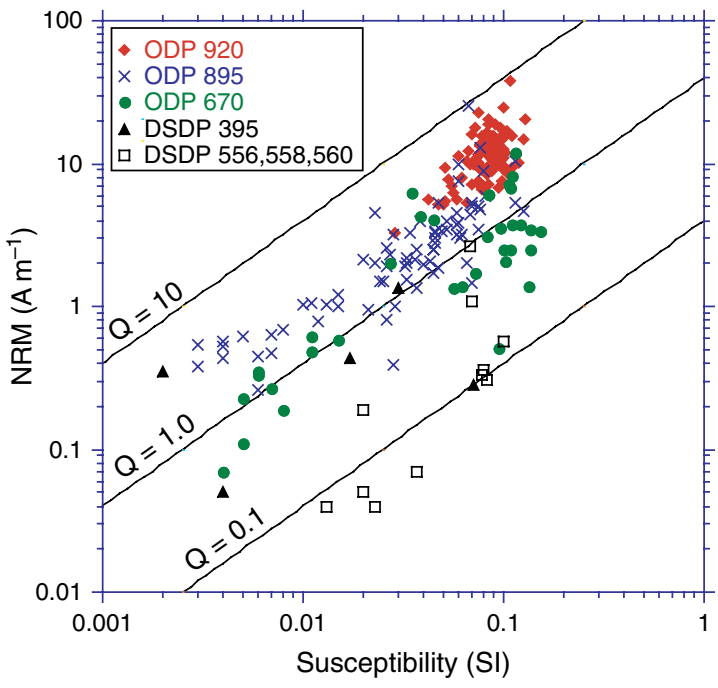

Figure 29 Log-log plot of NRM and susceptibility of oceanic serpentinized peridotite samples from various DSDP and ODP drill sites (data compiled by Oufi et al., 2002). Distribution of values compared to lines of constant $Q$ (Königsberger ratio of remanent to induced magnetization; calculated for field of $40 \mathrm{~A} \mathrm{~m}^{-1}$ ) shows that remanence is greater than induced magnetization in most samples. NRM data have not been reduced to equatorial values.

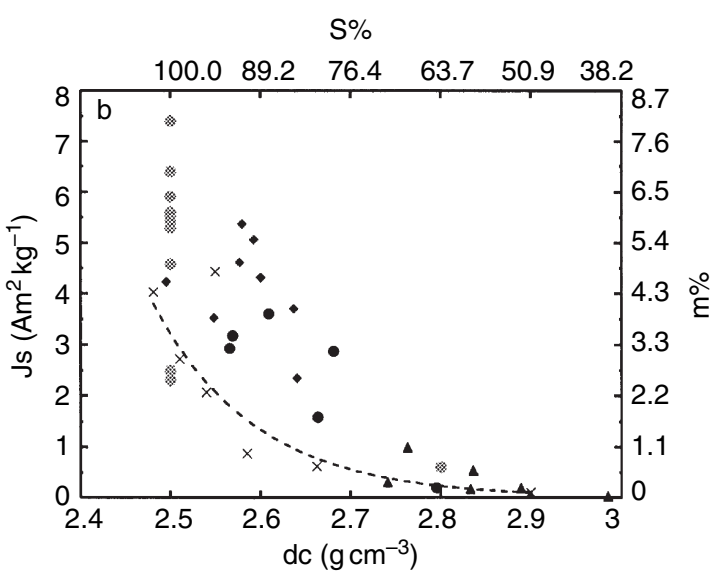

Figure $\mathbf{3 0}$ Saturation magnetization (Js) as a function of corrected density (dc) of serpentinized peridotite samples from various DSDP and ODP sites, showing how percentage of magnetite $(\mathrm{m} \%)$ increases with degree of serpentinization (S\%). Dashed curve is best-fitting relationship between Js and dc for a subset of samples. After Oufi O, Cannat M, and Horen $\mathrm{H}$ (2002) Magnetic properties of variably serpentinized abyssal peridotites. Journal of Geophysical Research 107: (B5): (doi:10.1029/2001JB000549).

magnetite (Oufi et al., 2002). Alteration assemblages that include even more $\mathrm{FeO}$-rich brucite may further suppress magnetite production, as evident in some of the lower magnetization samples from Sites 895 and
670 (Figure 29). Most dredged peridotites and some drillcore samples (particularly from breccias or fault zones) have experienced post-serpentinization lowtemperature oxidation, as evidenced by the presence of maghemite (e.g., Nazarova et al., 2000). Although magnetic properties may vary considerably, the geometric mean intensity $\left(2.1 \mathrm{~A} \mathrm{~m}^{-1}\right.$ equatorial value including results from Leg 209; Table 2) and average Königsberger ratio of $\sim 2$ suggest that both remanent and induced magnetization from oceanic serpentinized peridotites may contribute significantly to magnetic anomalies. The influence of serpentinized peridotites on the anomaly pattern, however, may largely be limited to fracture zones and slow-spreading ridges where mantle-derived peridotite exposures are relatively common.

Although many serpentinites may predominantly have a viscous remanence, the origin of the remanence in oceanic serpentinized peridotites is likely to include a chemical remanence and perhaps also a partial thermoremanence as demonstrated by remanence directions that deviate substantially from the present field direction (e.g., Garces and Gee, 2007). Temperature estimates for serpentinization based on oxygen isotope fractionation between magnetite and serpentine vary widely, though most serpentinites from Hess Deep and the MARK area yield temperatures conservatively estimated as $>350^{\circ} \mathrm{C}$ (Agrinier and Cannat, 1997; FrühGreen et al., 1996). Based on these relatively high temperatures and the simple demagnetization behavior of MARK area peridotites, Lawrence et al. (2002) suggested that much of remanence might be thermal in origin. While coarse-grained magnetite is abundant, values of $M_{\mathrm{rs}} / M_{\mathrm{s}}$ as high as 0.4 , as well as direct grain size estimates from image analysis indicate that relatively fine-grain magnetite is also present (Lawrence et al., 2002; Oufi et al., 2002). These finer particles are presumably responsible for the relatively stable remanence in the MARK area peridotites, which was used to infer that little tilting occurred during uplift and exposure (Lawrence et al., 2002).

\subsubsection{Crustal Accretion and Structure of the Magnetic Source}

Crustal accretionary processes exert a fundamental control on the spatial distribution of magnetization sources, limiting the temporal resolution of the 
geomagnetic signal resolvable from marine magnetic anomalies and, in some cases, modulating their shape (skewness). In addition, the remanent magnetization vector may be rotated during accretion (e.g., tilt due to lava loading) or by subsequent tectonic deformation. Any tectonic rotation of the magnetic source layer about a ridge-parallel rotation axis will result in an equivalent phase shift of the magnetic anomaly (Cande and Kent, 1985). Anomalous skewness, the phase shift not accounted for by a standard thin layer block model (Cande, 1976), therefore provides a strong constraint on any tectonic tilt of the magnetization source, as well as nonvertical polarity boundaries. In the discussion below, we address the consequences of the (generally accepted) pattern of nonvertical magnetic boundaries separately from the effects related to (more speculative) rotation of the magnetic source.

\subsubsection{Nonvertical Magnetic Boundaries}

The pattern of magnetization boundaries (isochrons) in the ocean crust is shown schematically in Figure 31. Isochrons within the extrusive layer are expected to dip toward the ridge (e.g., Kidd, 1977) as new lavas progressively cover pre-existing flows. The resulting sloping (sigmoidal) magnetization boundary in the extrusives can be conveniently modeled by a gaussian filter applied to the standard magnetization block model. The transition zone width, the width over which $90 \%$ of the magnetization change occurs, is approximately four times the standard deviation $(\sigma)$ of the gaussian filter (Atwater and Mudie, 1973). In a classic survey at $21^{\circ} \mathrm{N}$ on the EPR, Macdonald et al. (1983) documented both the validity of this general model, as well as the spatial extent of lava spillover onto pre-existing flows by comparing the location of the reversal boundary inferred from near-bottom magnetic anomaly data and the polarity of individual volcanic features at the surface from submersible observations. The surface polarity boundary was displaced (away from the ridge) by $250-500 \mathrm{~m}$ relative to the vertically averaged polarity boundary determined from the near-bottom anomaly data, suggesting a transition zone width of $1.4-1.8 \mathrm{~km}$ at this intermediate $\left(60 \mathrm{~mm} \mathrm{yr}^{-1}\right.$ full rate) spreading rate (Macdonald et al., 1983). Comparable transition zone widths $(\sim 1.5-3.0 \mathrm{~km})$ have been determined from near-bottom anomaly data at intermediate to superfast (up to $150 \mathrm{~mm} \mathrm{yr}^{-1}$ full rate) spreading ridges (Bowers et al., 2001; Sempere et al., 1987). Less focused accretion at slow-spreading ridges likely results in broader transition zones (Sempere et al., 1987), though the spreading rate dependence has not been well established.

The narrow $(1-3 \mathrm{~km})$ transition zone widths (which represent an upper bound due to the effects of minor extension and the $\sim 7 \mathrm{ky}$ (Clement, 2004) necessary for the field to reverse) imply a relatively high-fidelity recording process at intermediateand fast-spreading ridges, compatible with the recognition of short polarity events (e.g., the $\sim 10 \mathrm{ky} \mathrm{Cobb}$ Mountain or Reunion events; Table 1) in anomaly profiles at these spreading rates. These estimates are also consistent with independent estimates of the width over which lavas accumulate. Submersible observations at intermediate- and fast-spreading ridges suggest that most volcanic activity is concentrated within $1 \mathrm{~km}$ of the axis (Karson et al., 2002; Perfit and Chadwick, 1998). Flows erupted offaxis or transported downslope may extend for a few kilometers from the ridge (Fornari et al., 1998; Perfit et al., 1994) and off-axis accumulation of lavas can significantly affect the pattern of magnetic anomalies (Gee et al., 2000; Schouten et al., 1999). The off-axis thickening of seismic Layer 2A (commonly interpreted as corresponding to the extrusive layer) within $1-3 \mathrm{~km}$ of the axis (e.g., Harding et al., 1993; Vera and Diebold, 1994) also suggests that lava accumulation occurs over a narrow zone comparable to the transition zone widths inferred from anomaly data.

The pattern of magnetization contrasts in the sheeted dikes and gabbros is less well constrained. The zone of dike intrusion, where mixed polarity dikes would occur (Figure 31), is likely much narrower than for the lava flows. In order to match seismic constraints and the sharp extrusive/dike boundary observed in ophiolites, Hooft et al. (1996) found that the zone of dike intrusion at the EPR must be less than a few hundred meters wide ( $1 \sigma$ of $10-$ $50 \mathrm{~m}$ ). To the extent that the lower crust is conductively cooled, polarity boundaries in the gabbroic portion of the crust should approximately follow the shape of the $580^{\circ} \mathrm{C}$ isotherm (Cande and Kent, 1976) (Figure 32). Half-space conductive cooling models (Oxburgh and Turcotte, 1969; Sclater and Francheteau, 1970) predict that magnetization isochrons in the gabbroic layer should dip away from the ridge at $4-30^{\circ}$ (for full spreading rates from 150 to $16 \mathrm{~km} \mathrm{My}^{-1}$, respectively). Near-bottom magnetic anomaly data from tectonic exposures of lower crustal gabbro at Atlantis Bank, together with inclination data from wireline rock drill samples and from the 


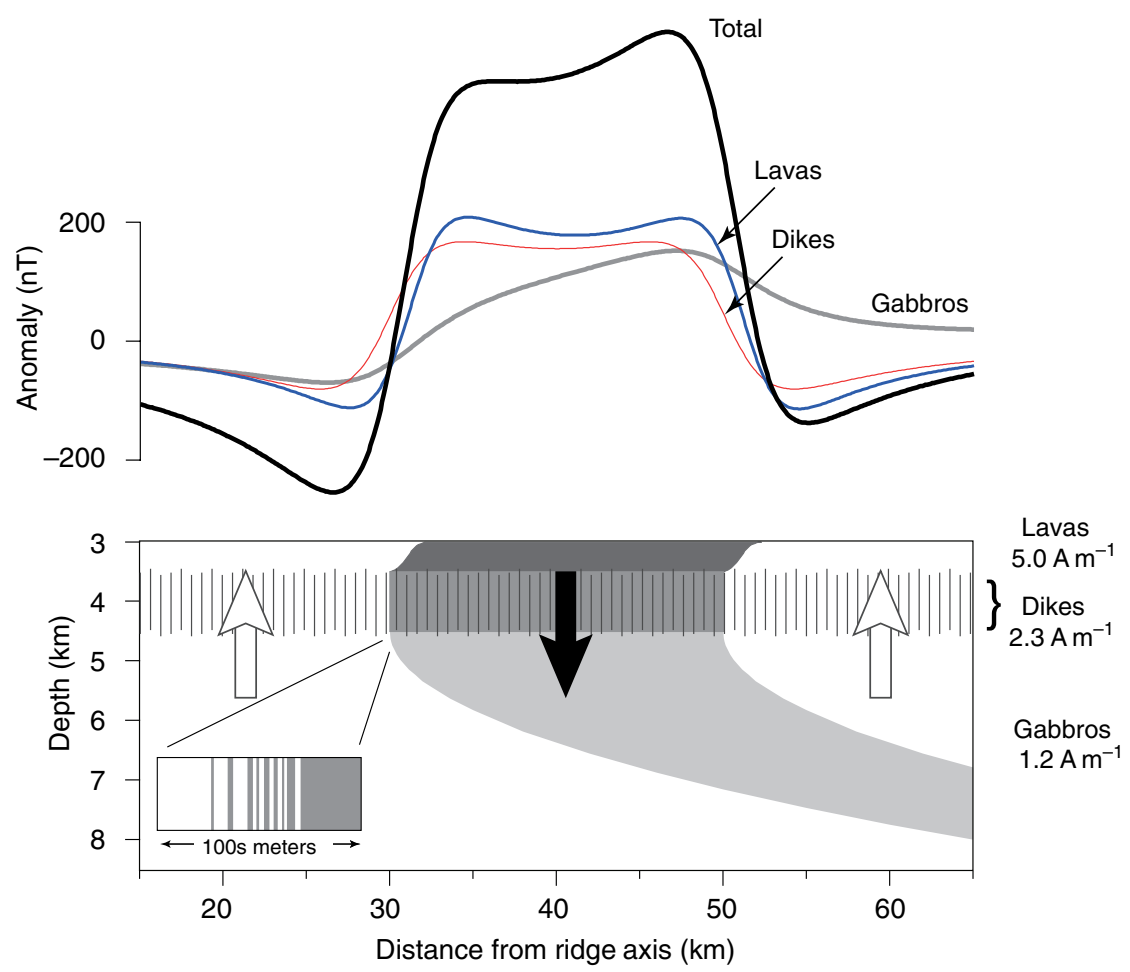

Figure 31 Schematic illustration of magnetization boundaries in oceanic crust (bottom) and magnetic anomaly models for these magnetic source bodies (top). The magnetization values of the three layers are based on the overall geometric mean values in Table 2. Anomalies are calculated for vertical magnetization and ambient field for a full spreading rate of $80 \mathrm{~km} \mathrm{My}^{-1}$. No gaussian filter has been applied to the magnetization.

$1.5 \mathrm{~km}$ penetration at Hole $735 \mathrm{~B}$, have been interpreted as indicating the presence of a sloping isochron with a present day dip of $\sim 25^{\circ}$ (Allerton and Tivey, 2001). However, the well-determined remanent inclination $\left(-71^{\circ}\right.$; Figure 26) from Hole $735 \mathrm{~B}$ suggests an outward tilt of about $20^{\circ}$, so that the original dip of this isochron was approximately $5^{\circ}$. While the dip direction is away from the ridge, as expected, the very shallow dip angle is difficult to reconcile with that expected $\left(\sim 30^{\circ}\right)$ from conductive cooling (John et al., 2004) at this slow-spreading ridge.

The effect of nonvertical magnetization boundaries on the shape and amplitude of anomalies should be minor for lavas and dikes but is significant for the gabbroic portion of the crust (Figure 31). For 1-3 km wide transitions in the extrusive layer, the corresponding anomaly is shifted slightly away from the ridge but there is little detectable effect on the anomaly shape or amplitude. Based on vertical magnetic profiling data from intermediate-spreading crust exposed at the Blanco escarpment, substantially broader $(\sim 10 \mathrm{~km})$ transition zone widths have been suggested (Tivey, 1996; Tivey et al., 1998a). While this novel profiling technique has considerable promise in mapping the distribution of polarities, the very broad transitions at the Blanco escarpment predict substantial changes in anomaly amplitude and shape that are not generally apparent. The narrow polarity transition in the sheeted dikes $\left(\sigma_{\text {dikes }}<<\right.$ $\left.\sigma_{\text {flows }}\right)$ is likewise not expected to significantly affect the anomaly shape or amplitude.

In contrast, the gently sloping boundaries in the gabbroic lower crust should give rise to significant anomalous skewness (Cande and Kent, 1976). Anomalies generated by such gently dipping polarity boundaries are illustrated in Figure 32 for a range of polarity interval lengths and spreading rates. The resulting anomalous skewness is most easily recognized for broad polarity intervals and amounts to a phase shift of $\sim 45^{\circ}$, in the same sense as global observations of anomalous skewness. The distortion is not a pure phase shift, however, as evidenced by the asymmetric shoulder at the older edge that coincides with the magnetization contrast at the base of the gabbroic layer. Although the anomaly shapes for 
Nonvertical polarity boundaries

in lower crust
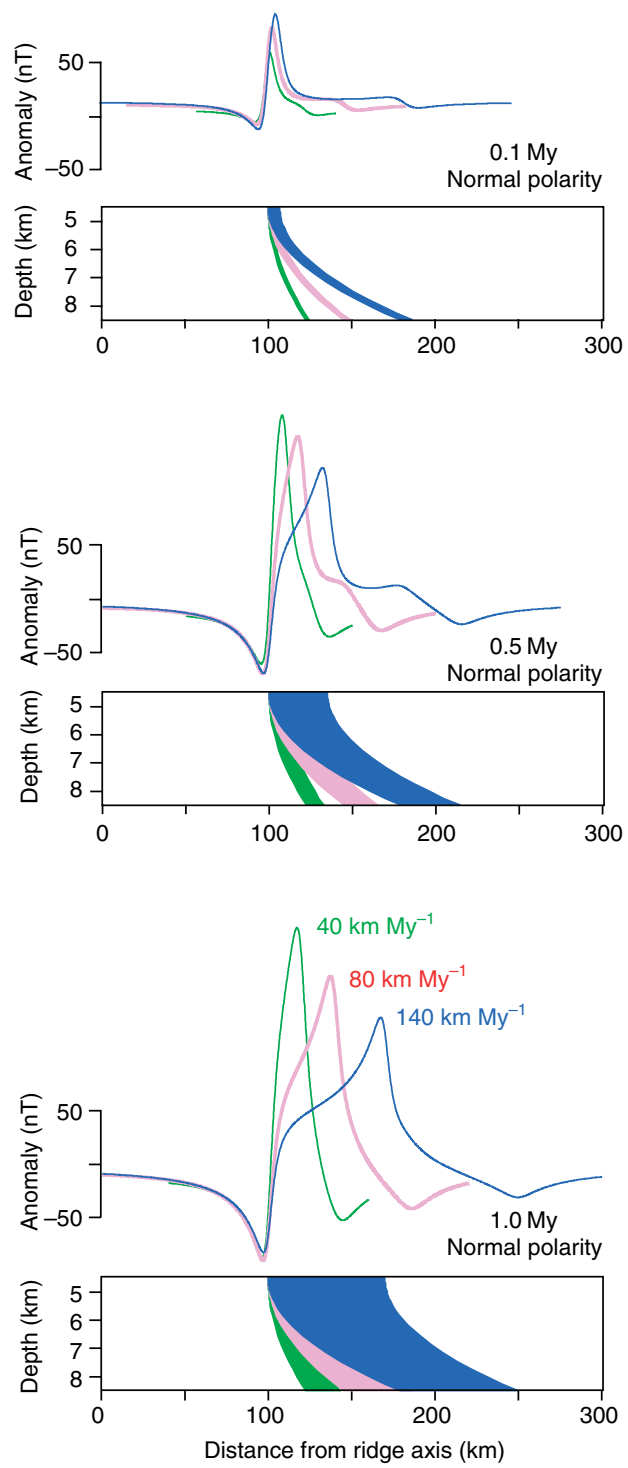

Rotation of remanence in lavas
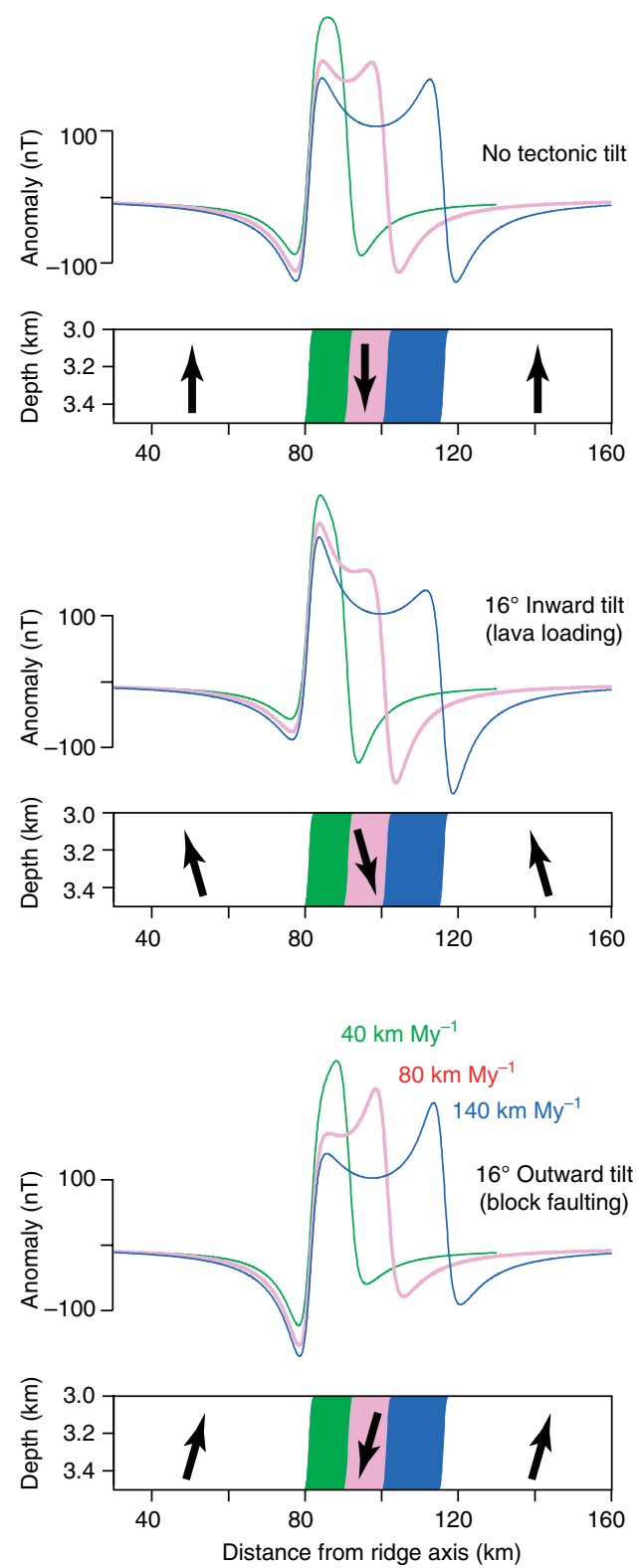

Figure 32 Magnetic anomaly models illustrating the effect of sloping cooling isotherms in gabbroic layer and various lava tilts. Left, conductively cooled magnetization boundaries in the gabbroic layer are illustrated for three different length polarity intervals $(0.1,0.5$, and $1.0 \mathrm{My})$ at three spreading rates. This normal polarity interval is indicated by the three shaded regions (green, red, blue for 40,80,140 km/My ${ }^{-1}$ full spreading rates). The corresponding magnetic anomalies have an anomalous skewness of $\sim 45^{\circ}$. Anomalies are calculated for vertical magnetization and ambient field. Right, effect of tilt of the extrusive layer on anomalies from a $0.5 \mathrm{My}$ normal polarity interval at the same three spreading rates. The sigmoidal magnetization boundary reflects lava accumulation over $\sim 2 \mathrm{~km}$ and introduces no detectable change in the anomaly shape (upper plot). Ridgeward or outward tilting of $16^{\circ}$ (the average tilt implied by lava accumulation over $\sim 2 \mathrm{~km}$ ) results in an equivalent amount of anomalous skewness.

narrow intervals or at different spreading rates appear quite different, the anomalous skewness introduced by a conductively cooled gabbroic layer is essentially independent of spreading rate. A three- layer source model (with subequal contributions from the lavas, dikes, and gabbros as indicated by the average remanence of these layers and their thickness and depth; Table 2) illustrates that the 
anomalous skewness imparted by the gabbroic layer results in an overall anomalous skewness of $\sim 10^{\circ}$ (Figure 31). This value is well within the range $\left(5-25^{\circ}\right.$ for a full spreading rate of $80 \mathrm{~km} \mathrm{My}^{-1}$ ) determined from global compilations of anomalous skewness data (e.g., Roest et al., 1992; Petronotis et al., 1992). Although rotations of the magnetic remanence direction (which are not included in the model shown in Figure 31) may result in additional anomalous skewness, such rotations are apparently not required to explain the modest anomalous skewness at intermediate and faster spreading rates.

\subsubsection{Rotations of the Magnetic Source Layer}

Normal faulting is an integral part of extensional seafloor spreading and therefore rotations, either toward or away from the ridge, about ridge parallel axes are not unexpected. Inward (toward ridge) dipping faults are dominant at all but the fastest spreading rates (Carbotte and Macdonald, 1990; Kriner et al., 2006), and even at superfast spreading rates these faults accommodate most of the strain (Bohnenstiehl and Carbotte, 2001). These inward dipping faults should result in outward tilt of the magnetic source layer, which will produce a phase shift $\left(1^{\circ}\right.$ for each $1^{\circ}$ of tilt) of the anomalies that is compatible with the observed sense of anomalous skewness (Figure 32; Cande, 1978).

Tilting in response to lava loading has recently been suggested as a potential way of rotating the remanence vector of seafloor lavas (Schouten and Denham, 2000; Schouten et al., 1999; Tivey et al., 2005). In these models, the sloping isochrons within the extrusive layer are taken as also reflecting the inward tilt of individual lava flows. The resulting downhole distribution of inclinations (possibly modified by later block rotation) can then be used to infer the average pattern of lava accumulation. This type of model requires that the remanence in relatively small intervals within the extrusive layer represent the time-averaged field direction, so that downhole trends in the average inclination can be detected. If prevalent, such lava loading would produce systematic inward tilt of the lavas and anomalous skewness in the opposite sense of that observed. The relatively thin extrusive layer and the generally narrow region over which flows accumulate limit the amount of tilting expected from lava loading. For accumulation of a $0.5 \mathrm{~km}$ thick extrusive layer over a typical transition zone width of $\sim 2 \mathrm{~km}$, the average dip of the isochrons (and therefore inward tilt of the remanence) is $\sim 16^{\circ}$, which is accompanied by a readily observable anomalous skewness of $16^{\circ}$ (Figure 32).

A significant number of drill sites sampling the extrusive layer have inclinations that deviate from expected values, and block rotations and/or lava loading undoubtedly contribute to some of these deviations. In the most recent (although 30 years ago) compilation of inclination results from drillcore data, Lowrie (1977) found that observed inclination values were well correlated with expected values, though the results exhibit appreciable scatter about the ideal 1:1 line. Although no significant bias toward either shallower or steeper inclinations was found, two aspects of the drill core data make it unlikely that any systematic bias (whether from block rotations or lava loading) would be evident. First, paleosecular variation can result in significant scatter even when the entire lava section is sampled (e.g., 504B; Figure 23) and so average inclination results from shallow penetration holes should be viewed with caution. Second, the lack of azimuthal orientation of the drillcore samples precludes recognition of a systematic sense for ridges that strike nearly $\mathrm{N}-\mathrm{S}$, as does much of the Pacific and Atlantic ridge system. In principle, E-W striking ridges might provide information on systematic tilt in the extrusives though it is unclear whether sufficient data exist to conduct such an analysis.

Magnetic anomaly shapes provide the most robust estimate of the average tilt of the magnetization source. Comparison of drillcore data from three relatively deep penetration holes in Cretaceous (M0 age) crust (Figure 33) and correlative anomaly shapes (Figure 34) illustrate how models of block tilting and lava loading can be independently evaluated. The mean inclinations in Holes 417A and 418A (where there is a polarity reversal at $500 \mathrm{mbsf}$ ) are eminently compatible with expected inclinations from Early Cretaceous paleopoles for the North America plate (Bosum and Scott, 1988; Levi, 1980). The inclinations from the upper portion of Hole $417 \mathrm{D}$ are steeper and have been attributed to tectonic tilting by some authors (Verosub and Moores, 1981), although Levi (1980) argues that the inclination data are compatible with paleosecular variation and do not demand any tectonic rotation. Schouten (2002) interprets the Hole 417A data (with reverse polarity inclination very similar to the expected value) as reflecting two oppositely directed tectonic tilts: a large initial tilt toward the ridge axis as function of lava loading (requiring the bulk of the lavas to 


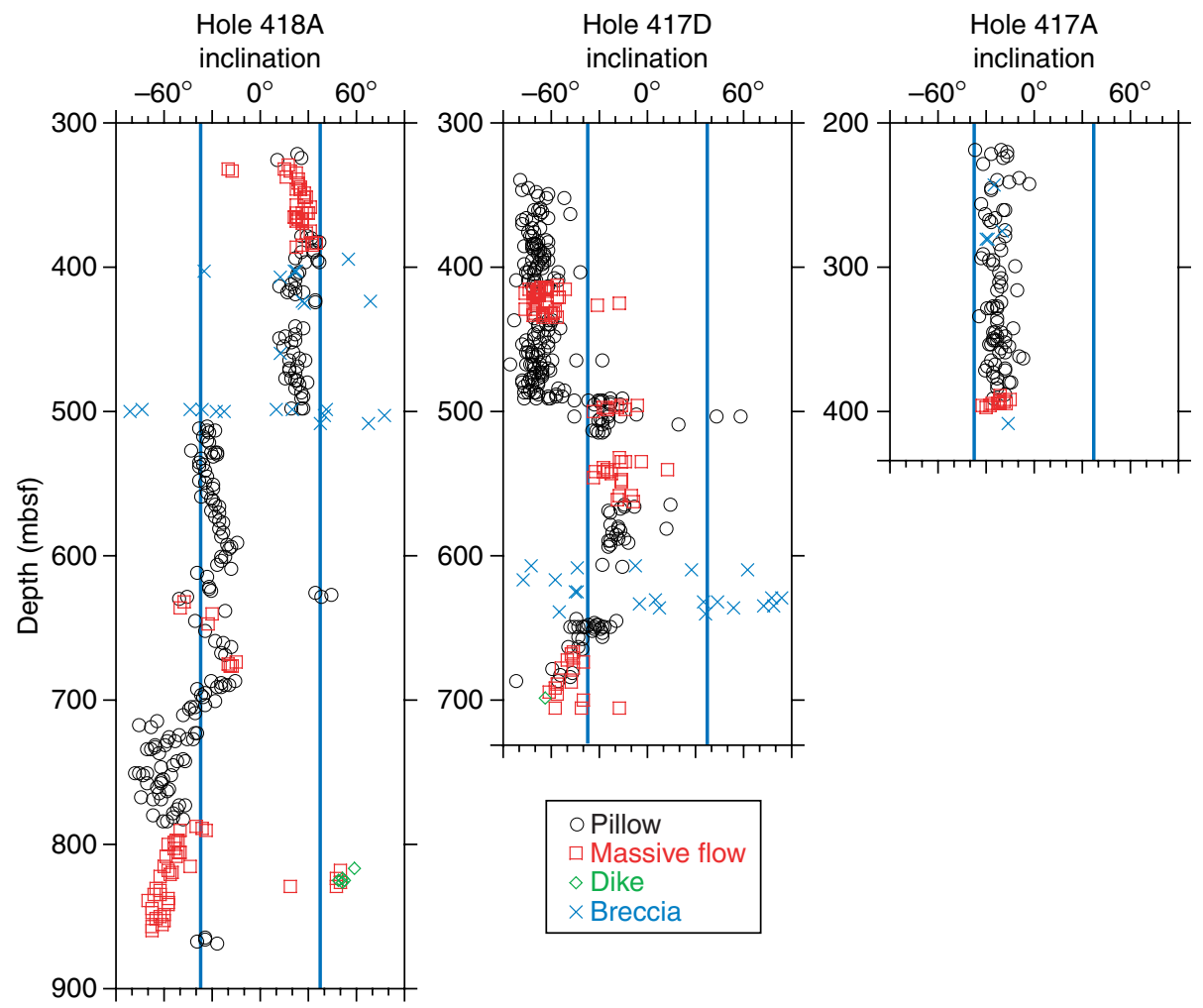

Figure 33 Stable remanent inclinations (i.e., after partial demagnetization to remove spurious components) from discrete samples from seafloor lavas at DSDP Holes 417A, 417D, and 418A. The heavy lines indicate the expected Cretaceous inclination values at the site. Data from Levi (1980).

accumulate within $300 \mathrm{~m}$ of the axis), followed by $41^{\circ}$ outward block tilting (Figure 34). Magnetic anomaly data across Anomaly M0, including from the immediate vicinity of Sites 417/418 (Figure 34; Cande and Kent, 1985), indicate the M0-age crust from both ridge flanks is characterized by little or no anomalous skewness and therefore little or no net tilt of the magnetic source. While such fortuitous offsetting tilts could, of course, explain the lack of anomalous skewness near Sites 417 and 418, this is unlikely to be generally applicable. The magnitude and sense of anomalous skewness indicate that substantial tilting (whether from lava loading or block rotation) is not generally applicable, at least for fast- and intermediate-spreading ridges where anomalous skewness magnitudes are generally small.

Relatively few observations are available that constrain possible rotations of the intrusive portion of the crust. Based on submersible studies of tectonic exposures of fast-spread crust at Hess Deep, much of the sheeted dike complex appears to have a systematic dip $\left(\sim 60^{\circ}\right)$ away from the ridge (Karson et al., 2002) although areas with approximately vertical dikes are also present (Francheteau et al., 1992). As with the lavas, anomalous skewness constraints suggest that such inward tilting of the sheeted dikes is unlikely to be a general feature, provided that the dike remanence is a significant contributor to the magnetic anomalies as available data seem to now indicate. Substantial rotations of the gabbroic layer have been documented at slow-spreading ridges. For example, tectonic tilts of $\sim 20^{\circ}$ have been well documented for gabbros at the Atlantis Bank (Dick et al., 1999) and even larger rotations $\left(40-80^{\circ}\right)$ have been reported from gabbros (and associated serpentinized peridotites) from the vicinity of the $15^{\circ} 20^{\prime} \mathrm{N}$ Fracture Zone in the Atlantic (Garces and Gee, 2007; Kelemen et al., 2004). The outward rotation of the gabbroic sections, presumably from flexural/isostatic adjustment in response to unloading, is compatible with the sense of anomalous skewness data. Although the magnitude of anomalous skewness appears to increase at slower spreading rates (Roest et al., 1992), the very large rotations noted from the $15^{\circ} 20^{\prime} \mathrm{N}$ area exceed the largest values of anomalous skewness and thus are unlikely to be representative of more typical slow spread crust. 
(a)

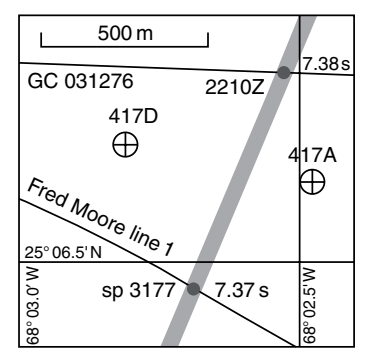

(b)

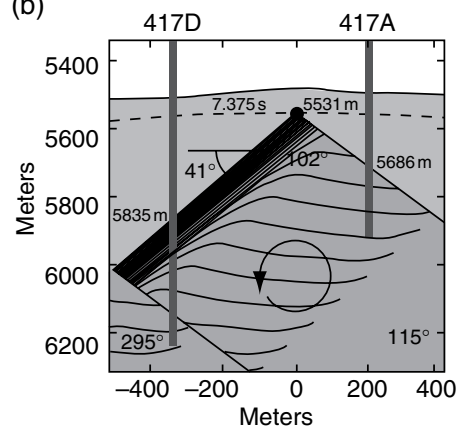

(c)
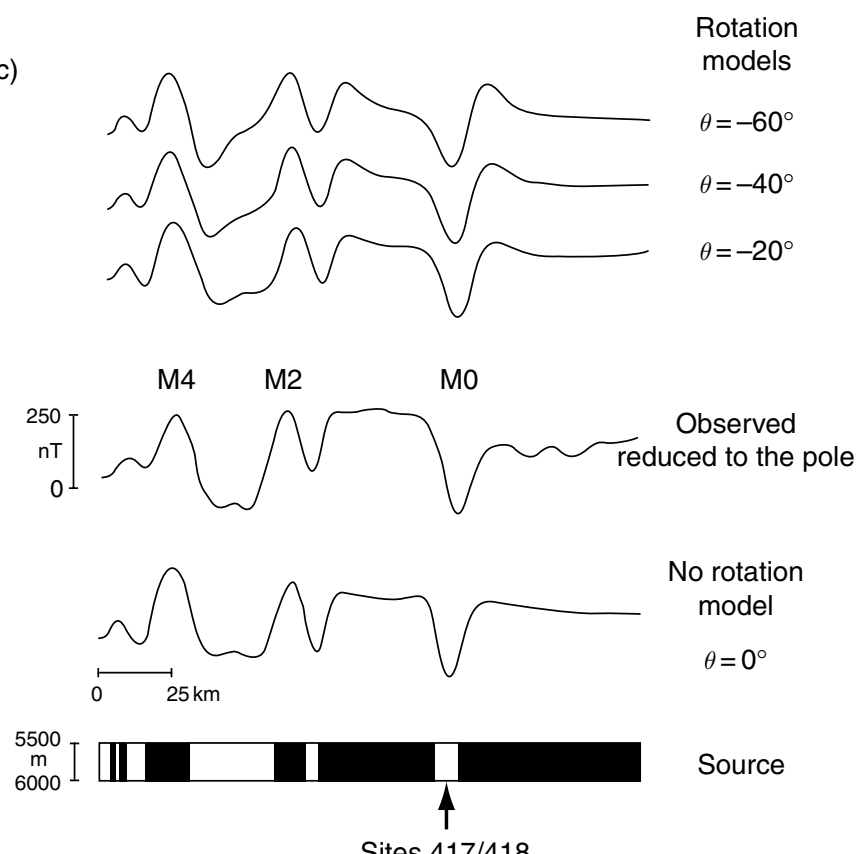

Figure 34 Tectonic rotation model for ODP Sites 417A and 417D (a) and (b) location map; (c) diagrammatic cross-section) from Schouten (2002), compared to observed and modeled magnetic anomaly data for a profile nearby Site 417A and 417D (from Cande and Kent, 1985). Note that the observed profile is matched best by a model with no tectonic rotation and is poorly represented by a model with $40^{\circ}$ of rotation suggested from inclination data at Sites 417A and 417D by Schouten (2002).

\subsubsection{Future Directions}

There is increasing evidence that marine magnetic anomalies are capable of recording a broad spectrum of geomagnetic field behavior, ranging from millennial-scale paleointensity variations to polarity reversals to apparent polar wander to, more speculatively, long-term changes in average field strength as suggested, for example, by the ramp in anomaly amplitudes at the older end of the M-sequence. However, because of the inherent ambiguity in determining source properties from potential field data, independent geomagnetic field estimates will be needed to guide and calibrate inferences made from magnetic anomalies. Here we highlight some general approaches - the use of autonomous vehicles, oriented samples, absolute paleointensity of near-ridge lavas, and measurements of the vector anomalous field - that are likely to significantly advance our understanding of the geomagnetic signal recorded in the oceanic crust, as well as our ability to utilize this information in addressing outstanding problems in crustal accretion processes.

One general area that is ripe for further development and applications is near-bottom observations, which are required to obtain high spatiotemporal resolution. Such near-bottom observations from towed systems (often incorporating side scan sonar or other 
instrument packages as well) have already provided seminal contributions in our understanding of the fine structure of anomalies and source geometries (e.g., Atwater and Mudie, 1973; Larson and Spiess, 1969). More recently, near-bottom data have been used to demonstrate the lineated (i.e., geomagnetic) nature of small-scale magnetic anomalies, which have been shown to mainly reflect paleointensity variations (Bowers et al., 2001; Bowles et al., 2003; Gee et al., 2000), and to examine crustal accretionary processes (e.g., Hussenoeder et al., 1996; Smith et al., 1999; Tivey et al., 2003). These towed packages are robust, proven marine geophysics tools but tend to be used sparingly because such wireline deployments require a dedicated vessel and slow towing speeds. An exciting recently developed alternative is $\mathrm{ABE}$ (Autonomous Benthic Explorer), which can be operated simultaneously with other shipboard programs. ABE is capable of following preprogrammed, closely spaced track lines at low altitudes (5-40 $\mathrm{m}$ above the seafloor) to yield fine-scale bathymetry and high-resolution magnetic data. An example of an $\mathrm{ABE}$ survey at $17^{\circ} \mathrm{S}$ on the EPR (Shah et al., 2003) is shown in Figure 35. In this study, a magnetic field low was found extending several kilometers along the axial trough, which was interpreted as reflecting the presence of a few-hundred-meter-wide region of weakly or nonmagnetic shallow dikes (Shah et al., 2003) but might also delineate lavas erupted during the recent (relative) geomagnetic intensity low (Figure 3). When combined with the submeter resolution bathymetry, ABE magnetic anomaly data also provide a powerful technique to examine the relationship between individual volcanic features and their corresponding anomaly signatures (e.g., Tivey et al., 1998b). Similar high-resolution anomaly data can also be obtained with the new generation of tethered vehicles, that allow far more motion control than towed systems and also may incorporate high-resolution swath mapping and sampling capabilities. Such high-resolution mapping on the Endeavor segment of the Juan de Fuca ridge has revealed circular $(\sim 100 \mathrm{~m}$ diameter $)$ anomaly lows that correlate with present-day and fossil hydrothermal upflow zones (Figure 36; Tivey and Johnson, 2002).

The more detailed magnetic anomaly observations that are possible with tethered vehicles, $\mathrm{ABE}$, and manned submersibles are nicely complemented by the availability of high-resolution sampling techniques that allow collection of fully oriented samples. Block samples oriented with the Geocompass (which uses a

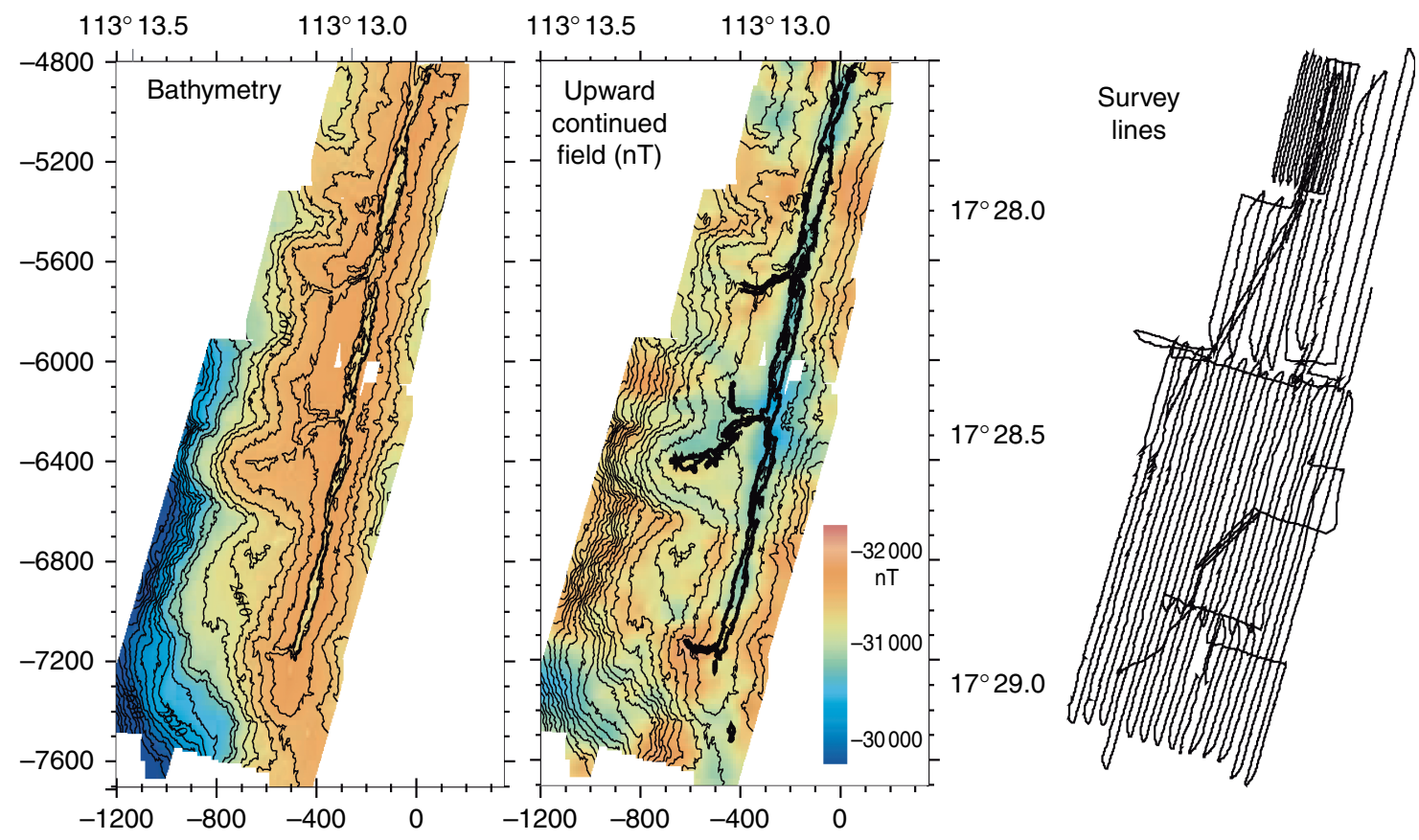

Figure 35 High resolution bathymetric (left) and magnetic data (center) obtained by an Autonomous Benthic Explorer (ABE) survey (tracks on right) on the East Pacific Rise at $17^{\circ} \mathrm{S}$. Note the presence of lower anomaly amplitudes along the axial summit trough (heavy lines in center figure). Modified from Shah AK, Cormier M-H, and Ryan WBF et al. (2003) Episodic dike swarms inferred from near-bottom magnetic anomaly maps at the southern East Pacific Rise. Journal of Geophysical Research 108(B2): 2097 (doi:10.1029/2001JB000564). 


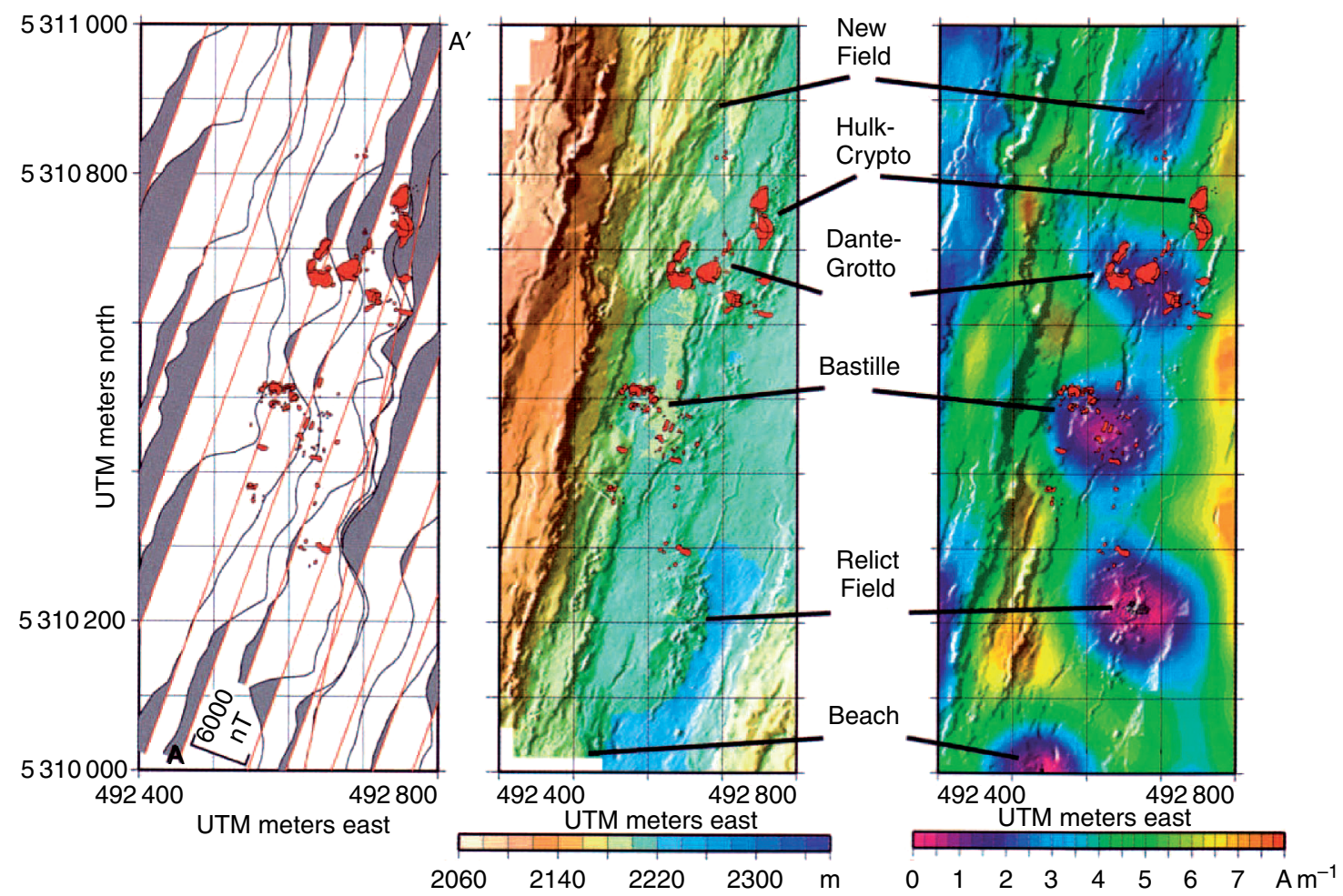

Figure 36 Near-bottom bathymetric and magnetic observations on the Endeavor segment of the Juan de Fuca Ridge showing hydrothermal burn-holes. Red areas indicate locations of active hydrothermal vents. Modified from Tivey MA and Johnson HP (2002) Crustal magnetization reveals subsurface structure of Juan de Fuca Ridge hydrothermal vent fields. Geology 30: 979-982.

compass and digital tilt meters to measure attitude) have been collected from submersible (Cogne et al., 1995; Hurst et al., 1994; Varga et al., 2004) and this technique has also been successfully used with tethered remotely operated vehicles (ROVs). Oriented samples from a wireline rockdrill (Allerton and Tivey, 2001) further expand the range of seafloor outcrops that can be sampled to address tectonic problems. Indirect information on the remanence direction can also be obtained from borehole magnetometer measurements with gyro-oriented logging (Bosum and Scott, 1988). Such borehole measurements have substantial advantages in characterizing the magnetic source region, since they can provide representative magnetization values by avoiding drilling-induced remanence and directly account for void and porosity effects on assessments of discrete sample values.

Our understanding of the neovolcanic zone at fastspreading ridges, especially the EPR, has evolved and become increasingly sophisticated in recent years as higher-resolution observations, such as with $\mathrm{ABE}$, became available. Placing accurate age constraints to determine eruptive recurrence intervals on near-axis lava flows have become increasingly important given the structural and volcanic complexity of the neovolcanic zone. In this regard, geomagnetic paleointensity of submarine basaltic glass (Pick and Tauxe, 1993) holds particular promise for placing quantitative age constraints on near-axis flows. For example, multispecimen Thellier paleointensity results from four independent samples distributed over several kilometers from a single (Animal Farm) flow on the EPR at $\sim 18^{\circ} \mathrm{S}$ were found to be in excellent mutual agreement $(35.6 \pm 1.0 \mu \mathrm{T})$, and by comparison to a geomagnetic reference curve projected to the site location, the Animal Farm paleointensity value indicated a fairly recent time of eruption (AD $1910 \pm 20)$ in general agreement with other observations (Carlut and Kent, 2000) (Figure 37). An integrated bathymetric, geochemical, and paleointensity study of adjacent and contrasting ridge segments at $\sim 15^{\circ} \mathrm{N}$ on the EPR (Carlut et al., 2004) and one at $9-10^{\circ} \mathrm{N}$ that involved the analysis of what may be the largest published dataset of absolute (Thellier) paleointensity 
(a)

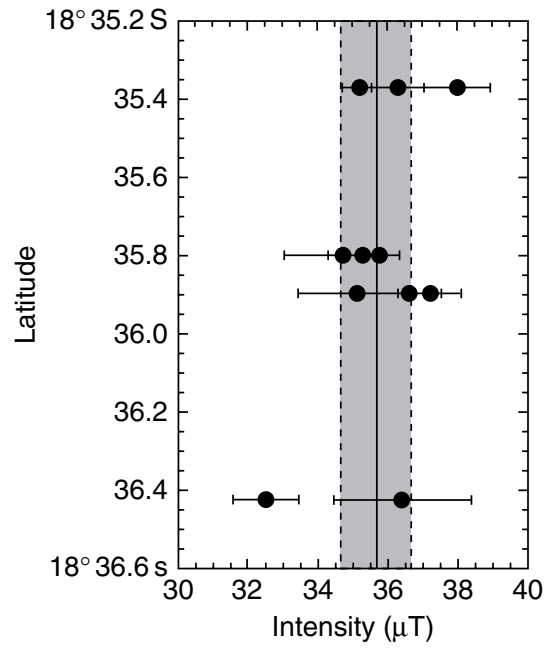

(b)

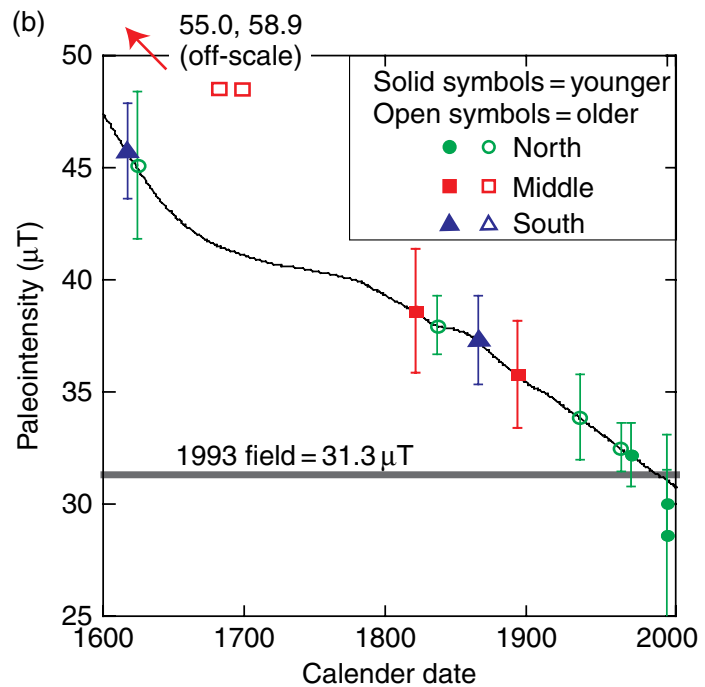

Figure 37 Absolute paleointensity results from submarine basaltic glass illustrating the potential as a dating tool for young mid-ocean ridge lavas. (a) Paleointensity results from multiple samples within a single flow (mapped by submersible) highlight the degree of reproducibility ( $\sim \mu \mathrm{T})$ possible. (b) Glass paleointensity results from the southern East Pacific Rise compared to global field model of Jackson et al. (2000) that illustrate how paleointensity data can be used to infer eruption ages. The ages inferred from this comparison are consistent with all geological data and radiometric dates from these flows. (a) Modified from Carlut J, Cormier M-H, Kent DV, Donnelly KE, and Langmuir CH (2004) Timing of volcanism along the northern East Pacific Rise based on paleointensity experiments on basaltic glasses. Journal of Geophysical Research 109: B04104 doi:10.1029/ 2003JB002672. (b) Modified from Bowles J, Gee JS, Kent DV, Bergmanis E, and Sinton J (2005) Cooling rate effects on paleointensity estimates in submarine basaltic glass and implications for dating young flows. Geochemistry Geophysics Geosystems 6: Q07002 doi:1029/2004GC000900.

determinations (551 accepted of 991 basalt glass samples analyzed; Bowles et al., 2006), further illustrate the potential for dating lavas and more generally, for discriminating whether eruptions were synchronous. A cooling rate bias in Thellier paleointensities was shown not to be as important as initially suspected in rapidly cooled submarine basaltic glasses (Bowles et al., 2005). However, terrain effects may be an important source of uncertainty in absolute plaeointensity values in some settings, such as the Juan de Fuca Ridge where there are large amplitude magnetic anomalies (Carlut and Kent, 2000). Ultimately, the reliability of paleointensities for dating depends on the reference field model, which could be improved considerably with higher quality (and better dated) Thellier data on archeological and geologic materials. This would also allow better calibration of sedimentary relative paleointensity records, which are used for making comparisons over time intervals beyond the radiocarbon-dated record (e.g., Gee et al., 2000).

Marine magnetic surveys have traditionally used total field sensors that rely on well-established physical constants (e.g. the proton gyromagnetic ratio for proton precession magnetometer) and thus provide accurate $(\sim \ln \mathrm{T})$ field intensity data with negligible drift. The utility of such total field measurements, however, is limited in certain geometries $(\mathrm{N} \backslash \mathrm{S}$ spreading ridges near the magnetic equator generate very low amplitude total field anomalies) and external field variations, particularly at low magnetic latitudes, may further inhibit the identification of spreadingrelated anomalies. The use of total field magnetic gradiometers, two sensors typically deployed with a horizontal separation of $>100 \mathrm{~m}$, allow recognition and removal of a significant portion of the external field variations (e.g., Roeser et al., 2002). With the development of high resolution $(\sim 0.01 \mathrm{nT})$ total field sensors, this technique shows considerable promise for facilitating the recognition of low-amplitude anomalies at equatorial latitudes. Measurement of the vector components of the anomalous field also provides two distinct advantages that may aid in recognition of lineated (geomagnetic) anomalies. Perhaps the most useful attribute of vector anomaly data is the ability to characterize, with a single profile, the degree to which the magnetic source is two dimensional (Blakely et al., 1973; Parker and O'Brien, 1997). Aeromagnetic vector profiles, where the sensor is typically mounted on a gyro-stabilized platform, have been used to estimate the spreading 
(a)
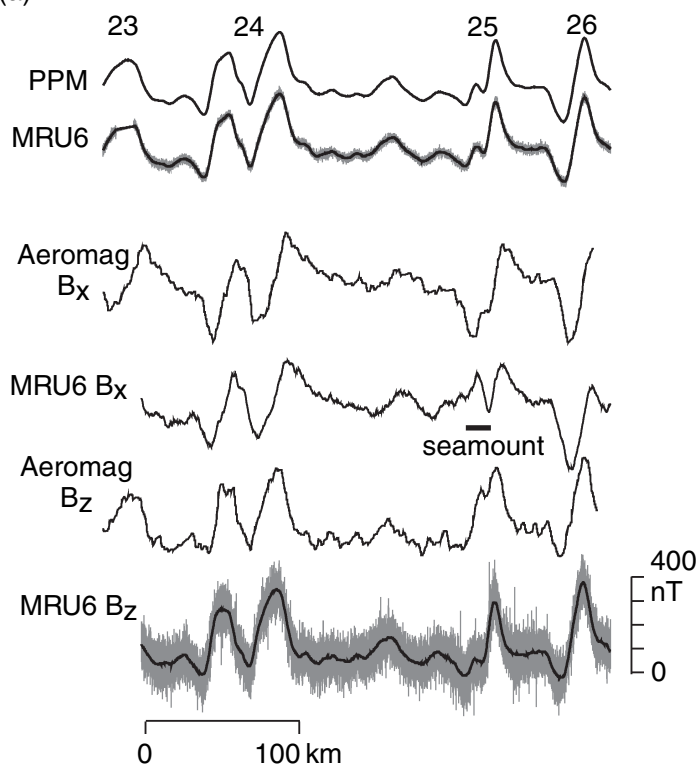

(b)

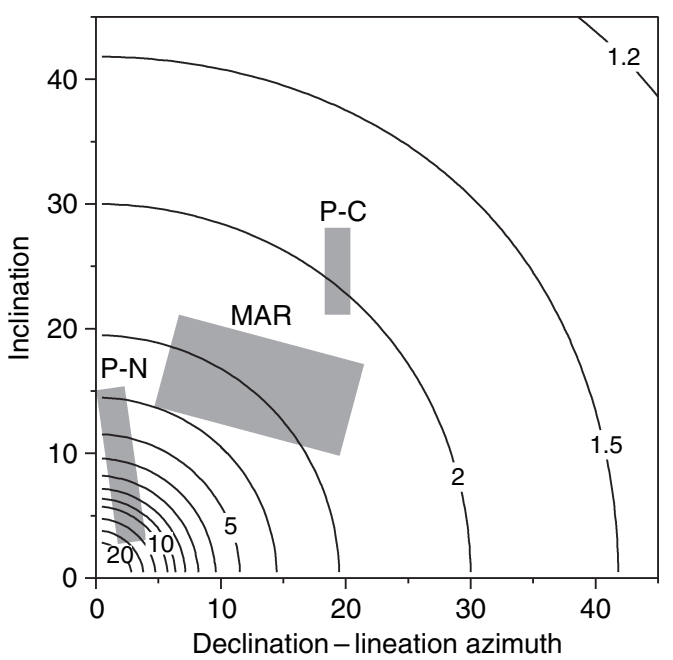

Figure 38 Anomaly data from a surface towed vector magnetometer and plot of amplitude ratio of vector components relative to total field anomalies (Gee and Cande, 2002). (a) Comparison of vector anomalies measured by aircraft and with towed vector magnetometer. Upper panel shows comparison of total field anomaly from proton precession magnetometer (PPM) and vector magnetometer (MRU6). Bz and Bx are the vertical and along track vector anomalies. (b) Ratio of amplitudes of vector components and total field anomaly (contours) for a perfectly two-dimensional source. This ratio depends on the angular difference between the spreading lineation and the ambient field declination, as well as the remanent inclination. The boxes delineate the range of these parameters for the equatorial Pacific-Nazca (P-N), Pacific-Cocos (P-C) and Mid-Atlantic Ridge (MAR) ridge systems.

lineation direction and to map low-amplitude anomalies in the equatorial Pacific (Horner-Johnson and Gordon, 2003; Parker and O'Brien, 1997). Shipboard three axis magnetometers have also been used to determine the location and azimuth of magnetization contrasts in several areas (e.g., Korenaga, 1995; Seama et al., 1993; Yamamoto et al., 2005). Towed vector magnetometer systems can effectively eliminate the ship effect and resolve vector anomalies on the order of 30-50 nT (Figure 38; Gee and Cande, 2002).

Although many high-resolution magnetic studies are conducted near the ridge crest, emerging technologies may also allow documentation of the seafloor geomagnetic signal throughout the ocean basins. A relevant new platform for vector and total field magnetic instruments would be on unmanned aerial vehicles (UAVs) for surveying in the marine environment. Deployments of UAVs from oceanographic research vessels would allow multifold increases in magnetic coverage at spatial resolutions comparable to sea-surface data. High-density magnetic data are necessary to quantitatively evaluate the relative contributions from a lineated or coherent geomagnetic source and nonlineated heterogeneities in the recording medium originating from crustal accretionary processes. Of particular interest are regions like the $\sim 25 \%$ of the ocean floor that is encompassed by the KQZ $(\sim 84-122 \mathrm{Ma})$, which remain virtually uncharted in terms of fundamental properties such as spreading history and the possible presence of lineations that might be related to geomagnetic variations. There are also virtually no deep crustal drill holes in the KQZ to document the magnetization of oceanic crust that formed in this unusual time interval of no geomagnetic reversals. Tools are thus available that should allow us to significantly increase our understanding of the source of oceanic magnetic anomalies and geomagnetic variations over timescales ranging from $10^{3}$ to $10^{8}$ years.

\section{Acknowledgments}

The authors gratefully acknowledge the support of various NSF grants over more than a decade that allowed much of this work to be completed. Lamont-Doherty Earth Observatory contribution 6992. 


\section{References}

Acton GD, Petronotis KE, Cape CD, Ilg SR, Gordon RG, and Bryan PC (1996) A test of the geocentric axial dipole hypothesis from an analysis of the skewness of the central marine magnetic anomaly. Earth and Planetary Science Letters 144: 337-346.

Agrinier P and Cannat M (1997) Oxygen-isotope constraints on serpentinization processes in ultramafic rocks from the MidAtlantic Ridge $\left(23^{\circ} \mathrm{N}\right)$. Proceedings of the Ocean Drilling Program, Scientific Results 153: 381-388.

Allerton S and Tivey MA (2001) Magnetic polarity structure of the lower oceanic crust. Geophysical Research Letters 28: 423-426.

Allerton S, Worm HU, and Stokking LB (1996) Paleomagnetic and rock magnetic properties of Hole 896A. Proceedings of the Ocean Drilling Program, Scientific Results 148: 217-226.

Anonymous (1979) Magnetostratigraphic polarity units-A supplementary chapter of the ISSC International Stratigraphic Code. Geology 7: 578-583.

Atwater T and Mudie JD (1973) Detailed near-bottom geophysical study of the Gorda Rise. Journal of Geophysical Research 78: 8665-8686.

Banerjee SK (1980) Magnetism of the oceanic crust: Evidence from ophiolite complexes. Journal of Geophysical Research 85: 3557-3566.

Bazin S, Harding AJ, Kent GM, et al. (2001) Three-dimensional shallow crustal emplacement at the 9 degrees $03 \mathrm{~N}$ overlapping spreading center on the East Pacific Rise: Correlations between magnetization and tomographic images. Journal of Geophysical Research 106: 16101-16117.

Berggren WA, Kent DV, Swisher CC, and Aubry MP (1995) A revised Cenozoic geochronology and chronostratigraphy. In: Berggren WA, Kent DV, Aubry MP, and Hardenbol J (eds.) Geochronology Time Scales and Global Stratigraphic Correlations, SEPM Special publication 54, pp. 129-212. Tulsa (OK): SEPM.

Beske-Diehl SJ (1990) Magnetization during low-temperature oxidation of sea-floor basalts - no largescale chemical remagnetization. Journal of Geophysical Research 95: 21413-21432.

Billups K, Palike H, Channell JET, Zachos JC, and Shackleton NJ (2004) Astronomic calibration of the Late Oligocene through Early Miocene geomagnetic polarity time scales. Earth and Planetary Science Letters 224: 33-44.

Blackman DK, lldefonse B, John BE, Ohara Y, Miller DJ, and MacLeod CJ (2006) Oceanic core complex formation, Atlantis Massif, Proceedings of the IODP-MI, Vol. 304/305. Integrated Ocean Drilling Program Management International, Inc., for the Integrated Ocean Drilling Program. http://iodp.tamu.edu/publications/exp304_305/ 30405title.htm (accessed on Jan 2007).

Blakely RJ (1974) Geomagnetic reversals and crustal spreading rates during the Miocene. Journal of Geophysical Research 79: 2979-2985.

Blakely RJ (1976) An age dependent, two-layer model for marine magnetic anomalies. American Geophysical Union Monographs 19: 227-234.

Blakely RJ, Cox A, and Lufer EJ (1973) Vector magnetic data for detecting short polarity intervals in marine magnetic profiles. Journal of Geophysical Research 78: 6977-6983.

Bleil U and Petersen N (1983) Variations in magnetization intensity and low-temperature titanomagnetite oxidation of ocean floor basalts. Nature 301: 384-388.

Bohnenstiehl DR and Carbotte SM (2001) Faulting patterns near $19^{\circ} 30^{\prime} \mathrm{S}$ on the East Pacific Rise: Fault formation and growth at a superfast spreading center. Geochemistry Geophysics Geosystems 2(9): doi:10.1029/2001GC000156.

Bosum W and Scott JH (1988) Interpretation of magnetic logs in basalt, Hole 418A: Proceedings of the Ocean Drilling Program, Scientific Results 102: 77-95.

Bowers NE, Cande SC, Gee JS, Hildebrand JA, and Parker RL (2001) Fluctuations of the paleomagnetic field during chron C5 as recorded in near-bottom marine magnetic anomaly data. Journal of Geophysical Research 106: 26379-26396.

Bowles J, Gee JS, Kent DV, Bergmanis E, and Sinton J (2005) Cooling rate effects on paleointensity estimates in submarine basaltic glass and implications for dating young flows. Geochemistry Geophysics Geosystems 6: Q07002 (doi:1029/2004GC000900).

Bowles J, Gee JS, Kent DV, Perfit M, Soule A, and Fornari D (2006) Paleointensity results from $9^{\circ}-10^{\circ} \mathrm{N}$ on the East Pacific Rise: Implications for timing and extent of eruptive activity. Geochemistry Geophysics Geosystems 7: Q06006 (doi:1029/2005GC001141).

Bowles J, Tauxe L, Gee J, McMillan D, and Cande SC (2003) The source of tiny wiggles in chron C5: A comparison of sedimentary relative intensity and marine magnetic anomalies. Geochemistry Geophysics Geosystems 4(6): 1049 (doi:10.1029/2002GC000489).

Cande SC (1976) A paleomagnetic pole from Late Cretaceous marine magnetic anomalies in the Pacific. Geophysical Journal of the Royal Astronomical Society 44: 547-566.

Cande SC (1978) Anomalous behavior of the paleomagnetic field inferred from the skewness of Anomalies 33 and 34. Earth and Planetary Science Letters 40: 275-286.

Cande SC and Gee JS (2001) Evidence for the rapid low-temperature alteration of oeceanic crust on the Pacific-Antarctic Ridge from the amplitude envelope of magnetic anomalies. Eos, Transactions American Geophysical Union 82: F348.

Cande SC and Kent DV (1976) Constraints imposed by the shape of marine magnetic anomalies on the magnetic source. Journal of Geophysical Research 81: 4157-4162.

Cande SC and Kent DV (1985) Comment on "Tectonic rotations in extensional regimes and their paleomagnetic consequences for ocean basalts" by K.L. Verosub and E.M. Moores. Journal of Geophysical Research 90(B6): 4647-4651.

Cande SC and Kent DV (1992a) A new geomagnetic polarity time scale for the Late Cretaceous and Cenozoic. Journal of Geophysical Research 97: 13917-13951.

Cande SC and Kent DV (1992b) Ultrahigh resolution marine magnetic anomaly profiles: A record of continuous paleointensity variations. Journal of Geophysical Research 97: 15075-15083.

Cande SC and Kent DV (1995) Revised calibration of the geomagnetic polarity time scale for the Late Cretaceous and Cenozoic. Journal of Geophysical Research 100: 6093-6095.

Cande SC and LaBrecque JL (1974) Behaviour of the Earth's paleomagnetic field from small scale marine magnetic anomalies. Nature 247: 26-28.

Cande SC, Larson RL, and LaBrecque JL (1978) Magnetic lineations in the Pacific Jurassic Quiet Zone. Earth and Planetary Science Letters 41: 434-440.

Cannat M (1993) Emplacement of mantle rocks in the seafloor at mid-ocean ridges. Journal of Geophysical Research 98: 4163-4172.

Cannat M, Karson JA, and Miller DJ (1995) Proceedings of the Ocean Drilling Program, Initial Reports 153: 798 (College Station, TX, Ocean Drilling Program).

Cannat M, Lagabrielle Y, Bougault $\mathrm{H}$, et al. (1997) Ultramafic and gabbroic exposures at the Mid-Atlantic Ridge: Geological mapping in the $15^{\circ} \mathrm{N}$ region. Tectonophysics 279: 193-213. 
Carbotte SM and Macdonald KC (1990) Causes of variation in fault-facing direction on the ocean floor. Geology 18: $749-752$.

Carlut J, Cormier M-H, Kent DV, Donnelly KE, and Langmuir $\mathrm{CH}$ (2004) Timing of volcanism along the northern East Pacific Rise based on paleointensity experiments on basaltic glasses. Journal of Geophysical Research 109: B04104 (doi:10.1029/2003JB002672).

Carlut J and Kent DV (2000) Paleointensity record in zero-age submarine basalt glasses: Testing a new dating technique for recent MORBs. Earth and Planetary Science Letters 183: 389-401.

Channell JET, Erba E, Nakanishi M, and Tamaki K (1995) Late Jurassic-Early Cretaceous time scales and oceanic magnetic anomaly block models. In: Berggren WA, Kent DV, Aubry M-P, and Hardenbol J (eds.) Geochronology, Time Scales and Global Stratigraphic Correlations, SEPM Special publication 54, pp. 51-63. Tulsa (OK): SEPM.

Channell JET, Galeotti S, Martin EE, Billups K, Scher HD, and Stoner JS (2003) Eocene to Miocene magnetostratigraphy, biostratigraphy, and chemostratigraphy at ODP Site 1090 (sub-Antarctic South Atlantic). Geological Society of America Bulletin 115: 607-623.

Channell JET, Lowrie W, Pialli P, and Venturi F (1984) Jurassic magnetic stratigraphy from Umbrian (Italian) land sections. Earth and Planetary Science Letters 68: 309-325.

Christeson GL, Purdy GM, and Fryer GJ (1992) Structure of young upper crust at the East Pacific Rise near 9 $30^{\prime} \mathrm{N}$. Geophysical Research Letters 19: 1045-1048.

Clement BM (2004) Dependence of the duration of geomagnetic polarity reversals on site latitude. Nature 428: 637-640.

Cogné JP and Humler E (2006) Trends and rhythms in global seafloor generation rate. Geochemistry Geophysics Geosystems 7: 17.

Cogné JP, Francheteau J, Courtillot V, et al. (1995) Large rotation of the Easter microplate as evidenced by oriented paleomagnetic samples from the ocean floor. Earth and Planetary Science Letters 136: 213-222.

Cox A (1968) Lengths of geomagnetic polarity intervals. Journal of Geophysical Research 73: 3247-3260.

Cox A, Doell RR, and Dalrymple GB (1964) Reversals of the Earth's magnetic field. Science 144: 1537-1543.

Cronin M, Tauxe L, Constable C, Selkin P, and Pick T (2001) Noise in the quiet zone. Earth and Planetary Science Letters 190: 13-30.

Day R, Osterhoudt M, and Bleil U (1983) Rock magnetism of igneous rocks from Deep Sea Drilling Project Sites 482, 483, and 485. Initial Reports of the Deep Sea Drilling Project 65: 727-736.

Detrick R, Honnorez J, Bryan WB, and Juteau T (1988) Proceedings of the Ocean Drilling Program, Initial Reports vol. 106/109: 249 (College Station, TX: Ocean Drilling Program).

Detrick RS, Harding AJ, Kent GM, Orcutt JA, Mutter JC, and Buhl P (1993) Seismic structure of the southern East Pacific Rise. Science 259: 499-503.

Dick HJB, Natland JH, Alt JC, et al. (2000) A long in situ section of the lower ocean crust: Results of ODP Leg 176 drilling at the Southwest Indian Ridge. Earth and Planetary Science Letters 179: 31-51.

Dick HJB, Natland JH, and Miller DJ (1999) Proceedings of the Ocean Drilling Program, Initial Reports 176, College Station, TX: Ocean Drilling Program.

Dick HJB, Schouten H, Meyer PS, et al. (1991) Tectonic evolution of the Atlantis II Fracture Zone. Proceedings of the Ocean Drilling Program, Scientific Results 118: 359-398.

Doubrovine PV and Tarduno JA (2004) Self-reversed magnetization carried by titanomaghemite in oceanic basalts. Earth and Planetary Science Letters 222: 959-969.
Dyment J and Arkani-Hamed J (1995) Spreading-ratedependent magnetization of the oceanic lithosphere inferred from the anomalous skewness of marine magnetic anomalies. Geophysical Journal International 121: 789-804.

Dyment J, Arkani-Hamed J, and Ghods A (1997) Contribution of serpentinized ultramafics to marine magnetic anomalies at slow and intermediate spreading centers: Insights from the shape of the anomalies. Geophysical Journal International 129: 691-701.

Evans HF and Channell JET (2003) Upper Miocene magnetic stratigraphy at ODP Site 1092 (sub-Antarctic South Atlantic): Recognition of 'cryptochrons' in C5n.2n. Geophysical Journal International 153: 483-496.

Evans HF, Westerhold T, and Channell JET (2004) ODP Site 1092: Revised composite depth section has implications for Upper Miocene 'cryptochrons'. Geophysical Journal International 156: 195-199.

Facey D, Housden J, and O'Reilly W (1985) A magneto-petrological study of rocks from Leg 83, Hole 504B, Deep Sea Drilling Project. Initial Reports of the Deep Sea Drilling Project 83: 339-346.

Fornari DJ, Haymon RM, Perfit MR, Gregg TKP, and Edwards MH (1998) Axial summit trough of the East Pacific Rise $9^{\circ}-10^{\circ} \mathrm{N}$ : Geological characteristics and evolution of the axial zone on fast spreading mid-ocean ridges. Journal of Geophysical Research 103: 9827-9855.

Francheteau J, Armijo R, Cheminee JL, Hekinian R, Lonsdale P, and Blum N (1992) Dyke Complex of the East Pacific Rise Exposed in the Walls of Hess Deep and the Structure of the Upper Oceanic-Crust. Earth and Planetary Science Letters 111: 109-121.

Früh-Green GL, Plas A, and Lecuyer C (1996) Petrologic and stable isotope constraints on hydrothermal alteration and serpentinization of the EPR shallow mantle at Hess Deep (Site 895). Proceedings of the Ocean Drilling Program, Scientific Results 147: 255-288.

Furuta T (1983) Magnetic properties of basalt samples from Holes 504B and 505B on the Costa Rica Rift, Deep Sea Drilling Project Legs 69 and 70. Initial Reports of the Deep Sea Drilling Project 69: 711-720.

Furuta T (1993) Magnetic properties and ferromagnetic mineralogy of oceanic basalts. Geophysical Journal International 113: 95-114.

Furuta T and Levi S (1983) Basement paleomagnetism of Hole 504B. Initial Reports of the Deep Sea Drilling Project 69: 697-703.

Gallet $Y$ and Hulot G (1997) Stationary and nonstationary behaviour within the geomagnetic polarity time scale. Geophysical Research Letters 24: 1875-1878.

Garces M and Gee JS (2007) Paleomagnetic evidence of large footwall rotations associated with low-angle faults at the Mid-Atlantic Ridge. Geology 35: 279-282.

Gee J and Kent DV (1994) Variations in layer 2A thickness and the origin of the central anomaly magnetic high. Geophysical Research Letters 21: 297-300.

Gee $J$ and Kent DV (1997) Magnetization of axial lavas from the southern East Pacific Rise (14 $\left.{ }^{\circ}-23^{\circ} \mathrm{S}\right)$ : Geochemical controls on magnetic properties. Journal of Geophysical Research 102: $24,873-24,886$.

Gee J and Kent DV (1998) Magnetic telechemistry and magmatic segmentation on the southern East Pacific Rise. Earth and Planetary Science Letters 164: 379-385.

Gee J and Kent DV (1999) Calibration of magnetic granulometric trends in oceanic basalts. Earth and Planetary Science Letters 170: 377-390.

Gee $J$ and Meurer WP (2002) Slow cooling of middle and lower oceanic crust inferred from multicomponent magnetizations of gabbroic rocks from the Mid-Atlantic Ridge south of the 
Kane fracture zone (MARK) area. Journal of Geophysical Research 107: 3-1/3-18.

Gee J, Natland JH, Hurst SD, and Nilsson K (1992) Magnetic properties of ocean crust samples from Hess Deep: Implications for marine magnetic anomalies. EOS, Transactions American Geophysical Union 73: 490.

Gee J, Schneider DA, and Kent DV (1996) Marine magnetic anomalies as recorders of geomagnetic intensity variations. Earth and Planetary Science Letters 144: 327-335.

Gee JS and Cande SC (2002) A surface-towed vector magnetometer. Geophysical Research Letters 29(14): doi: 10.1029/ 2002GL015245

Gee JS, Cande SC, Hildebrand JA, Donnelly K, and Parker RL (2000) Geomagnetic intensity variations over the past $780 \mathrm{kyr}$ obtained from near-seafloor magnetic anomalies. Nature 408: 827-832.

Gee JS, Lawrence RM, and Hurst SD (1997) Remanence characteristics of gabbros from the MARK area: Implications for crustal magnetization. Proceedings of the Ocean Drilling Program, Scientific Results 153: 429-436.

Gillis K, Mevel C, and Allan J (1993) Proceedings of the Ocean Drilling Program, Initial Reports 147: 366 (College Station, TX, Ocean Drilling Program).

Gradstein FM, Ogg JG, and Smith AG (2004) A Geologic Time Scale 2004, 589 pp. Cambridge: Cambridge University Press.

Grommé CS, Mankinen EA, Marshall M, and Coe RS (1979) Geomagnetic paleointensities by the Thelliers' method from submarine pillow basalts: Effects of seafloor weathering. Journal of Geophysical Research 84: 3553-3575.

Guyodo Y and Valet J-P (1999) Global changes in intensity of the Earth's magnetic field during the past $800 \mathrm{kyr}$. Nature 399: 249-252.

Hall JM and Muzzatti A (1999) Delayed magnetization of the deeper kilometer of oceanic crust at Ocean Drilling Project Site 504. Journal of Geophysical Research 104: 12843-12851.

Handschumacher DW, Sager WW, Hilde TWC, and Bracey DR (1988) Pre-Cretaceous tectonic evolution of the Pacific plate and extension of the geomagnetic polarity reversal time scale with implications for the origin of the Jurassic 'Quiet Zone'. Tectonophysics 155: 365-380.

Harding AJ, Kent GM, and Orcutt JA (1993) A multichannel seismic investigation of upper crustal structure at $9^{\circ} \mathrm{N}$ on the East Pacific Rise: Implications for crustal accretion. Journal of Geophysical Research 98: 13925-13944.

Harrison CGA (1987) Marine magnetic anomalies-the origin of the stripes. Annual Review of Earth and Planetary Science Letters 15: 505-543.

Hartl P, Tauxe L, and Constable C (1993) Early Oligocene geomagnetic field behavior from Deep Sea Drilling Project Site 522. Journal of Geophysical Research 98: 19649-19665.

Heirtzler JR, Dickson GO, Herron EM, Pitman WC, and Le Pichon X (1968) Marine magnetic anomalies, geomagnetic field reversals, and motions of the ocean floor and continents. Journal of Geophysical Research 73: 2119-2136.

Helsley CE and Steiner MC (1969) Evidence for long intervals of normal polarity during the Cretaceous period. Earth and Planetary Science Letters 5: 325-332.

Hilgen FJ (1991) Extension of the astronomically calibrated (polarity) time scale to the Miocene/Pliocene boundary. Earth and Planetary Science Letters 107: 349-368.

Hooft EEE, Schouten H, and Detrick RS (1996) Constraining crustal emplacement processes from the variation in seismic layer 2A thickness at the East Pacific Rise. Earth and Planetary Science Letters 142: 289-309.

Horner-Johnson BC and Gordon RG (2003) Equatorial Pacific magnetic anomalies identified from vector aeromagnetic data. Geophysical Journal International 155: 547-556.
Hurst SD, Karson JA, and Verosub KL (1994) Paleomagnetism of tilted dikes in fast spread oceanic crust exposed in the Hess Deep Rift: Implications for spreading and rift propagation. Tectonics 13: 789-802.

Hussenoeder SA, Tivey MA, Schouten H, and Searle RC (1996) Near-bottom magnetic survey of the Mid-Atlantic Ridge axis, $24^{\circ}-24^{\circ} 40^{\prime} \mathrm{N}$ : Implications for crustal accretion at slow spreading ridges. Journal of Geophysical Research 10: 22051-22069.

Irving E (1970) The mid-Atlantic Ridge at $45^{\circ} \mathrm{N}$. XIV. Oxidation and magnetic properties of basalt; review and discussion. Canadian Journal of Earth Sciences 7: 1528-1538.

Irving E and Pullaiah G (1976) Reversals of the geomagnetic field, magnetostratigraphy, and relative magnitude of paleosecular variation in the Phanerozoic. Earth Science Reviews 12: 35-64.

Jackson A, Jonkers ART, and Walker MR (2000) Four centuries of geomagnetic secular variation from historical records. Philosophical Transactions of the Royal Society London A 358: 957-990.

John BE, Foster DA, Murphy JM, et al. (2004) Determining the cooling history of insitu lower oceanic crust - Atlantis Bank, SW Indian Ridge. Earth and Planetary Science Letters 222: $145-160$.

Johnson HP (1978) Rock magnetic properties of igneous rock samples - Leg 45. Initial Reports of the Deep Sea Drilling Project 45: 397-406.

Johnson HP and Atwater T (1977) Magnetic study of basalts from the Mid-Atlantic Ridge, lat $37^{\circ} \mathrm{N}$. Geological Society of America Bulletin 88: 637-647.

Johnson HP, Kent DV, Tivey MA, Gee JS, Larson RL, and Embley RW (1997) Conference on the Magnetization of the Oceanic Crust Steers Future Research. EOS, Transactions, American Geophysical Union 78: 199-200.

Johnson HP and Pariso JE (1993) Variations in oceanic crusta magnetization: Systematic changes in the last 160 million years. Journal of Geophysical Research 98: 435-445.

Johnson HP and Salem BL (1994) Magnetic properties of dikes from the oceanic upper crustal section. Journal of Geophysical Research 99: 21733-21740.

Johnson HP and Tivey MA (1995) Magnetic properties of zeroage oceanic crust; a new submarine lava flow on the Juan de Fuca ridge. Geophysical Research Letters 22: 175-178.

Juarez MT, Osete ML, Melendez G, Langereis CG, and Zijderveld JDA (1994) Oxfordian magnetostratigraphy of the Aguilon and Tosos sections (Iberian Range, Spain) and evidence of a pre-Oligocene overprint. Earth and Planetary Science Letters 85: 195-211.

Juarez MT, Tauxe L, Gee JS, and Pick T (1998) The intensity of the Earth's magnetic field over the past 160 million years. Nature 394: 878-881.

Juster TC, Grove TL, and Perfit MR (1989) Experimental constraints on the generation of FeTi basalts, andesites, and rhyodacites at the Galapagos spreading center, $85^{\circ} \mathrm{W}$ and $95^{\circ}$ W. Journal of Geophysical Research 94: 9251-9274.

Karson JA, Klein EM, Hurst SD, et al. (2002) Structure of uppermost fast-spread oceanic crust exposed at the Hess Deep Rift: Implications for subaxial processes at the East Pacific Rise. Geochemistry Geophysics Geosystems 3(1): 4 (doi:10.129/2001GC000155).

Kelemen PB, Kikawa E, and Miller DJ (2004) Proceedings of the Ocean Drilling Program, Initial Reports 209: (College Station, TX, Ocean Drilling Program).

Kelso PR, Banerjee SK, and Worm HU (1991) The effect of lowtemperature hydrothermal alteration on the remanent magnetization of synthetic titanomagnetites; a case for acquisition of chemical remanent magnetization. Journal of Geophysical Research 96: 19545-19553. 
Kent DV and Gee J (1994) Grain size-dependent alteration and the magnetization of oceanic basalts. Science 265: 1561-1563.

Kent DV and Gee J (1996) Magnetic alteration of zero-age oceanic basalt. Geology 24: 703-706.

Kent DV, Honnorez BM, Opdyke ND, and Fox PJ (1978) Magnetic properties of dredged oceanic gabbros and the source of marine magnetic anomalies. Geophysical Journal of the Royal Astronomical Society 55: 513-537.

Kidd RGW (1977) The nature and shape of the sources of marine magnetic anomalies. Earth and Planetary Science Letters 33: 310-320.

Kikawa E and Ozawa K (1992) Contribution of oceanic gabbros to sea-floor spreading magnetic anomalies. Science 258: 796-799.

Kikawa E and Pariso JE (1991) Magnetic properties of gabbros from Hole 735B, Southwest Indian Ridge. Proceedings of the Ocean Drilling Program, Scientific Results 118: 285-307.

Kinoshita H, Furuta T, and Kawahata H (1985) Magnetic properties and alteration in basalt, Hole 504B, Deep Sea Drilling Project Leg 83. Initial Reports of the Deep Sea Drilling Project 83: $331-338$.

Klitgord KD (1976) Sea-floor spreading: The central anomaly magnetization high. Earth and Planetary Science Letters 29: 201-209.

Korenaga J (1995) Comprehensive analysis of marine magnetic vector anomalies. Journal of Geophysical Research 100: 365-378.

Korte M and Constable CG (2005) The geomagnetic dipole moment over the last 7000 years - new results from a global model. Earth and Planetary Science Letters 236: 348-358.

Krasa D, Shcherbakov VP, Kunzmann T, and Petersen N (2005) Self-reversal of remanent magnetization in basalts due to partially oxidized titanomagnetites. Geophysical Journal International 162: 115-136.

Krijgsman W and Kent DV (2004) Non-uniform occurrence of short-term polarity fluctuations in the geomagnetic field? New results from Middle to Late Miocene sediments of the North Atlantic (DSDP Site 608). In: Channell JET, Kent DV, Lowrie W, and Meert J (eds.) AGU Geophysical Monograph 145: Timescales of the Paleomagnetic Field, pp. 161-174. Washington, DC: American Geophysical Union.

Kriner KA, Pockalny RA, and Larson RL (2006) Bathymetric gradients of lineated abyssal hills: Inferring seafloor spreading vectors and a new model for hills formed at ultra-fast rates. Earth and Planetary Science Letters 242: 98-110.

Lancelot YP, Larson RL, and Fisher A (1990) Proceedings of the Ocean Drilling Program, Initial Reports 129: 488 (College Station, TX, Texas A \& M University, Ocean Drilling Program). Lanci L and Lowrie W (1997) Magnetostratigraphic evidence that 'tiny wiggles' in the oceanic magnetic anomaliy record represent geomagnetic paleointensity variations. Earth and Planetary Science Letters 148: 581-592.

Lanci L, Pares JP, Channell JET, and Kent DV (2004) Miocene Magnetostratigraphy from Equatorial Pacific sediments (ODP Site 1218, Leg 199). Earth and Planetary Science Letters 226: 207-224.

Lanci L, Pares JP, Channell JET, and Kent DV (2005) Oligocene magnetostratigraphy from equatorial Pacific sediments (ODP Sites 1218 and 1219, Leg 199). Earth and Planetary Science Letters 237: 617-634.

Larson RL (1977) Early Cretaceous breakup of Gondwanaland off western Australia. Geology 5: 57-60.

Larson RL and Chase CG (1972) Late Mesozoic evolution of the western Pacific Ocean. Geological Society of America Bulletin 83: 3627-3644.

Larson RL and Hilde TWC (1975) A revised time scale of magnetic reversals for the Early Cretaceous and Late Jurassic. Journal of Geophysical Research 80: 2586-2594.
Larson RL and Pitman WC (1972) Worldwide correlation of Mesozoic magnetic anomalies, and its implications. Geological Society of America Bulletin 83: 3645-3662.

Larson RL and Spiess FN (1969) The East Pacific Rise crest: A near-bottom geophysical profile. Science 163: 68-71.

Lawrence RM, Gee JS, and Karson JA (2002) Magnetic anisotropy of serpentinized peridotites from the MARK area: Implications for the orientation of mesoscopic structures and major fault zones. Journal of Geophysical Research 107: 14.

Levi S (1980) Paleomagnetism and some magnetic properties of basalts from the Bermuda Triangle. Initial Reports of the Deep Sea Drilling Project 51,52,53: 1363-1378.

Levi S, Audunsson H, Duncan RA, Kristjansson L, Gillot P-Y, and Jakobsson SP (1990) Late Pleistocene geomagnetic excursion in Icelandic lavas: Confirmation of the Laschamp excursion. Earth and Planetary Science Letters 96: 443-457.

Lewis BTR, Snydsman WE, McClain JS, Holmes ML, and Lister CRB (1983) Site survey results at the mouth of the Gulf of California, Leg 65, Deep Sea Drilling Project: Initial Reports of the Deep Sea Drilling Project 65: 309-317.

Lourens LJ, Hilgen FJ, Shackleton NJ, Laskar J, and Wilson D (2004) The Neogene period. In: Gradstein FM, Ogg JG, and Smith AG (eds.) A Geologic Time Scale 2004, pp. 409-440. Cambridge: Cambridge University Press.

Lowrie W (1977) Intensity and direction of magnetization in oceanic basalts. Journal of the Geological Society of London 133: 61-82.

Lowrie W and Alvarez W (1981) One hundred million years of geomagnetic polarity history. Geology 9: 392-397.

Lowrie W and Kent DV (2004) Geomagnetic polarity timescales and reversal frequency regimes. In: Channell JET, Kent DV, Lowrie W, and Meert J (eds.) AGU Geophysical Monograph 145: Timescales of the Paleomagnetic Field, pp. 117-129. Washington, DC: American Geophysical Union.

Macdonald KC (1977) Near-bottom magnetic anomalies, asymmetric spreading, oblique spreading, and tectonics of the Mid-Atlantic Ridge near lat $37^{\circ} \mathrm{N}$. Geological Society of America Bulletin 88: 541-555.

Macdonald KC, Miller SP, Luyendyk BP, Atwater T, and Shure L (1983) Investigation of a Vine-Matthews magnetic lineation from a submersible: The source and character of marine magnetic anomalies. Journal of Geophysical Research 88: 3403-3418.

Marshall M and Cox A (1971) Magnetism of pillow basalts and their petrology. Geological Society of America Bulletin 82: 537-552.

Marshall M and Cox A (1972) Magnetic changes in pillow basalt due to sea-floor weathering. Journal of Geophysical Research 77: 6459-6469.

Matzka J, Krasa D, Kunzmann T, Schult A, and Petersen N (2003) Magnetic state of 10-40 Ma old ocean basalts and its implications for natural remanent magnetization. Earth and Planetary Science Letters 206: 541-553.

McElhinny MW and Larson RL (2003) Jurassic dipole low defined from land and sea data. EOS, Transactions of the American Geophysical Union 84: 362-366.

McFadden PL and Merrill RT (2000) Evolution of the geomagnetic reversal rate since $160 \mathrm{Ma}$ : Is the process continuous?. Journal of Geophysical Research 105: 28455-28460.

McFadden PL, Merrill RT, and McElhinny MW (1988) Dipole/ quadrupole family modeling of paleosecular variation. Journal of Geophysical Research 93: 11583-11588.

Mejia V, Opdyke ND, and Perfit MR (1996) Paleomagnetic field intensity recorded in submarine basaltic glass from the East Pacific Rise, the last 69 KA. Geophysical Research Letters 23: 475-478.

Merrill RT, McElhinny MW, and McFadden PL (1996) The Magnetic Field of the Earth: Paleomagnetism, the Core, and the Deep Mantle, 531 pp. San Diego: Academic Press. 
Miller DJ and Christensen NI (1997) Seismic velocities of lower crustal and upper mantle rocks from the slow-spreading Mid-Atlantic Ridge, south of the Kane Transform Zone (MARK). Proceedings of the Ocean Drilling Program, Scientific Results 153: 437-454.

Nakanishi M, Tamaki K, and Kobayashi K (1989) Mesozoic magnetic anomaly lineations and seafloor spreading history of the Northwestern Pacific. Journal of Geophysical Research 94: 15437-15462.

Nakanishi M, Tamaki K, and Kobayashi K (1992) A new Mesozoic isochron chart of the Northwestern Pacific Ocean: Paleomagnetic and tectonic implications. Geophysical Research Letters 19: 693-696.

Nakanishi M and Winterer EL (1998) Tectonic history of the Pacific-Farallon-Phoenix triple junction from Late Jurassic to Early Cretaceous: An abandoned Mesozoic spreading system in the Central Pacific Basin. Journal of Geophysical Research 103: 12453-12468.

Natland JH (2002) Magnetic susceptibility as an index of the lithology and composition of gabbros, ODP Leg 176, Hole 735B, Southwest Indian Ridge. Proceedings of the Ocean Drilling Program, Scientific Results 176.

Nazarova KA (1994) Serpentinized peridotites as a possible source for oceanic magnetic anomalies. Marine Geophysical Researches 16: 455-462.

Nazarova KA, Wasilewski PJ, and Dick HJB (2000) Magnetic study of serpentinized harsburgites from the Islas Orcadas Fracture Zone. Marine Geophysical Researches 21: 475-488.

O'Reilly W (1984) Rock and Mineral Magnetism, 220 pp. New York: Chapman and Hall.

Ogg JG and Lowrie W (1986) Magnetostratigraphy of the Jurassic/Cretaceous boundary. Geology 14: 547-550.

Oufi O, Cannat M, and Horen H (2002) Magnetic properties of variably serpentinized abyssal peridotites. Journal of Geophysical Research 107(B5): doi:10.1029/2001JB000549.

Oxburgh ER and Turcotte DL (1969) Increased estimate for heat flow at oceanic ridges. Nature 223: 1354-1355.

Özdemir O and O'Reilly W (1981) High-temperature hysteresis and other magnetic properties of synthetic monodomain titanomagnetites. Physics of the Earth and Planetary Interiors 25: 406-418.

Pariso JE and Johnson HP (1989) Magnetic properties and oxide petrography of the sheeted dike complex in Hole 504B. Proceedings of the Ocean Drilling Program, Scientific Results 111: 159-167.

Pariso JE and Johnson HP (1991) Alteration processes at Deep Sea Drilling Project Ocean Drilling Program Hole 504B at the Costa Rica Rift - Implications for magnetization of oceanic crust. Journal of Geophysical Research 96: 11703-11722.

Pariso JE and Johnson HP (1993a) Do Layer 3 rocks make a significant contribution to marine magnetic anomalies? In situ magnetization of gabbros at Ocean Drilling Program Hole 735B. Journal of Geophysical Research 98: 16033-16052.

Pariso JE and Johnson HP (1993b) Do lower crustal rocks record reversals of the Earth's magnetic field? Magnetic petrology of oceanic gabbros from Ocean Drilling Program Hole 735B. Journal of Geophysical Research 98: 16013-16032.

Pariso JE, Kelso P, and Richter C (1996a) Paleomagnetism and rock magnetic properties of gabbro from Hole 894G, Hess Deep. Proceedings of the Ocean Drilling Program, Scientific Results 147: 373-381.

Pariso JE, Rommevaux C, and Sempere J-C (1996b) Threedimensional inversion of marine magnetic anomalies: Implications for crustal accretion along the Mid-Atlantic Ridge $\left(28^{\circ}-31^{\circ} 30^{\prime} \mathrm{N}\right)$. Marine Geophysical Researches 18: $85-101$.
Pariso JE, Stokking LB, and Allerton S (1995) Rock magnetism and magnetic mineralogy of a 1-km section of sheeted dikes, Hole 504B. Proceedings of the Ocean Drilling Program. Scientific Results 137/140: 253-262.

Parker RL and O'Brien MS (1997) Spectral analysis of vector magnetic field profiles. Journal of Geophysical Research 102: 24815-24824.

Pechersky DM, Tikhonov LV, and Pertsev NN (1983a) Magnetic properties of basalts, Deep Sea Drilling Project Legs 69 and 70. Initial Reports of the Deep Sea Drilling Project 69: 705-710.

Pechersky DM, Tikhonov LV, and Zolotarev BP (1983b) Rock magnetism and paleomagnetism of basalts drilled during Deep Sea Drilling Project Leg 65. Initial Reports of the Deep Sea Drilling Project 65: 717-726.

Perfit MR and Chadwick WW (1998) Magmatism at mid-ocean ridges: Constraints from volcanological and geochemical investigations. In: Buck WR (ed.) Faulting and Magmatism at Mid-Ocean Ridges, Geophysical Monograph Series 106, pp. 59-115. Washington, DC: AGU.

Perfit MR, Fornari DJ, Smith MC, Bender JF, Langmuir $\mathrm{CH}$, and Haymon RM (1994) Small-scale spatial and temporal variations in mid-ocean ridge crest magmatic processes. Geology 22: 375-379.

Perram LJ, Macdonald KC, and Miller SP (1990) Deep-tow magnetics near $20^{\circ} \mathrm{S}$ on the East Pacific Rise: A study of short wavelength anomalies at a very fast spreading center. Marine Geophysical Researches 12: 235-245.

Petronotis KE, Gordon RG, and Acton GD (1992) Determining palaeomagnetic poles and anomalous skewness from marine magnetic anomaly skewness data from a single plate. Geophysical Journal International 109: 209-224.

Pettigrew TJ, Casey JF, and Miller DJ (1999) Proceedings of the Ocean Drilling Program, Initial Reports 179. (College Station, TX: Ocean Drilling Program).

Pick T and Tauxe L (1993) Holocene paleointensities: Thellier experiments on submarine basaltic glass from the East Pacific Rise. Journal of Geophysical Research 98: 17949-17964.

Pick T and Tauxe L (1994) Characteristics of magnetite in submarine basaltic glass. Geophysical Journal International 119: 116-128.

Pitman WC and Heirtzler JR (1966) Magnetic anomalies over the Pacific-Antarctic ridge. Science 154: 1164-1171.

Pitman WC, Herron EM, and Heirtzler JR (1968) Magnetic anomalies in the Pacific and sea floor spreading. Journal of Geophysical Research 73: 2069-2085.

Plank T, Ludden JN, and Escutia C (2000) Proceedings of the Ocean Drilling Program, Initial Reports 185: (accessed Jan 2007) http://www-odp.tamu.edu/publications/185 IR/ 185TOC.HTM. (College Station, TX: Texas A\&M University, Ocean Drilling Program).

Pockalny RA, Larson RL, Viso RF, and Abrams LJ (2002) Bathymetry and gravity data across a mid-Cretaceous triple junction in the southwest Pacific basin. Geophysical Research Letters 29: 1007.

Pockalny RA, Smith A, and Gente P (1995) Spatial and temporal variablilty of crustal magnetization of a slowly spreading ridge: Mid-Atlantic Ridge $\left(20^{\circ}-24^{\circ} \mathrm{N}\right)$. Marine Geophysical Research 17: 301-320.

Prévot M, Derder ME-M, McWilliams M, and Thompson J (1990) Intensity of the Earth's magnetic field: Evidence for a Mesozoic dipole low. Earth and Planetary Science Letters 97: 129-139.

Raymond CA and LaBrecque JL (1987) Magnetization of the oceanic crust: Thermoremanent magnetization or chemical remanent magnetization? Journal of Geophysical Research 92: 8077-8088.

Renne PR, Scott GR, Glen JMG, and Feinberg JM (2002) Oriented inclusions of magnetite in clinopyroxene: Source of 
stable remanent magnetization in gabbros of the Messum Complex, Namibia. Geochemistry Geophysics Geosystems 3(12): 1079 (doi:10.1029/2002GC000319).

Roberts AP and Lewin-Harris JC (2000) Marine magnetic anomalies: Evidence that 'tiny wiggles' represent short-period geomagnetic polarity intervals. Earth and Planetary Science Letters 183: 375-388.

Robinson PT, Von Herzen RP, and Adamson AC (1989) Proceedings of the Ocean Drilling Program, Initial Reports 118: 826 (College Station, TX, Ocean Drilling Program).

Roeser HA, Steiner C, Schreckenberger B, and Block M (2002) Structural development of the Jurassic Magnetic Quiet Zone off Morocco and identification of Middle Jurassic magnetic lineations. Journal of Geophysical Research 107(10): doi:10.1029/2000JB000094.

Roest WR, Arkani-Hamed J, and Verhoef J (1992) The seafloor spreading rate dependence of the anomalous skewness of marine magnetic anomalies. Geophysical Journal International 109: 653-669.

Roperch P, Bonhommet N, and Levi S (1988) Paleointensity of the earth's magnetic field during the Laschamp excursion and its geomagnetic implications. Earth and Planetary Science Letters 88: 209-219.

Ryall PJ and Ade-Hall JM (1975) Radial variation of magnetic properties in submarine pillow basalt. Canadian Journal of Earth Sciences 12: 1959-1969.

Sager WW, Weiss MA, Tivey MA, and Johnson HP (1998) Geomagnetic polarity reversal model of deep-tow profiles from the Pacific Jurassic 'Quiet Zone'. Journal of Geophysical Research 103: 5269-5286.

Sayanagi K and Tamaki K (1992) Long-term variations in magnetization intensity with crustal age in the Northeast Pacific, Atlantic, and Southeast Indian Oceans. Geophysical Research Letters 12: 2369-2372.

Schneider DA (1988) An estimate of the long-term non-dipole field from marine magnetic anomalies. Geophysical Research Letters 15: 1105-1108.

Schneider DA (1995) Paleomagnetism of some Leg 138 sediments: Detailing Miocene magnetostratigraphy. Proceedings of the Ocean Drilling Program, Scientific Results 138: 59-72.

Schouten H (2002) Paleomagnetic inclinations in DSDP Hole 417D reconsidered: Secular variation or variable tilting? Geophysical Research Letters 29(7): doi:10.1029/ 2001 GL013581.

Schouten H and Cande SC (1976) Paleomagnetic poles from marine magnetic anomalies. Geophysical Journal of the Royal Astronomical Society 44: 567-575.

Schouten H and Denham CR (2000) Comparison of volcanic construction in the Troodos ophiolite and oceanic crust using paleomagnetic inclinations from Cyprus Crustal Study Project (CCSP) CY-1 and CY-1A and Ocean Drilling Program (ODP) 504B drill cores. In: Dilek Y, Moores EM, Elthon D, and Nicolas A (eds.) Ophiolites and Oceanic Crust: New Insights from Field Studies and the Ocean Drilling Program, Geological Society of America Special Paper 349, pp. 181-194. Boulder, CO: Geological Society of America.

Schouten $\mathrm{H}$ and McCamy K (1972) Filtering marine magnetic anomalies. Journal of Geophysical Research 77: 7089-7099.

Schouten H, Tivey MA, Fornari DJ, and Cochran JR (1999) Central anomaly magnetization high: Constraints on the volcanic construction and architecture of seismic layer $2 \mathrm{~A}$ at a fast-spreading mid-ocean ridge, the EPR at $9^{\circ} 30-50 \mathrm{~N}$. Earth and Planetary Science Letters 169: 37-50.

Sclater JG and Francheteau J (1970) The implications of terrestrial heat flow observations on current tectonic and geochemical models of the crust and upper mantle of the Earth. Geophysical Journal of the Royal Astronomical Society 20: 509-542.
Seama N, Nogi Y, and Isezaki N (1993) A new method for precise determination of the position and strike of magnetic boundaries using vector data of the geomagnetic anomaly field. Geophysical Journal International 113: 155-164.

Selkin PA, Gee JS, Tauxe L, Meurer WP, and Newell AJ (2000) The effect of remanence anisotropy on paleointensity estimates: A case study from the Archean Stillwater Complex. Earth and Planetary Science Letters 183: 403-416.

Selkin PA and Tauxe L (2000) Long-term variations in paleointensity. Philosophical Transactions of the Royal Society of London A 358: 1065-1088.

Sempere J-C, Macdonald KC, Miller SP, and Shure L (1987) Detailed study of the Brunhes/Matuyama reversal boundary on the East Pacific Rise at $19^{\circ} 30^{\prime}$ S: Implications for crustal emplacement processes at an ultra fast spreading center. Marine Geophysical Researches 9: 1-23.

Shackleton NJ, Berger A, and Peltier WR (1990) An alternative astronomical calibration of the lower Pleistocene timescale based on ODP Site 677. Transactions of the Royal Society of Edinburgh, Earth Sciences 81: 251-261.

Shackleton NJ, Hall MA, Raffi I, Tauxe L, and Zachos J (2000) Astronomical calibration age for the Oligocene-Miocene boundary. Geology 28: 447-450.

Shah AK, Cormier M-H, Ryan WBF, et al. (2003) Episodic dike swarms inferred from near-bottom magnetic anomaly maps at the southern East Pacific Rise. Journal of Geophysical Research 108(B2): 2097 (doi:10.1029/2001JB000564).

Shau Y-H, Torii M, Horng C-S, and Peacor DR (2000) Subsolidus evolution and alteration of titanomagnetite in ocean ridge basalts from Deep Sea Drilling Project/Ocean Drilling Program Hole 504B, Leg 83: Implications for the timing of magnetization. Journal of Geophysical Research 105: 23635-23649.

Sinton JM and Detrick RS (1992) Mid-ocean ridge magma chambers. Journal of Geophysical Research 97: 197-216.

Sinton JM, Smaglik SM, Mahoney JJ, and Macdonald KC (1991) Magmatic processes at superfast spreading midocean ridges: Glass compositional variations along the East Pacific Rise $13^{\circ}-23^{\circ}$ S. Journal of Geophysical Research 96: 6133-6156.

Smith DK, Tivey MA, Schouten H, and Cann JR (1999) Locating the spreading axis along $80 \mathrm{~km}$ of the Mid-Atlantic Ridge south of the Atlantis Transform. Journal of Geophysical Research 104: 7599-7612.

Smith GM (1990) The magnetic structure of the marine basement. Reviews in Aquatic Sciences 2: 205-227.

Smith GM and Banerjee SK (1985) Magnetic properties of basalts from Deep Sea Drilling Project Leg 83: The origin of remanence and its relation to tectonic and chemical evolution. Initial Reports of the Deep Sea Drilling Project 83: 347-357.

Smith GM and Banerjee SK (1986) Magnetic structure of the upper kilometer of the marine crust at Deep Sea Drilling Project Hole 504B, Eastern Pacific Ocean. Journal of Geophysical Research 91: 10337-10354.

Speranza F, Satolli S, Mattioli E, and Calamita F (2005) Magnetic stratigraphy of Kimmeridgian-Aptian sections from Umbria-March (Italy): New details on the M polarity sequence. Journal of Geophysical Research 110: B12109.

Stein CA and Stein S (1994) Comparison of plate and asthenosperic flow models for the thermal evolution of oceanic lithosphere. Geophysical Research Letters 21: 709-712.

Steiner MB, Ogg JG, Melendez G, and Sequeiros L (1985) Jurassic magnetostratigraphy, 2. Middle-Late Oxfordian of Aguilon, Iberian cordillera, northern Spain. Earth and Planetary Science Letters 76: 151-166.

Swift BA and Johnson HP (1984) Magnetic properties of the Bay of Islands ophiolite suite and implications for the magnetization of oceanic crust. Journal of Geophysical Research 89: 3291-3308. 
Talwani M, Windisch CC, and Langseth MG (1971) Rekjanes Ridge crest: A detailed geophysical study. Journal of Geophysical Research 76: 473-517.

Tarduno JA, Cottrell RD, and Smirnov AV (2001) High geomagnetic intensity during the Mid-Cretaceous from Thellier analyses of single plagioclase crystals. Science 291: 1779-1782.

Tauxe L and Hartl P (1997) 11 million years of Oligocene geomagnetic field behaviour. Geophysical Journal International 128: 217-229.

Tauxe L and Kent DV (2004) A simplified statistical model for the geomagnetic field and the detection of shallow bias in paleomagnetic inclinations: Was the ancient magnetic field dipolar?. In: Channell JET, Kent DV, Lowrie W, and Meert J (eds.) Geophysical Monograph 145: Timescales of the Paleomagnetic Field, pp. 101-115. Washington, DC: AGU.

Tauxe $L$ and Staudigel $\mathrm{H}$ (2004) Strength of the geomagnetic field in the Cretaceous Normal Superchron: New data from submarine basaltic glass of the Troodos Ophiolite. Geochemistry, Geophysics, Geosystems 5(2): doi:10.1029/ $2003 G C 000635$.

Tivey M (1996) Vertical magnetic structure of ocean crust determined from near-bottom magnetic field measurements. Journal of Geophysical Research 101: 20275-20296.

Tivey M, Johnson HP, Fleutelot C, et al. (1998a) Direct measurement of magnetic reversal boundaries in a cross-section of oceanic crust. Geophysical Research Letters 25: 3631-3634.

Tivey M, Kona PA, and Kleinrock MC (1996) Reduced crustal magnetization beneath relict hydrothermal mounds: TAG hydrothermal field, Mid-Atlantic Ridge, $26^{\circ}$ N. Geophysical Research Letters 23: 3511-3514.

Tivey M, Larson R, Schouten H, and Pockalny R (2005) Downhole magnetic measurements of ODP Hole 801C: Implications for Pacific oceanic crust and magnetic field behavior in the Middle Jurassic. Geochemistry Geophysics Geosystems 6: Q04008 doi:10.1029/2004GC000754.

Tivey M, Schouten H, and Kleinrock MC (2003) A near-bottom magnetic survey of the Mid-Atlantic Ridge axis at $26 \mathrm{~N}$ : Implications for the tectonic evolution of the TAG segment. Journal of Geophysical Research 108(B5): 2277 (doi:10.1029/2002JB001967).

Tivey MA and Johnson HP (1987) The Central Anomaly Magnetic High: Implications for ocean crust construction and evolution. Journal of Geophysical Research 92: 12685-12694.

Tivey MA and Johnson HP (2002) Crustal magnetization reveals subsurface structure of Juan de Fuca Ridge hydrothermal vent fields. Geology 30: 979-982.

Tivey MA, Johnson HP, Bradley A, and Yoerger D (1998b) Thickness of a submarine lava flow determined from nearbottom magnetic field mapping by autonomous underwater vehicle. Geophysical Research Letters 25: 805-808.

Tivey MA, Sager WW, Lee S-M, and Tominaga M (2006) Origin of the Pacific Jurassic quiet zone. Geology 34: 789-792.

Tivey MA and Tucholke BE (1998) Magnetization of 0-29 Ma ocean crust on the Mid-Atlantic Ridge, $25^{\circ} 30^{\prime}$ to $27^{\circ} 10^{\prime} \mathrm{N}$. Journal of Geophysical Research 103: 17807-17826.

Toft PB, Arkani-Hamed J, and Haggerty SE (1990) The effects of serpentinization on density and magnetic susceptibility: A petrophysical model. Physics of the Earth and Planetary Interiors 65: 137-157.

Varga RJ, Karson JA, and Gee JS (2004) Paleomagnetic constraints on deformation models for uppermost oceanic crust exposed at the Hess Deep Rift: Implications for axial processes at the East Pacific Rise. Journal of Geophysical Research 109: B02104 (doi:10.1029/2003JB002486).

Vera EE and Diebold JB (1994) Seismic imaging of oceanic layer $2 \mathrm{~A}$ between $9^{\circ} 30^{\prime} \mathrm{N}$ and $10^{\circ} \mathrm{N}$ on the East Pacific Rise from two-ship wide-aperture profiles. Journal of Geophysical Research 99: 3031-3041.
Verosub KL and Moores EM (1981) Tectonic rotations in extensional regimes and their paleomagnetic consequences for oceanic basalts. Journal of Geophysical Research 86: 6335-6349.

Vine FJ (1966) Spreading of the ocean floor: New evidence. Science 154: 1405-1415.

Vine FJ and Matthews DH (1963) Magnetic anomalies over oceanic ridges. Nature 199: 947-949.

Vine FJ and Moores EM (1972) A model for the gross structure, petrology and magnetic properties of oceanic crust. Geological Society of America Memoir 132: 195-205.

Vogt PR and Johnson GL (1973) Magnetic telechemistry of oceanic crust? Nature 245: 373-375.

Wallick BP and Steiner MB (1992) Paleomagnetic and rock magnetic properties of Jurassic Quiet Zone basalts, Hole 801C. Proceedings of the Ocean Drilling Program, Scientific Results 129: 455-470.

Wang D, Van der Voo R, and Peacor DR (2005) Why is the remanent magnetic intensity of Cretaceous MORB so much higher than that of Mid- to Late Cenozoic MORB? Geosphere 1(3): 138-146 (doi: 10.1130/GES00024.1).

Wang D, Van der Voo R, and Peacor DR (2006) Low-temperature alteration and magnetic changes of variably altered pillow basalts. Geophysical Journal International 164: 25-35.

Weissel JK and Hayes DE (1972) Magnetic anomalies in the Southeast Indian Ocean. In: Hayes DE (ed.) Antarctic Research Series, 19: Antarctic Oceanology II: The Australian-New Zealand Sector, pp. 165-196. Washington, D.C: American Geophysical Union.

Wilson DS and Hey RN (1981) The Galapagos axial magnetic anomaly: Evidence for the Emperor event within the Brunhes and for a two-layer magnetic source. Geophysical Research Letters 8: 167-188.

Wilson DS and Hey RN (1995) History of rift propagation and magnetization intensity for the Cocos-Nazca spreading center. Journal of Geophysical Research 100: 10041-10056.

Wilson DS, Teagle DAH, and Acton GD (2003) Proceedings of the Ocean Drilling Program, Initial Reports, 2006. College Station, TX: Ocean Drilling Program.

Wilson DS, Teagle DAH, Alt JC, et al. (2006) Drilling to gabbro in intact ocean crust. Science 312: 1016-1020.

Wittpenn NA, Harrison CGA, and Handschumacher DW (1989) Crustal magnetization in the South Atlantic from inversion of magnetic anomalies. Journal of Geophysical Research 94: 15463-15480.

Worm H-U (2001) Magnetic stability of oceanic gabbros from ODP Hole 735B. Earth and Planetary Science Letters 193: 287-302.

Worm H-U and Bach W (1996) Chemical remanent magnetization in oceanic sheeted dikes. Geophysical Research Letters 23: 1123-1126.

Worm H-U, Bohm V, and Bosum W (1996) Implications for the sources of marine magnetic anomalies derived from magnetic logging in Holes 504B and 896A. Proceedings of the Ocean Drilling Program, Scientific Results 148: 331-338.

Xu W, Geissman JW, Van der Voo R, and Peacor DR (1997a) Electron microscopy of $\mathrm{Fe}$ oxides and implications for the origin of magnetizations and rock magnetic properties of Banded Series rocks of the Stillwater Complex, Montana. Journal of Geophysical Research 102: 12139-12157.

Xu W, Peacor D, Van der Voo R, Dollase W, and Beaubouef R (1996) Modified lattice parameter/Curie temperature diagrams for titanomagnetite/titanomaghemite within the quadrilateral $\mathrm{Fe}_{3} \mathrm{O}_{4}-\mathrm{Fe}_{2} \mathrm{TiO}_{4}-\mathrm{Fe}_{2} \mathrm{O}_{3}-\mathrm{Fe}_{2} \mathrm{TiO}_{5}$. Geophysical Research Letters 23(20): 2811-2814 (doi:10.1029/ 96GL01117).

Xu W, Peacor DR, Dollase W, Van der Voo R, and Beaubouef R (1997b) Transformation of titanomagnetite to titanomaghemite: 
A slow, two-step, oxidation-ordering process in nature. American Mineralogist 82: 1101-1110.

Xu W, Van der Voo R, Peacor DR, and Beaubouef RT (1997c) Alteration and dissolution of fine-grained magnetite and its effects on magnetization of the ocean floor. Earth and Planetary Science Letters 151: 279-288.

Yamamoto M, Seama N, and Isezaki N (2005) Geomagnetic paleointensity over 1.2 Ma from deep-tow vector magnetic data across the East Pacific Rise. Earth Planets and Space 57: 465-470.

Yang S, Odah H, and Shaw J (2000) Variations in the geomagnetic dipole moment over the last 12000 years. Geophysical Journal International 140: 158-162.

Zhou W, Peacor DR, Van der Voo R, and Mansfield JF (1999a) Determination of lattice parameter, oxidation state, and composition of individual titanomagnetite/titanomaghemite grains by transmission electron microscopy. Journal of Geophysical Research 104: 17689-17702.

Zhou W, Van der Voo R, and Peacor DR (1999b) Preservation of pristine titanomagnetite in older ocean-floor basalts and its significance for paleointensity studies. Geology 27: 1043-1046.

Zhou W, Van der Voo R, Peacor DR, Wang D, and Zhang Y (2001) Low-temperature oxidation in MORB of titanomagnetite to titanomaghemite: A gradual process with implications for marine magnetic anomaly amplitudes. Journal of Geophysical Research 106: 6409-6421.

Zhou W, Van der Voo R, Peacor DR, and Zhang Y (2000) Variable Ti-content and grain size of titanomagnetite as a function of cooling rate in very young MORB. Earth and Planetary Science Letters 179: 9-20.

\section{Relevant Website}

http://www.fugroairborne.com - Fugro Airborne Surveys is a versatile and technologically advanced airborne survey company. 